UNIVERSIDADE DE BRASÍLIA - UnB

FACULDADE DE ECONOMIA, ADMINISTRAÇÃO, CONTABILIDADE - FACE PROGRAMA DE PÓS-GRADUAÇÃO EM ADMINISTRAÇÃO - PPGA

DELCIENE APARECIDA OLIVEIRA PEREIRA

GESTÃO DA INFORMAÇÃO ASSOCIADA AO PROCESSO DE DIMENSIONAMENTO DE FORÇA DE TRABALHO: ESTUDO DE CASO NO MINISTÉRIO DA SAÚDE

BRASÍLIA - DF 
DELCIENE APARECIDA OLIVEIRA PEREIRA

GESTÃO DA INFORMAÇÃO ASSOCIADA AO PROCESSO DE DIMENSIONAMENTO DE FORÇA DE TRABALHO: ESTUDO DE CASO NO MINISTÉRIO DA SAÚDE

Dissertação apresentada ao Programa de PósGraduação em Administração da Universidade de Brasília, como requisito parcial à obtenção do título de Mestre Profissional em Administração Pública.

Orientador: Prof. Dr. Antônio Isidro da Silva Filho

BRASÍLIA - DF

2016 


\title{
GESTÃO DA INFORMAÇÃO ASSOCIADA AO PROCESSO DE DIMENSIONAMENTO DE FORÇA DE TRABALHO: ESTUDO DE CASO NO MINISTÉRIO DA SAÚDE
}

Dissertação apresentada ao Programa de Pós-Graduação em Administração da Faculdade de Economia, Administração, Contabilidade e Gestão Pública da Universidade de Brasília (PPGA/FACE/UnB) como requisito parcial à obtenção do grau de Mestre em Administração Pública. Aprovada em de de 2016. Banca examinadora constituída por:

Prof. Dr. Antônio Isidro da Silva Filho

Universidade de Brasília

Orientador

\author{
Prof $^{a}$. Dr ${ }^{\mathrm{a}}$. Marina Figueiredo Moreira \\ Universidade de Brasília \\ Examinadora Interna
}

Prof. Dr. André Luiz Marques Serrano

Universidade de Brasília

Examinador Externo

Prof. Dr. Pedro Paulo Murce Meneses

Universidade de Brasília

Examinador Suplente 
Ao meu esposo, Marcelo, e meu filho, João, por todo amor, apoio e compreensão. 


\section{AGRADECIMENTOS}

A Deus por me permitir vivenciar essa experiência que expandiu meus horizontes.

Ao meu marido, Marcelo, pelo apoio incondicional e pela ajuda nos cuidados com nosso filho, João, durante esses dois anos de estudo.

Ao meu orientador, Prof. Dr. Antônio Isidro-Filho, pela contribuição valorosa, pelos conselhos, por partilhar de sua sabedoria comigo e ter muita paciência nos meus momentos de ansiedade.

Aos estimados professores do PPGA que me ensinaram muito nesses dois anos de mestrado e fizeram dessa experiência uma divisora de águas em minha formação.

À professora Marina e ao professor André, membros da banca examinadora, pelas sugestões fundamentais para o aperfeiçoamento desse estudo.

Aos meus colegas do mestrado, pelo apoio, momentos de descontração e desabafos.

Às minhas amigas Carol e Rosangela pelo companheirismo e ajuda em todos os momentos.

Às pessoas que entrevistei e que se dispuseram a doar um pouco do seu tempo para contribuir com essa pesquisa.

Ao Ministério da Saúde por me autorizar a realizar esse estudo na instituição.

A todos que contribuíram de alguma maneira para a realização dessa pesquisa e não estão citadas nominalmente aqui. 


\section{RESUMO}

O Dimensionamento de Força de Trabalho (DFT) é uma importante ferramenta gerencial para melhorar o planejamento de força de trabalho no setor público, uma vez que subsidia a tomada de decisão sobre o quantitativo e perfis das equipes necessárias à prestação de serviços à população. A realização do DFT requer diversas informações relativas à estratégia, aos processos, à estrutura, às pessoas e à legislação. As informações de processos são o elemento central das metodologias de dimensionamento. Assim, esse estudo buscou avaliar a presença de práticas de Gestão da Informação (GI) de processos de trabalho no contexto do DFT em um órgão público. Trata-se de uma pesquisa de natureza empírica, descritiva, transversal e com abordagem qualitativa. Por meio da realização de entrevistas com atores-chave e da pesquisa documental, foi possível identificar que a metodologia do órgão faz uso de informações de processo relativas à produção, ao tempo, à complexidade dos processos, ao nível de informatização e ao valor agregado. Foram identificadas na literatura práticas de GI, categorizadas nas quatro etapas do processo de GI proposto por Davenport (1998): determinação de exigências informacionais (categoria 1), obtenção (categoria 2), distribuição (categoria 3) e uso (categoria 4). Os resultados do estudo apontaram que as práticas estão presentes no contexto estudado. São adotadas na instituição $72 \%$ das práticas referentes à categoria 1 e $20 \%$ das práticas relativas à categoria 2. Há adoção parcial de 14\%, 50\% e 100\% de práticas concernentes às categorias 1,2 e 3 , respectivamente. Não foi identificada adoção das práticas referentes à categoria 4. Conclui-se que as informações de processos de trabalho não estão suficientemente organizadas para serem utilizadas pelo DFT e que isso fragiliza esse processo. Dessa forma, o órgão precisa investir no fortalecimento das práticas de GI para superar as deficiências apontadas nesse estudo.

Palavras-chave: Dimensionamento de força de trabalho. Gestão da informação. Processos de trabalho. 


\begin{abstract}
Workforce Dimensioning is an important managerial tool for improving workforce planning in the public sector, since it supports decision making on the quantitative and staffing profiles required to provide services to the population. The realization of the workforce dimensioning requires diverse information regarding the strategy, processes, structure, people, legislation. Process information is the core element of design methodologies. Thus, this study sought to evaluate the presence of information management practices of work processes in the context of the workforce dimensioning in a public agency. This is an empirical, descriptive, transversal and qualitative approach. Through interviews with key actors and documentary research, it was possible to identify that the agency's methodology makes use of process information related to production, time, complexity of processes, level of computerization and added value. Information management practices were identified in the literature categorized in the four stages of the process proposed by Davenport (1998), determination of information requirements (category 1), obtaining (category 2), distribution (category 3 ) and use (category 4). The results of the study indicated that practices are present in the context studied, that $72 \%$ of practices referring to category 1 and $20 \%$ of practices related to category 2 are adopted in the institution. There is partial adoption of $14 \%, 50 \%$ and $100 \%$ of practices concerning categories 1, 2 and 3, respectively. It was not identified adoption of practices related to category 4 . It is concluded that work process information is not sufficiently organized to be used by the workforce dimensioning and that this weakens this process. Thus, the agency needs to invest in strengthening the information management practices to overcome the deficiencies pointed out in this study.
\end{abstract}

Keywords: Workforce dimensioning. Information management. Work processes. 


\section{LISTA DE FIGURAS}

Figura 1 - Aspectos organizacionais que fornecem inputs/informações para o processo de DFT 38

Figura 2 - Objeto da pesquisa: práticas de gestão de informação relativas aos processos de

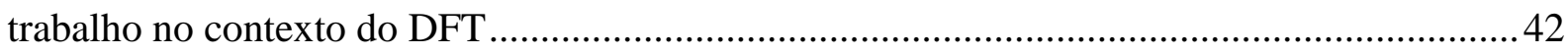

Figura 3 - Processo de transformação de inputs em outputs .................................................. 44

Figura 4 - Processo genérico de gerenciamento da informação ............................................ 46

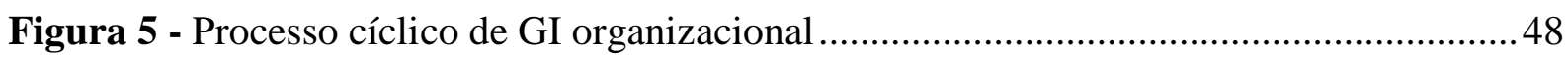

Figura 6 - Fluxo da informação nas organizações ............................................................. 49

Figura 7 - Estrutura organizacional do Ministério da Saúde ................................................53

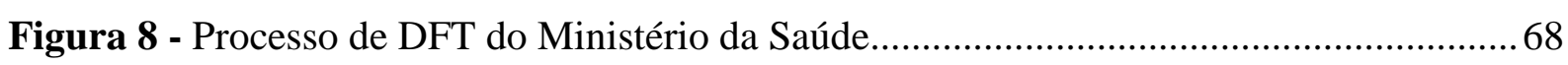




\section{LISTA DE QUADROS}

Quadro 1 - Conceitos adotados para DFT 29

Quadro 2 - Estudos empíricos da literatura nacional sobre DFT 32

Quadro 3 - Inputs/informações apontadas como necessárias nos estudos de DFT 36

Quadro 4 - Informações relativas aos processos utilizados como insumos/inputs no DFT .... 41

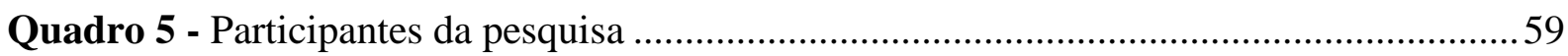

Quadro 6 - Práticas associadas às etapas do processo de GI.................................................63

Quadro 7 - Critérios utilizados para sintetizar os resultados da pesquisa .............................64

Quadro 8 - Síntese das informações sobre a adoção das práticas referentes à Categoria 1 ....81

Quadro 9 - Síntese das informações sobre a adoção das práticas referentes à Categoria 2 .. 102

Quadro 10 - Síntese das informações sobre a adoção das práticas referentes à Categoria 3113

Quadro 11 - Síntese das informações sobre a adoção das práticas referentes à Categoria 4120

Quadro 12 - Resultados da adoção de práticas de GI relativos às informações de processos no contexto do DFT. 


\section{LISTA DE SIGLAS}

$\begin{array}{ll}\text { APF } & \text { Administração Pública Federal } \\ \text { BI } & \text { Business Intelligence } \\ \text { BPM } & \text { Business Process Management } \\ \text { CGESP } & \text { Coordenação-Geral de Gestão de Pessoas } \\ \text { CNES } & \text { Cadastro Nacional de Estabelecimento de Saúde } \\ \text { CODIPE } & \text { Coordenação de Inovação de Processos e de Estruturas Organizacionais } \\ \text { DASP } & \text { Departamento Administrativo do Serviço Público } \\ \text { DATASUS } & \text { Departamento de Informática do SUS } \\ \text { DFT } & \text { Dimensionamento de Força de Trabalho } \\ \text { ENAP } & \text { Escola Nacional de Administração Pública } \\ \text { FNS } & \text { Fundo Nacional de Saúde } \\ \text { GI } & \text { Gestão da Informação } \\ \text { GESPÚBLICA } & \text { Programa Nacional de Gestão Pública e Desburocratização } \\ \text { MPOG } & \text { Ministério do Planejamento, Orçamento e Gestão } \\ \text { MS } & \text { Ministério da Saúde } \\ \text { NPM } & \text { New Public Management } \\ \text { NEMS/CE } & \text { Núcleo Estadual do Ministério da Saúde no Ceará } \\ \text { PDTI } & \text { Plano Diretor de Tecnologia de Informação } \\ \text { PNDP } & \text { Política Nacional de Desenvolvimento de Pessoal } \\ \text { SUS } & \text { Sistema Único de Saúde } \\ \text { TQM } & \text { Total Quality Management } \\ \text { UnB } & \text { Universidade de Brasília }\end{array}$




\section{SUMÁRIO}

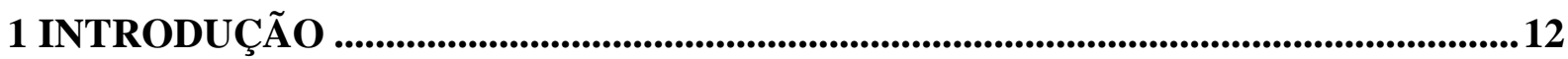

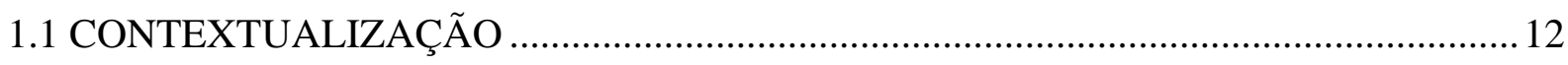

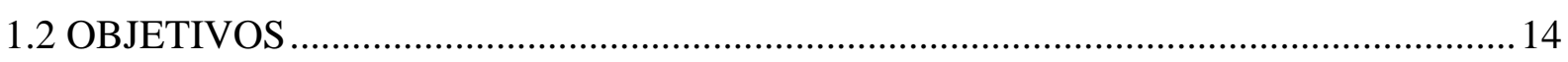

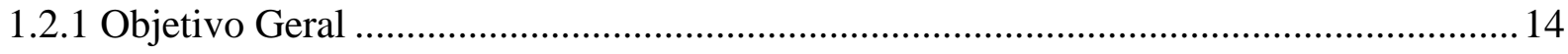

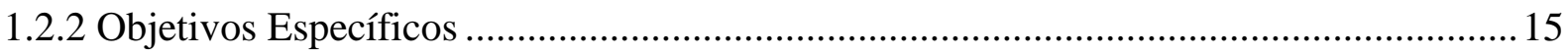

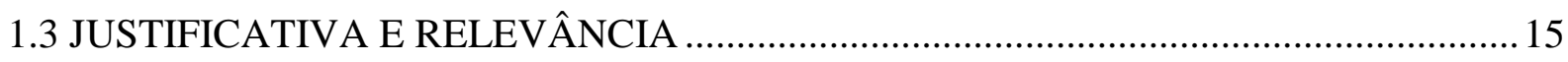

2 REFERENCIAL TEÓRICO ............................................................................................18

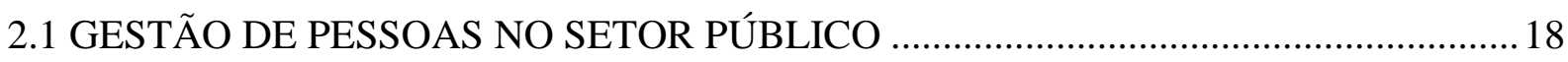

2.2 DIMENSIONAMENTO DE FORÇA DE TRABALHO (DFT) ………….......................25

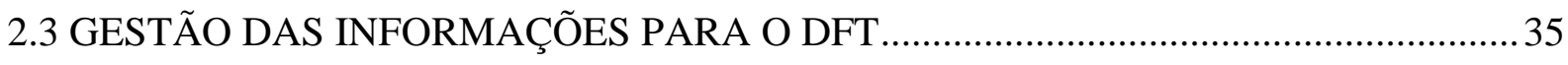

3 MÉTODOS, PROCEDIMENTOS E TÉCNICAS DE PESQUISA ..................................52

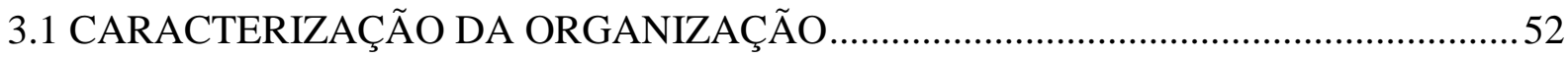

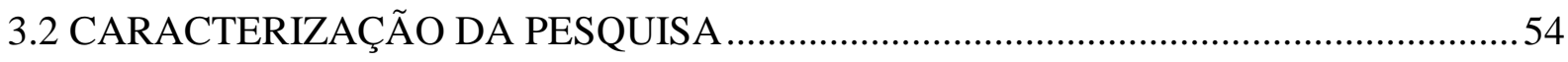

3.3 CARACTERIZAÇÃO DOS INSTRUMENTOS DE PESQUISA ……………………......56

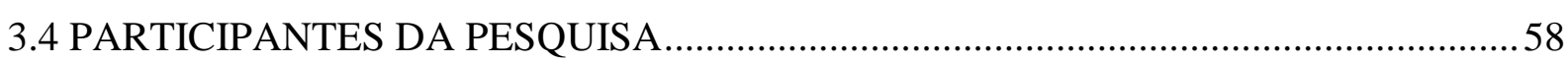

3.5 PROCEDIMENTOS DE COLETAS E ANÁLISE DE INFORMAÇÕES ............................60

4 RESULTADOS E DISCUSSÕES ...........................................................................................66

4.1 QUANTO ÀS INFORMAÇÕES RELATIVAS A PROCESSOS REQUERIDAS PELO

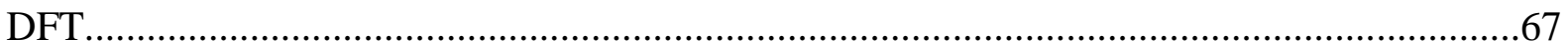

4.2 QUANTO À DETERMINAÇÃO DAS EXIGÊNCIAS INFORMACIONAIS ................... 71

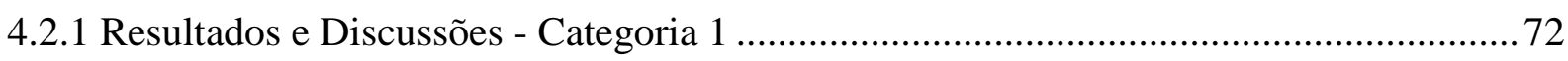

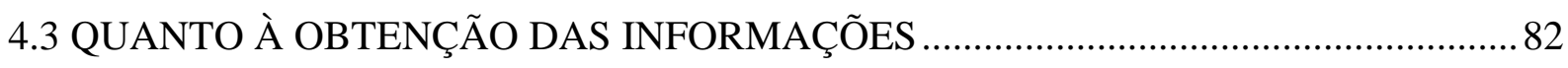

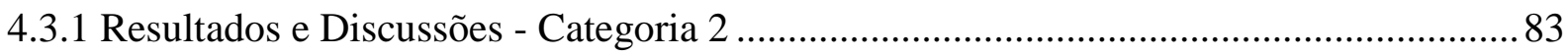

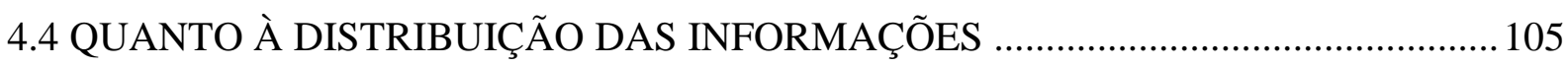

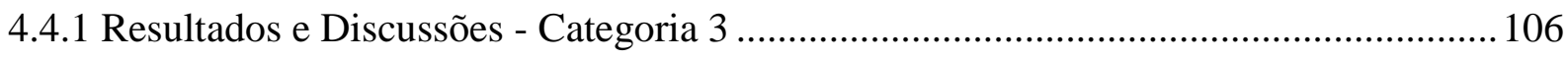

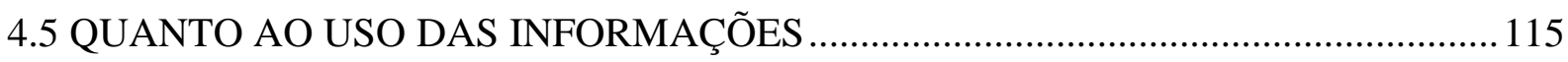

4.5.1 Resultados e Discussões - Categoria 4 …………………………………………...115

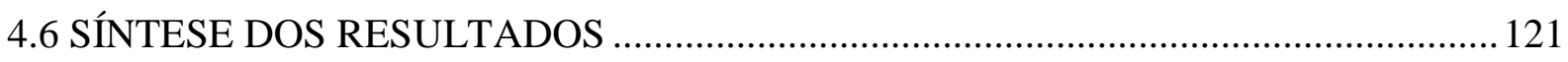

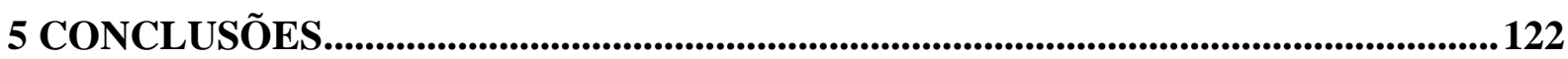

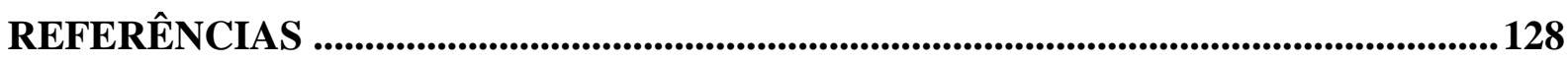

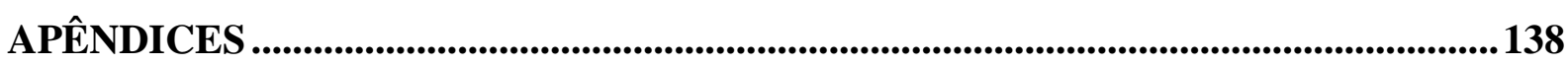

APÊNDICE I - FORMULÁRIO DE ANÁLISE DOCUMENTAL ………………………...138 
APÊNDICE II - ROTEIRO DE ENTREVISTA - GRUPO 1 139

APÊNDICE III - ROTEIRO DE ENTREVISTA - GRUPO 2 ............................................ 140

APÊNDICE IV - ROTEIRO DE ENTREVISTA - GRUPO 3 ........................................... 141

APÊNDICE V - TERMO DE CONSENTIMENTO LIVRE E ESCLARECIDO ................. 142 APÊNDICE VI - ARTIGOS QUE FIZERAM PARTE DO ESTUDO BIBLIOMÉTRICO .143 


\section{INTRODUÇÃO}

\subsection{CONTEXTUALIZAÇÃO}

Um questionamento frequente nas organizações prestadoras de serviço é se a força de trabalho existente é qualificada e suficiente para o atendimento das demandas dos usuários (LI; CHEN; CAI, 2007). De acordo com o "Referencial Básico de Governança aplicável a Órgãos e Entidades da Administração Pública" (BRASIL, 2014), a disponibilidade de pessoal com perfil adequado e em quantidade suficiente é fundamental para que os serviços públicos sejam prestados adequadamente. Essa publicação destaca, ainda, a provisão adequada de força de trabalho como fator essencial para que uma instituição pública cumpra sua missão.

Nesse sentido, Isidro-Filho e Serrano (2016, p. 4) afirmam que o "dimensionamento da força de trabalho é uma ferramenta fundamental para se fazer afirmações concretas sobre a quantidade de trabalhadores necessários em uma organização”. Consonante com essa afirmativa, Vianna et al (2013) argumentam que se deve conhecer a necessidade de pessoal primeiro, para em seguida planejar a força de trabalho. Essa etapa inicial consiste na implantação de um processo de dimensionamento que forneça indicadores quantitativos e qualitativos de trabalhadores para uma determinada organização. $\mathrm{O}$ "uso sistemático de informações geradas a partir da aplicação de uma metodologia cientificamente fundamentada para o dimensionamento de pessoal é imprescindível" (VITURI et al, 2011, p. 554). Essa sistematização fornece também informações importantes para vários outros processos de trabalho como estimativa de investimentos em formação e capacitação de pessoal, ocupação de espaço físico e aquisição de equipamentos (VIANNA et al, 2013).

No entanto, embora se reconheça a relevância da adoção de práticas de dimensionamento para definição de quadros de pessoal adequados, são poucos os estudos 
desenvolvidos no Brasil acerca desse tema (VIANNA et al, 2013). Ainda, segundo esses autores, a maior concentração dos estudos é na área de assistência à saúde.

De acordo com publicação do Ministério do Planejamento, Orçamento e Gestão (MPOG) “dimensionar significa calcular ou preestabelecer as dimensões ou proporções de algo. Tarefa bastante complexa quando se trata de força de trabalho na Administração Pública Federal", tanto devido a sua estrutura, "quanto pela complexidade de suas atividades" (BRASIL, 2006a, p. 9). Na gestão da saúde pública brasileira, esse se torna um desafio ainda maior devido à variedade e à complexidade dos processos de trabalho e à multidisciplinariedade dos perfis envolvidos na condução das políticas públicas de saúde.

Mesmo reconhecendo o desafio de dimensionar a força de trabalho no setor público, o Ministério da Saúde, órgão responsável pela formulação e gestão federal das políticas de saúde - Lei $\mathrm{n}^{\circ} 8.080$, de setembro de 1990 -, fez constar no planejamento estratégico, como uma das estratégias de aprimoramento da política de gestão de pessoas, a iniciativa de realizar um projeto com o objetivo de desenvolver e de implantar um processo de Dimensionamento de Força de Trabalho (DFT) capaz de evidenciar os quantitativos e perfis de trabalhadores necessários para execução dos processos de trabalho e, consequentemente, cumprimento da missão do Órgão. Esse projeto representa uma inovação para a instituição, considerando que os esforços para formação dos quadros de pessoal foram realizados baseados em percepções e não por meio da aplicação de uma metodologia de DFT. Para viabilização desse projeto, foi construída em 2014 uma parceria entre o Ministério da Saúde e a Universidade de Brasília (UnB).

A metodologia de DFT construída por meio de coprodução (OSTROM, 1996; GALLOUJ; WEINSTEIN, 1997; REIS, 2015) contempla duas etapas: quantitativa e qualitativa. Na etapa quantitativa são identificados os processos de trabalho e seus produtos, o percentual de tempo dedicado pelas equipes para esses processos e as variáveis relativas aos trabalhadores 
(quantitativo, idade, absenteísmo, faltas, férias, dentre outras). Na etapa qualitativa são identificados os perfis requeridos, a complexidade e o valor agregado dos processos de trabalho, além da sazonalidade.

O elemento central da metodologia do DFT são os processos de trabalho, considerando que as demais variáveis são analisadas em função desses e de seus resultados (produtos ou serviços). Ocorre que, no decorrer da execução do projeto piloto, foi constatado que havia fragilidades nas unidades com relação às informações referentes aos processos de trabalho. Diante disso, surgiram os seguintes questionamentos: o Ministério da Saúde adota práticas de gestão da informação no que se refere às informações de processos de trabalho? Essas informações estão preparadas para atender às demandas do DFT?

O processo de gestão da informação, de acordo com Davenport (1998), é caracterizado pelas etapas referentes à definição das exigências, à obtenção, à distribuição e ao uso das informações no contexto organizacional, que é essencial para a tomada de decisão.

O foco desse estudo é o conjunto de informações referentes aos processos de trabalho, que são insumos para o DFT. Esse recorte deve-se à compreensão de que se trata de informações críticas para o dimensionamento e, também, estratégicas para melhorar a tomada de decisão administrativa, bem como para subsidiar a formulação de planos estratégicos da organização.

Considerando o escopo dessa pesquisa, foram definidos os objetivos geral e específicos a seguir.

\subsection{OBJETIVOS}

\subsubsection{Objetivo Geral}

Avaliar o grau de adoção de práticas de gestão da informação de processos no contexto do Dimensionamento de Força de Trabalho no MS. 


\subsubsection{Objetivos Específicos}

i. Identificar as exigências de informação de processos no contexto do dimensionamento de força de trabalho;

ii. Identificar práticas de gestão da informação de processos no contexto do dimensionamento da força de trabalho;

iii. Verificar a adoção das práticas de gestão de informação de processos pelo órgão pesquisado.

\subsection{JUSTIFICATIVA E RELEVÂNCIA}

Vianna et al (2013, p. 946) afirmaram que os estudos sobre dimensionamento são escassos na "literatura científica nacional", sendo que as publicações existentes, geralmente, têm como foco processos assistenciais de instituições hospitalares. Nesse mesmo sentido, Neis et al (2011, p. 8) recomendam que os estudos sobre dimensionamento sejam realizados, considerando "a lacuna na produção do conhecimento sobre essa temática".

Diante de tais afirmações, essa pesquisa pretende contribuir com os estudos acerca do processo de DFT, que, embora seja apontado em algumas referências como essencial para o adequado planejamento de pessoal (VIANNA et al, 2013; MARINHO; VASCONCELLOS, 2007; PEREIRA et al, 2011), carece de maior exploração e compreensão de algumas questõeschave, como, por exemplo, em relação ao conjunto de informações necessário para a implantação desse processo nas organizações.

A literatura consultada para a realização dessa pesquisa evidencia que as informações essenciais para o processo de DFT são relativas ao contexto externo e interno à organização. No ambiente interno, percebe-se que a definição do tipo, padrão e quantidade de serviços prestados são elementos centrais dos estudos (CHENSO et al, 2004; DAL BEN; GAIDZINSKI, 2007). E é a partir desses, da análise das disponibilidades de pessoal, recursos tecnológicos e 
materiais, que são identificadas as necessidades quantitativas e qualitativas de força de trabalho para execução das estratégias organizacionais.

Foi observado, também, na literatura pesquisada, que nenhum dos estudos explora a análise dos insumos informacionais utilizados no processo de DFT, mesmo reconhecendo sua importância. Pereira et al, (2011), por exemplo, afirmam que a informação organizada e disponível para uso por esse processo é essencial para a geração dos resultados que subsidiarão a tomada de decisão gerencial acerca da força de trabalho.

Nesse sentido, esse estudo espera contribuir com a literatura sobre dimensionamento de força de trabalho ao realizar uma exploração dos insumos informacionais essenciais para esse processo, identificar práticas de gestão da informação e aplicar ao contexto do DFT, para verificar o atendimento às exigências de informação, obtenção, distribuição e utilização das informações, considerando que isso é essencial para que o DFT produza resultados de qualidade para subsidiar a tomada de decisão gerencial. Essa pesquisa possibilitará, ainda, um olhar acurado sobre informações relativas aos processos de trabalho, considerando que essas são imprescindíveis em metodologias de dimensionamento.

Outra contribuição à literatura será decorrente da articulação entre o tema desse estudo (DFT) com o tema da Gestão da Informação (GI), oriundo da Ciência da Informação, para produção de conhecimento acerca do dimensionamento. Percebe-se que, embora pouco explorado, esses dois temas são indissociáveis, considerando que o processo de dimensionamento faz intenso uso de insumos informacionais para gerar os resultados que serão utilizados para subsidiar a tomada de decisão organizacional referente ao quantitativo e perfis de trabalhadores necessários à viabilização de políticas públicas.

Essa pesquisa também possui relevância prática e social, uma vez que nesse estudo de caso busca-se verificar a adoção de práticas de GI no contexto do DFT no órgão pesquisado, considerando que essas são importantes para garantir a disponibilidade das informações para o 
processo de dimensionamento de força de trabalho. Essa é uma importante ferramenta gerencial, por meio da qual o órgão pesquisado busca definir o quantitativo e o perfil adequado de trabalhadores para o cumprimento de sua missão e o alcance de seus objetivos estratégicos. Estratégias para assegurar a disponibilidade e a qualidade das informações para o DFT permitem a geração de resultados confiáveis que subsidiarão o apropriado planejamento e a contratação de pessoal, principalmente, em face do contexto atual de recursos escassos e exigência crescente por eficiência, eficácia e efetividade da gestão pública. Acrescenta-se que a alocação dos perfis e a quantidade de trabalhadores precisam estar associadas à produção dos processos de trabalho que são entregues ao cidadão pelo órgão. Corroborando essa afirmativa, Schikmann (2010) assevera que a população tem elevado seu nível de exigência em relação à prestação de serviço pelo setor público e requerido que a atuação do Estado seja focada no alcance de resultados efetivos e, consequentemente, satisfação das demandas sociais.

Esse estudo está estruturado da seguinte forma: Capítulo 1 - Introdução contextualização, objetivos e justificativa; Capítulo 2 - dedicado à apresentação do embasamento teórico da pesquisa; Capítulo 3 - descreve os métodos e técnicas requeridos, considerando o objeto da pesquisa; Capítulo 4 - apresenta os resultados e discussões; e Capítulo 5 - conclusões. 


\section{REFERENCIAL TEÓRICO}

Este capítulo é composto por quatro seções. A primeira parte aborda a gestão de pessoas no setor público. A segunda seção é dedicada ao tema DFT, tópico em que são apresentados: breve histórico, bibliografia, conceitos, estudos empíricos realizados por pesquisadores brasileiros e informações associadas ao processo de DFT. A terceira seção é referente à Gestão da Informação como elemento essencial para assegurar a disponibilidade e a qualidade das informações para o processo de DFT.

\subsection{GESTÃO DE PESSOAS NO SETOR PÚBLICO}

O processo de transformação e adaptação das organizações ao contexto turbulento e instável que passou a vigorar a partir da década de 1990 afetou todas as áreas organizacionais, em especial, a área de gestão de pessoas. Essa área passou a ser o diferencial estratégico das organizações (VILLARDI et al, 2011). O seu papel, até então, centrado na execução de atividades rotineiras e burocráticas passou a ter o desafio de ser estratégico, de modo a auxiliar as organizações nos processos de transformação (DESSLER, 2003; CAMARGO et al, 2010; VILLARDI et al, 2011). Para ser efetiva, a gestão de pessoas passou a lançar mão de novas políticas e práticas alinhadas à estratégia organizacional (DESSLER, 2003; CAMARGO et al, 2010).

Segundo Villardi et al (2011, p. 305), na iniciativa privada, é "reconhecida a relevância da proposta de gestão estratégica de pessoas e sua capacidade para obtenção de vantagens competitivas para as organizações”. No entanto, no setor público, as políticas e práticas ainda se encontram, na maioria das vezes, desarticuladas das estratégias institucionais. Embora se reconheça, de acordo com Siqueira e Mendes (2009, p. 242), que a gestão de pessoas “tem papel singular na modernização do Estado, a fim de garantir a implementação adequada das mais diversas políticas públicas". 
No Brasil, as ações direcionadas à a modernização da gestão de pessoas no setor público foram iniciadas a partir da década de 1990 “com a agenda de reforma do aparelho de Estado, em implantação no país" (PACHECO, 2002, p. 104). Essa reforma foi baseada nos ideais do movimento da New Public Management (NPM), iniciado em países da Europa a partir da década de 1980.

As políticas e práticas de gestão de pessoas no setor público brasileiro, locus do presente estudo, foram ao longo da história definidas pelos modelos de administração pública adotado no país (patrimonialista, burocrático e gerencial).

A Administração Patrimonialista predominou no Brasil de 1821 a 1930 (BRESSERPEREIRA, 2001). Até a proclamação da República, a prática patrimonialista era realizada pela Família Real que lançava mão do patrimônio público para satisfazer suas necessidades e distribuir benesses aos seus agregados como, por exemplo, "garantir empregos para a classe média pobre ligada por laços de família ou de agregação aos proprietários rurais” (BRESSERPEREIRA, 2001, p. 5).

O Modelo Burocrático weberiano prevaleceu nas organizações públicas em todo o mundo durante o século XX (SECCHI, 2009). A formalidade, a impessoalidade e o profissionalismo são as principais características desse modelo. No Brasil, o modelo burocrático teve início com o governo de Getúlio Vargas (BRESSER-PEREIRA, 2001; MARCELINO, 2003; ARAÚJO; PEREIRA, 2012) em um contexto de sociedade capitalista, industrial e regime político autoritário. A princípio foi criado o Conselho Federal do Serviço Público Civil que posteriormente se transformou no Departamento Administrativo do Serviço Público (DASP), órgão responsável “por promover a estruturação básica do aparelho administrativo, instituir o concurso público, as regras para admissão e os treinamentos dos servidores públicos" (ARAÚJO; PEREIRA, 2012, p. 1181). 
As principais ações do DASP na condução da reforma burocrática foram, segundo Bresser-Pereira (2001, p 11):

Ingresso no serviço público por concurso, critérios gerais e uniformes de classificação
de cargos, organização dos serviços de pessoal e de seu aperfeiçoamento sistemático,
administração orçamentária, padronização das compras do Estado, racionalização
geral de métodos.

A criação dos departamentos de pessoal da Administração Pública foi uma ação estruturante necessária para a profissionalização dos quadros de pessoal, conforme os “pressupostos do modelo" burocrático (CAMÕES, 2013, p. 29). No entanto, de acordo com essa autora, essas iniciativas não se traduziram em uma política de recursos humanos significativa para suprir as necessidades estatais.

A Reforma Burocrática passou por vários momentos de desaceleração em função de mudanças políticas, criando espaço para manifestação de práticas patrimonialistas e clientelistas que atuavam contra os movimentos de "prosseguir com a Reforma Burocrática" (BRESSER-PEREIRA, 2001, p.13). No entanto, o que se via era a instituição de controles administrativos amplos com o objetivo de se evitar o retorno dessas práticas no setor público (CAMÕES, 2013).

As correntes defensoras do desenvolvimento econômico ganharam mais força nos governos pós Getúlio Vargas, em oposição ao Modelo Burocrático que era visto como incompatível com o momento que o país vivia de busca pelo desenvolvimento e, inclusive, promoveram estudos com foco em uma nova reforma da Administração Pública, que não tiveram desdobramentos em função do início da Ditadura Militar no país em 1964 (BRESSERPEREIRA, 2001; MARCELINO, 2003).

Durante o Regime Militar permaneceu inicialmente o Modelo Burocrático. No entanto, já em 1967, com a edição do Decreto-Lei nº 200, foram conduzidas reformas importantes e com características gerenciais. Um exemplo disso foi “o processo de descentralização políticoadministrativo - vários campos de domínio governamental passaram para a esfera privada e 
houve o empoderamento dos governos locais" (CAMÕES, 2013, p. 32). O impacto dessa normativa na formação e na gestão dos quadros de pessoal foi expresso, principalmente, pelo fortalecimento da meritocracia, da possibilidade de contratação de empregados celetistas e da "atenção especial ao desenvolvimento de recursos humanos para o sistema de planejamento" (BRESSER-PEREIRA, 2001, p. 15). Diferentemente, Costa (2008, p. 275) afirma que houve baixo êxito do movimento reformista de 1967 devido à "dissociação entre planejamento, modernização e recursos humanos" e à "pouca prioridade à área de recursos humanos", ocasionado o surgimento de diversos órgãos públicos, marginalização do funcionalismo e descontinuidade administrativa.

A compreensão pelos militares de que o Modelo Burocrático se apresentava como barreira ao desenvolvimento do país promoveu a substituição desse pelo modelo chamado "Administração para o Desenvolvimento" (BRESSER-PEREIRA, 2001; MARCELINO, 2003). Essa mudança representou, em resumo, a "expansão da intervenção do Estado na vida econômica e social”, a "substituição das atividades de funcionários estatutários por celetistas e a criação de entidades da Administração descentralizadas para realização da intervenção econômica do Estado" (MARCELINO, 2003, p. 644). De acordo com Bresser-Pereira (2001), esse modelo provocou alterações significativas na área de pessoal ao limitar a concepção de carreira aos níveis mais baixos da Administração, enquanto que o alto escalão era selecionado por meio de processos baseados nas diretrizes desenvolvimentistas e os preenchimentos dos cargos obedeciam a critérios definidos pelo dirigente máximo do país.

Com a redemocratização do país, a partir da década de 1980, o que se viu foi a retomada ao Modelo Burocrático. A Administração Pública tornou-se "hierárquica e rígida" e a "distinção entre Administração Direta e Indireta praticamente desaparecia” (BRESSER-PEREIRA, 2001, p. 19). 
No tocante à formação dos quadros de pessoal, a Constituição Federal de 1988 instituiu o Regime Jurídico Único no plano federal, que foi reproduzido nos demais entes da Federação, e a obrigatoriedade de concurso público para ingresso no funcionalismo, como medidas para romper com as práticas nepotistas e patrimonialistas presentes no serviço público (BRESSERPEREIRA, 2001; OCDE, 2010). Por outro lado, esse regime favoreceu a criação de "carreiras privilegiadas, sobretudo nas áreas jurídicas e de fiscalização, com salários muito acima da média", provocando o surgimento de movimentos corporativistas e carreiristas distanciados da real finalidade da Administração Pública (COSTA, 2008, p. 280).

Outros dois fatores que marcaram a volta aos ideais burocráticos foram a criação da Escola Nacional de Administração Pública (ENAP), como unidade responsável pela capacitação dos servidores públicos, e a criação da carreira de Especialistas em Políticas Públicas e Gestão Governamental. Segundo Bresser-Pereira (2001, p. 21), essa carreira "recebeu uma orientação rigorosamente burocrática, voltada para a crítica do passado patrimonialista, ao invés de voltar-se para o futuro e para a modernidade de um mundo em rápida mudança, que se globaliza e se torna mais competitivo a cada dia”.

Algumas das críticas ao Modelo Burocrático foram relativas à forma de gestão das pessoas. Segundo Secchi (2009), foram alguns dos pontos objetos de críticas: impactos negativos da prescrição de tarefas aos empregados; efeitos desvirtuados da exigência de comportamentos mecânicos e acríticos; desestímulo à competição com uso de critério de senioridade, que pode fomentar o corporativismo entre os empregados e afastá-los do objetivo principal da organização que é atender as demandas dos clientes/usuários; não observância de necessidades singulares pelos empregados devido à impessoalidade; desestímulo para inovar e criar (SECCHI, 2009).

Com o esgotamento do Modelo Burocrático, surgiu na segunda metade do século XX o movimento da Nova Administração Pública (New Public Management). Esse modelo ganhou 
força a partir da década de 1980, principalmente na Europa, como alternativa à grave crise vivenciada pelo Estado e como alternativa na busca de mecanismos para melhorar a atuação pública (BRESSER-PEREIRA, 1996, GUIMARÃES et al, 2003; SECCHI, 2009).

As características básicas da $N P M$ são: ação do Estado deverá ser orientada ao cidadão e ao alcance de resultados; maior autonomia ao corpo gerencial em pontos estratégicos da ação pública, mas com responsabilização e controle de resultados pelo cidadão; descentralização e fomento para inovar e criar; utilização de instrumentos de contratualização, mediante controle, para melhorar a eficiência na provisão de serviços públicos; e diminuição da interferência política na atuação do corpo burocrático (BRESSER-PEREIRA, 1996; ABRUCIO; SANO, 2008). Em resumo, a "preocupação central da Nova Gestão Pública é com a combinação entre a flexibilização da gestão e o aumento da responsabilização da Administração Pública" (ABRUCIO; SANO, 2008, p. 66).

De acordo com Camões (2013, p. 29), "inserida no contexto da reforma administrativa proposta pelo $N P M$, a retórica da gestão estratégica de pessoas exerceu grande influência também no setor público". Com isso, tanto o regramento como as relações de trabalho entram na pauta de discussão. Longo (2007, p. 137) afirma que "as reformas da gestão pública do emprego e dos recursos humanos apresentam entre si diferenças significativas em relação ao alcance das mudanças nos vários países”, mas, de forma geral, as transformações ocorridas nessa área no âmbito público foram direcionadas à descentralização com responsabilização dos gestores de linha, à flexibilização nas "práticas de gestão de pessoas" e às alterações nas relações de trabalho. De acordo com esse autor, são muitas as barreiras que dificultam a transformação da gestão de pessoas no setor público, como recomenda o NPM, principalmente em relação às questões de natureza culturais, legais, descontinuidades e resistência à avaliação e à medição. Nesse sentido, Camões (2013, p.30) afirma que "melhorar a gestão de pessoas é um dos principais desafios da gestão pública e o que enfrenta maiores obstáculos e resistências”. 
No contexto brasileiro, as reformas administrativas mudaram algumas práticas e valores, mas foram movimentos desarticulados com os vários setores da sociedade e com o próprio corpo burocrático, resultando em mudanças incrementais, que não conseguiram romper totalmente com modelos anteriores (SECCHI, 2009). Embora se reconheça avanços significativos como a instituição do Programa Nacional de Gestão Pública e Desburocratização (GESPÚBLICA), por meio do Decreto $\mathrm{n}^{\circ}$ 5.378, 23 de fevereiro de 2005, com foco na realização de mudanças nas instituições públicas que possibilitassem a modernização do setor público e sua profissionalização (BRASIL, 2005a), e a Política Nacional de Desenvolvimento de Pessoal (PNDP), regulamentada por meio do Decreto $n^{\circ} .5 .707,23$ de fevereiro de 2006 (BRASIL, 2006b).

O reflexo desses movimentos na gestão de pessoas no serviço público federal foi marcado por "mudanças fragmentadas e incompletas, com pouca direção geral estratégica e sucessivas políticas descontinuadas em relação ao número de pessoal e remunerações” (OCDE, 2010, p. 11).

Percebe-se que a melhoria de resultados e a satisfação dos cidadãos são pilares desse modelo de gestão pública. Assim, a implementação desse modelo pressupõe o bom gerenciamento do corpo de trabalhadores das instituições, que poderá ser alcançado por meio de mudanças nas políticas e práticas de gestão de pessoas. Nesse sentido, o êxito nos esforços de reforma pública está condicionado às modificações na gestão das pessoas, uma vez que o potencial de contribuição da força de trabalho depende de estar alocada adequadamente na instituição (INGRAHAM; PETERS; MOYNIHAN, 2000).

No nível federal, os órgãos públicos enfrentam alguns desafios para adequação das políticas e práticas de gestão de pessoas às estratégias organizacionais. Dentre eles, destaca-se a baixa autonomia conferida pelo poder central de recursos humanos às instituições, no que 
concerne à definição das alternativas mais adequadas às suas próprias necessidade, conforme se depreende do estudo conduzido por Fonseca et al (2013).

Embora se reconheça que a forma de organização do setor público federal impõe limitações à ação dos órgãos, esforços são empreendidos no sentido de desenvolver estratégias que possibilitem a melhoria da eficiência, da eficácia e da efetividade das instituições.

É nesse contexto de mudança de práticas em gestão de pessoas no setor público, com objetivo de adequar a força de trabalho às estratégias e à missão organizacionais e, consequentemente, melhorar a prestação de serviço à sociedade, que se estabelece a importância do tema DFT, que será abordado no tópico a seguir. De acordo com Reis et al. (2015), a viabilização do dimensionamento da força de trabalho, juntamente com o planejamento e a definição de estratégias de alocação do quadro de pessoal, confere maior efetividade à gestão de pessoas no ambiente organizacional.

\subsection{DIMENSIONAMENTO DE FORÇA DE TRABALHO (DFT)}

Os primeiros movimentos com foco no DFT ocorrem na área da saúde e são datados do século XIX. A enfermeira Florence Nightingale, que havia passado por uma experiência na Guerra da Criméia, descreveu durante a Revolução Industrial a necessidade de força de trabalho na área de enfermagem (MAGALHÃES; RIBOLDI; DALL'AGNOL, 2009). O método adotado era baseado na experiência e intuição (GONÇALVES, 2007).

Com o surgimento da Administração Científica, ocorrida no final do século XIX e início do século XX, um novo método de dimensionar o quantitativo de empregados foi proposto. A definição era baseada no tempo que um determinado empregado-padrão precisava para realizar a tarefa, multiplicado pela quantidade de tarefa a ser realizada (MARINHO; VASCONCELLOS, 2007). 
Nos últimos 20 anos, com base em pesquisa bibliográfica realizada, percebe-se que as metodologias de DFT passaram por mudanças substanciais, incorporando outros aspectos para definição dos quadros de pessoal nas organizações.

Essa pesquisa bibliográfica foi realizada no período de outubro a novembro de 2015 nas bases de informações da CAPES e SPELL. As palavras-chave e strings de busca utilizados foram os seguintes: dimensionamento e força de trabalho; dimensionamento e recursos humanos; dimensionamento e equipes; estimativa e força de trabalho; estimativa e recursos humanos; estimativa e equipes; planejamento e força de trabalho; planejamento e recursos humanos; planejamento e equipes; manpower planning e staff sizing.

Para a realização das buscas foram aplicados os seguintes critérios: artigos científicos, publicados no período de 1995 a 2015, revisados por pares, que abordavam conceitos relativos a planejamento de recursos humanos, dimensionamento de pessoal, cálculo de pessoal, estimativa de pessoal e alocação de recursos humanos. Os 320 artigos que retornaram das bases foram submetidos à leitura do resumo ou abstract para verificar a pertinência com o tema pesquisado. Caso essa identificação não fosse possível, procedia-se a leitura da introdução, não sendo suficiente, era realizada a leitura de todo o conteúdo para se definir pela seleção ou não. Com a aplicação desses critérios, 40 artigos foram selecionados, lidos e categorizados. A rol de artigos que fizeram parte do estudo bibliométrico encontra-se no APÊNDICE VI dessa pesquisa.

Foi utilizada como instrumento para a categorização dos artigos uma planilha formato Excel preparada especificamente para classificação das informações quanto às seguintes características: (i) ano de publicação do artigo, se nacional ou estrangeiro, escopo do estudo (teórico ou aplicado), esfera de aplicação; e (ii) metodológicas: natureza da pesquisa, delineamento, natureza dos dados, método, recorte temporal e amostragem. Nesse instrumento também foi inserida a categorização dos estudos de acordo com cinco variáveis teóricas: adoção 
do termo produção, proposição de metodologia de dimensionamento, adoção do termo informação, adoção dos termos tomada de decisão; e se o estudo foi realizado no setor de saúde. O percentual de artigos nacionais (53\%) e internacionais (47\%) foi relativamente equilibrado. Houve maior concentração de estudos nos anos de 2007, 2011, 2013 e 2014, com $15 \%$ em cada um desses anos, totalizando $60 \%$. A pesquisa bibliográfica evidenciou que a maioria dos artigos analisados adota os termos "dimensionamento de pessoal" (60\%). Os estudos são predominantemente aplicados (72\%) e 65\% foram realizados no setor de saúde. Isso mostra a necessidade de ampliar o número de pesquisas em outras áreas, considerando a relevância do assunto para as organizações. Em relação ao delineamento, 70\% dos estudos são descritivos e $65 \%$ são estudos de caso.

Foi aplicado o teste qui-quadrado, com nível de significância de 0,05, para verificar a possibilidade de associação entre variáveis da pesquisa. Para tanto, foram testados: (i) se pesquisas realizadas no setor de saúde possuíam associação com a esfera de aplicação (pública e privada) - o teste foi positivo, com valor-p 0,0068; (ii) se os estudos que abordavam o termo “informação" também abordavam "tomada de decisão" - foi evidenciado que há associação, com valor-p 0,0002; e (iii) se a natureza da pesquisa (empírico e teórico) possuía alguma associação com a nacionalidade do periódico (nacional e estrangeiro) - foi evidenciado associação com valor-p 0,0042.

O recorte temporal transversal foi o mais utilizado (75\%), já que os dados das pesquisas não consideraram séries históricas. A amostra não-probabilística foi utilizada em $73 \%$ dos artigos pesquisados. Geralmente, essa escolha é feita pela conveniência e viabilidade de aplicação.

Buscou-se, também, com a pesquisa bibliográfica, verificar a articulação realizada entre “informação" ou "gestão da informação" e DFT. Em 37\% dos artigos, foi enfatizada a 
necessidade da disponibilidade de informações-chave para a realização de estudos de DFT nas organizações.

Mesmo considerando fatores limitantes, como a busca somente em duas bases de informações e dois idiomas (português e inglês), a realização dessa bibliometria foi importante porque evidenciou como o tema DFT vem sendo estudado nos últimos 20 anos. Foi possível verificar também que há associação entre o tema dimensionamento e informação. A pesquisa contribuiu, ainda, para a construção desse referencial teórico.

O estudo realizado por Li, Chen e Cai (2007) evidenciou que a partir da década de 1970 foram publicados estudos apresentando novas técnicas de dimensionamento de pessoal. Nos anos de 1980, os modelos de dimensionamento de pessoal passaram a ser classificados em dois grupos: (i) exploratórios: oferecem aos gestores informações que possibilitam compreender o funcionamento da mão de obra e como essa responde aos diferentes estímulos. Esses modelos podem ser simples e aplicáveis à maioria das organizações ou mais robustos com aplicação de simulação estocástica, que permite avaliar aspectos específicos de todo o sistema de pessoal; e (ii) modelos normativos: utilizando técnicas de programação linear, possibilitando a análise de conjuntos de informações e categorias de informações do sistema de pessoal, aumentando a precisão das informações necessárias à tomada de decisão relativa, por exemplo, recrutamento, promoção, formação, postos de trabalho, despesas salariais e requisitos da força de trabalho em cada período (LI; CHEN; CAI, 2007).

No contexto brasileiro, estudos sobre DFT surgiram a partir da década de 1990 e, predominantemente, na área da saúde. Estudo conduzido pela pesquisadora Raquel Rapone Gaidzinski em 1998, na área de enfermagem, tornou-se referência para pesquisas posteriores.

A partir dos anos 2000, percebe-se um aumento, ainda tímido considerando a relevância do tema, no número de estudos acerca do DFT, inclusive em outros setores como logística, tecnologia da informação, indústria e em outros serviços públicos (VIANNA et al, 2013). 
No âmbito da Administração Pública brasileira, dois marcos regulatórios foram criados na tentativa de definir diretrizes e parâmetros para o dimensionamento da força de trabalho: primeiro pelo Conselho Federal de Enfermagem, por meio da Resolução n ${ }^{\circ} 293$ de 2004, de 21 de setembro de 2004 (BRASIL, 2004), e segundo no âmbito das Instituições Federais de Ensino, em decorrência da publicação da Lei n 11.091, de 12 de janeiro de 2005 (BRASIL, 2005b).

Embora tenha crescido o número de estudos científicos sobre o tema, percebe-se que não há um consenso na literatura acerca do conceito de DFT. No Quadro 1 é possível perceber que alguns autores consideram o dimensionamento como sinônimo de planejamento de força de trabalho, outros entendem que se trata da primeira etapa do processo de planejamento de recursos humanos.

Quadro 1 - Conceitos adotados para DFT

(Continua)

\begin{tabular}{|c|c|}
\hline AUTOR & DEFINIÇÃO \\
\hline Santos (1998, p. 70) & $\begin{array}{l}\text { "[...] é a especificação quantitativa e qualitativa do pessoal a ser empregado na } \\
\text { realização de determinada atividade". }\end{array}$ \\
\hline Leão et al (2002, p. 17) & $\begin{array}{l}\text { "O dimensionamento dos quantitativos humanos parte do pressuposto de que } \\
\text { todas as classes de atores em análise tiveram as cadeias de atividades de todos os } \\
\text { processos de que participam engenhadas". }\end{array}$ \\
\hline $\begin{array}{l}\text { Sohoni, Johnson e Bailey } \\
\text { (2004) }\end{array}$ & $\begin{array}{l}\text { O objetivo do planejamento de recursos humanos é estimar os níveis de força de } \\
\text { trabalho para atender as necessidades de produção. }\end{array}$ \\
\hline Nicola e Anselmi (2005) & $\begin{array}{l}\text { Processo sistemático aplicado com objetivo de evidenciar o quantitativo e cargos } \\
\text { necessários à prestação do serviço, garantindo qualidade e segurança ao paciente. }\end{array}$ \\
\hline $\begin{array}{l}\text { Marinho e Vasconcellos } \\
(2007, \text { p. 66) }\end{array}$ & $\begin{array}{l}\text { Projeto dimensionamento é "uma pequena etapa de um processo maior de } \\
\text { Planejamento Estratégico de Recursos Humanos". }\end{array}$ \\
\hline Oliveira et al (2007) & $\begin{array}{l}\text { Metodologia que permite a definição adequada das equipes considerando a } \\
\text { demanda a ser atendida e os níveis de serviços acordados. }\end{array}$ \\
\hline Pereira et al (2011) & $\begin{array}{l}\text { O dimensionamento de força de trabalho é um processo sistematizado que } \\
\text { embasa o planejamento e a avalição quanti-qualitativa de pessoal, necessário à } \\
\text { prestação de serviço. }\end{array}$ \\
\hline $\begin{array}{l}\text { Bonfim et al. (2012, p. } \\
1463)\end{array}$ & $\begin{array}{l}\text { "(...) não é somente um processo técnico, mas também, ético-político e } \\
\text { correlacionado a diversos fatores". }\end{array}$ \\
\hline $\begin{array}{l}\text { Vianna et al. }(2013, \mathrm{p} . \\
926)\end{array}$ & $\begin{array}{l}\text { "(...) pode ser considerado a etapa inicial do processo de provimento de pessoal, } \\
\text { tem por objetivo antever o quantitativo e a composição de profissionais } \\
\text { necessários ao desenvolvimento das atividades diárias de assistência". }\end{array}$ \\
\hline Porto e Neves (2014) & $\begin{array}{l}\text { Aplicação de metodologia que considere variáveis relativas às atividades } \\
\text { realizadas e permita quantificar o quadro de pessoal necessário a unidade. }\end{array}$ \\
\hline
\end{tabular}

Fonte: elaborado pela autora. 
Quadro 1 - Conceitos adotados para DFT

(Conclusão)

\begin{tabular}{|l|l|}
\hline \multicolumn{1}{|c|}{ AUTOR } & \multicolumn{1}{c|}{ DEFINIÇÃO } \\
\hline $\begin{array}{l}\text { Machado e Dal Poz (2015, } \\
\text { p.241) }\end{array}$ & $\begin{array}{l}\text { O dimensionamento consiste na aplicação de metodologias capazes de subsidiar } \\
\text { a contratação, alocação e distribuição eficaz de profissionais que "assegurem a } \\
\text { oferta de serviços de saúde com qualidade e segurança". }\end{array}$ \\
\hline $\begin{array}{l}\text { Isidro-Filho e Serrano } \\
(2016, \text { p.5) }\end{array}$ & $\begin{array}{l}\text { Dimensionamento "envolve a fixação de parâmetros adequados ao quadro de } \\
\text { servidores públicos, estabelecidos a partir de uma abordagem quanti-qualitativa". }\end{array}$ \\
\hline
\end{tabular}

Fonte: elaborado pela autora.

O planejamento de recursos humanos é um processo de trabalho inerente à gestão de pessoal (GUERRY, 2011). Planejar o quantitativo de pessoal é necessário para o alcance dos objetivos, embora se reconheça que se trata de uma das atividades mais importante e mais difícil para as grandes organizações (SOHONI; JOHNSON; BAILEY, 2004; VIANNA et al, 2013).

De acordo com Fairbairn (2014), o planejamento de recursos humanos pode ser abordado em duas perspectivas: (i) macro: relacionada à organização do mercado de trabalho, emprego, regulação e incentivo à formação e ao desenvolvimento de habilidades necessárias ao desenvolvimento da economia de um país, baseado em estratégias e políticas de oferta e demanda; ou (ii) micro: relativa às estratégias organizacionais para garantir o uso mais efetivo da mão de obra, tornando-a mais produtiva e minimizando o desperdício de recursos humanos. Esse autor afirma que, em qualquer uma dessas dimensões, o planejamento de recursos humanos auxilia na identificação das lacunas de competências críticas, essenciais e, consequentemente, na definição de estratégias para buscá-las ou desenvolvê-las.

No caso das organizações, os estudos são realizados internamente (na perspectiva micro) na tentativa de otimizar a alocação de sua força de trabalho (FAIRBAIRN, 2014).

A ausência de parâmetros claros para avaliação e planejamento de força de trabalho leva à definição dos quadros de pessoal de forma intuitiva ou com o uso acrítico de fórmulas disponíveis na literatura (DAL BEN; GAIDZINSKI, 2007). Assim, a realização de um estudo de dimensionamento rompe com a subjetividade identificada e apresenta embasamento teórico e metodológico (NICOLA; ANSELMI, 2005). 
Compreendendo a importância para a definição de quadros de pessoal, devido ao seu impacto na eficácia e nos custos dos serviços prestados, o dimensionamento tem sido considerado uma importante ferramenta de gestão organizacional (DAL BEN; GAIDZINSKI, 2007). Corroborando essa ideia, estudos mostram que o dimensionamento é uma tecnologia que auxilia no processo decisório relativo à força de trabalho, fornecendo informações importantes para o estabelecimento de números e perfis de trabalhadores necessários ao atendimento das demandas dos usuários (NICOLA; ANSELMI, 2005; DIMITRIOU; TSANTAS, 2010; VIANNA et al, 2013; PAIXÃO et al, 2015; ISIDRO-FILHO; SERRANO, 2016).

É preciso ressaltar, ainda, que os processos de trabalho podem ter suas práticas vigentes reorganizadas e melhoradas a partir dos resultados (outputs) gerados pelo dimensionamento de pessoal (NICOLA; ANSELMI, 2005; MATSUSHITA et al, 2005; GAIDZINSKI et al, 2009; MAYA et al, 2011; VITURI et al, 2011; BONFIM et al, 2012; GRIFFITHS; PRESHAW, 2014; LADIER; ALPAN; PENZ, 2014; CRUZ et al, 2014; PAIXÃO et al, 2015).

No contexto brasileiro, percebe-se que as organizações públicas e privadas têm estruturado processos de DFT como estratégias para o alinhamento do quadro de pessoal aos objetivos organizacionais. A partir de buscas realizadas nas bases de informações da CAPES, SPELL e Google Scholar, foram selecionados onze estudos empíricos (Quadro 2) que exemplificam com que objetivo o dimensionamento da força de trabalho tem sido utilizado pelas organizações brasileiras, os métodos empregados e os resultados alcançados. Algumas dessas pesquisas são referenciadas em outros estudos sobre o tema e seus parâmetros utilizados para desenvolvimento de novos estudos. 
Quadro 2 - Estudos empíricos da literatura nacional sobre DFT

(Continua)

\begin{tabular}{|c|c|c|c|}
\hline AUTOR & OBJETIVO & MÉTODO & RESULTADOS \\
\hline Santos (1998) & $\begin{array}{l}\text { Avaliar a evolução dos índices de } \\
\text { produtividade do capital investido } \\
\text { e da mão-de-obra da Petrobrás no } \\
\text { decorrer dos anos e suas relações } \\
\text { com o dimensionamento } \\
\text { quantitativo e qualitativo da força } \\
\text { de trabalho da estatal }\end{array}$ & $\begin{array}{l}\text { Estudo de caso } \\
\text { com } \\
\text { abordagem } \\
\text { qualitativa e } \\
\text { quantitativa }\end{array}$ & $\begin{array}{l}\text { 1- Nos períodos de maior produtividade } \\
\text { havia também aumento de mão-de-obra e } \\
\text { de capital investido; } \\
\text { 2- Os gerentes entrevistados apontaram } \\
\text { para a tendência na diminuição da força de } \\
\text { trabalho total e também na mudança dos } \\
\text { perfis dos empregados, que buscaram mais } \\
\text { especialistas e generalistas, em detrimento } \\
\text { de outras categorias. }\end{array}$ \\
\hline $\begin{array}{l}\text { Leão et al. } \\
\text { (2002) }\end{array}$ & $\begin{array}{l}\text { Propor metodologia que possibilite } \\
\text { a determinação do número de } \\
\text { empregados necessários à } \\
\text { execução das funções e também } \\
\text { descrever os cargos e necessidades } \\
\text { de treinamento } \\
\end{array}$ & $\begin{array}{l}\text { Teórico } \\
\text { descritivo com } \\
\text { abordagem } \\
\text { qualitativa }\end{array}$ & $\begin{array}{l}\text { O método proposto, adaptado da } \\
\text { metodologia IDEF (Identification } \\
\text { Definition), é adequado a atividades } \\
\text { desempenhadas em linhas produção, pois } \\
\text { possui enfoque taylorista; }\end{array}$ \\
\hline $\begin{array}{l}\text { Nicola e } \\
\text { Anselmi } \\
(2005)\end{array}$ & $\begin{array}{l}\text { Dimensionar o quadro de } \\
\text { profissionais de enfermagem de } \\
\text { uma unidade hospitalar }\end{array}$ & $\begin{array}{l}\text { Estudo de caso } \\
\text { com } \\
\text { abordagem } \\
\text { qualitativa e } \\
\text { quantitativa }\end{array}$ & $\begin{array}{l}\text { 1- Quadro de enfermagem inferior em } 50 \% \\
\text { do necessário e um excedente de } 29,2 \% \text { de } \\
\text { profissionais técnicos de auxiliares de } \\
\text { enfermagem; } \\
\text { 2- A metodologia de dimensionamento } \\
\text { adotada evidenciou desequilíbrio no } \\
\text { quantitativo de pessoal, que estava gerando } \\
\text { vários problemas na prestação de serviço e } \\
\text { na satisfação dos trabalhadores. }\end{array}$ \\
\hline $\begin{array}{l}\text { Oliveira et al. } \\
(2007)\end{array}$ & $\begin{array}{l}\text { Investigar como ocorre o } \\
\text { dimensionamento de pessoal nos } \\
\text { Centros de Operações de Redes e } \\
\text { estabelecer indicadores e métricas } \\
\text { voltados para a manutenção dos } \\
\text { contratos }\end{array}$ & $\begin{array}{l}\text { O estudo de } \\
\text { caso, com } \\
\text { abordagem } \\
\text { quantitativa }\end{array}$ & $\begin{array}{l}\text { 1- É preciso estabelecer o atendimento } \\
\text { máximo para aplicar a Teoria de Filas no } \\
\text { serviço de provimento de serviços de } \\
\text { telecomunicações; } \\
\text { 2- Com aplicação desse parâmetro é } \\
\text { possível mapear a capacidade da equipe do } \\
\text { Datacenter em cumprir os Acordos de } \\
\text { Níveis de Serviços com certa precisão. }\end{array}$ \\
\hline $\begin{array}{l}\text { Marinho e } \\
\text { Vasconcellos } \\
(2007)\end{array}$ & $\begin{array}{l}\text { Desenvolver e aplicar metodologia } \\
\text { de dimensionamento de pessoal. }\end{array}$ & $\begin{array}{l}\text { Estudo de caso, } \\
\text { abordagem } \\
\text { qualitativa e } \\
\text { quantitativa }\end{array}$ & $\begin{array}{l}\text { A metodologia desenvolvida e aplicada em } \\
\text { uma instituição pública mostrou-se } \\
\text { adequada para definição do quadro ideal de } \\
\text { profissionais e também para outras políticas } \\
\text { da organização, como treinamento e } \\
\text { desenvolvimento, salarial e de terceirização. }\end{array}$ \\
\hline $\begin{array}{l}\text { Neis et al. } \\
(2012, \text { p. } 422)\end{array}$ & $\begin{array}{l}\text { Mensurar o tempo efetivo de } \\
\text { trabalho de enfermagem de um } \\
\text { centro de material e esterilização. }\end{array}$ & $\begin{array}{l}\text { Estudo de caso, } \\
\text { abordagem } \\
\text { quantitativa }\end{array}$ & $\begin{array}{l}\text { O resultado da pesquisa apontou que o } \\
\text { tempo efetivo médio de trabalho é } 81,20 \% \text {, } \\
\text { considerado excelente pela literatura acerca } \\
\text { do tema. }\end{array}$ \\
\hline $\begin{array}{l}\text { Bonfim et al. } \\
(2012)\end{array}$ & $\begin{array}{l}\text { Identificar as atividades de } \\
\text { enfermagem na Atenção Primária } \\
\text { em Saúde para subsidiar o } \\
\text { dimensionamento dos } \\
\text { trabalhadores. }\end{array}$ & $\begin{array}{l}\text { O estudo de } \\
\text { caso adotou a } \\
\text { triangulação de } \\
\text { métodos e } \\
\text { abordagem } \\
\text { qualitativa e } \\
\text { quantitativa. }\end{array}$ & $\begin{array}{l}\text { 1- Poucas pesquisas adotam o método de } \\
\text { revisão de literatura em conjunto com o } \\
\text { mapeamento; } \\
\text { 2- As atividades identificadas confirmaram } \\
\text { o cotidiano das práticas da enfermagem na } \\
\text { Atenção Primária à Saúde; } \\
\text { 3- As atividades identificadas possibilitarão } \\
\text { a adoção de uma linguagem comum, } \\
\text { facilitando estudo complementares. }\end{array}$ \\
\hline
\end{tabular}

Fonte: elaborado pela autora. 
Quadro 2 - Estudos empíricos da literatura nacional sobre DFT

(Conclusão)

\begin{tabular}{|c|c|c|c|}
\hline AUTOR & OBJETIVO & MÉTODO & RESULTADOS \\
\hline $\begin{array}{l}\text { Vianna et al. } \\
(2013)\end{array}$ & $\begin{array}{l}\text { Revisar a literatura acerca do tema } \\
\text { dimensionamento da força de } \\
\text { trabalho, com vistas a subsidiar a } \\
\text { escolha de um modelo a ser } \\
\text { utilizado no âmbito da Atenção } \\
\text { Primária em Saúde. }\end{array}$ & $\begin{array}{l}\text { Revisão de } \\
\text { literatura, com } \\
\text { abordagem } \\
\text { qualitativa e } \\
\text { quantitativa }\end{array}$ & $\begin{array}{l}\text { 1- Evidência de que há poucos estudos } \\
\text { brasileiros acerca do tema e que os métodos } \\
\text { identificados, predominantemente na área } \\
\text { da saúde, geralmente abordam categorias } \\
\text { específicas de profissionais e consideram } \\
\text { grande número de variáveis; } \\
\text { 2- Não foi possível identificar um modelo } \\
\text { específico a ser adotado pela Atenção } \\
\text { Primária em Saúde, carecendo assim de } \\
\text { mais pesquisas. }\end{array}$ \\
\hline $\begin{array}{l}\text { Porto e Neves } \\
\text { (2014) }\end{array}$ & $\begin{array}{l}\text { Identificar a força de trabalho } \\
\text { necessária ao pleno funcionamento } \\
\text { do sistema prisional do governo do } \\
\text { estado de Minas Gerais }\end{array}$ & $\begin{array}{l}\text { Estudo de caso, } \\
\text { com } \\
\text { abordagem } \\
\text { quantitativa }\end{array}$ & $\begin{array}{l}\text { 1- O quantitativo de pessoal dimensionado } \\
\text { ficou muito próximo do quadro já existente, } \\
\text { contrariando a expectativa dos gestores do } \\
\text { sistema; } \\
\text { 2- O estudo apontou para a necessidade de } \\
\text { revisão dos perfis para determinados postos } \\
\text { de trabalho, aspecto não contemplado no } \\
\text { estudo. }\end{array}$ \\
\hline $\begin{array}{l}\text { Machado e } \\
\text { Dal Poz } \\
\text { (2015) }\end{array}$ & $\begin{array}{l}\text { Realizar revisão sistemática da } \\
\text { literatura com objetivo de } \\
\text { identificar metodologias que } \\
\text { permitam o eficaz } \\
\text { dimensionamento da força de } \\
\text { trabalho em saúde. }\end{array}$ & $\begin{array}{l}\text { Estudo com } \\
\text { abordagem } \\
\text { qualitativa e } \\
\text { quantitativa }\end{array}$ & $\begin{array}{l}\text { 1- Todas as metodologias de } \\
\text { dimensionamento analisadas apresentam } \\
\text { limitações e que a grande concentração dos } \\
\text { estudos é no campo da enfermagem; } \\
\text { 2- Os resultados da pesquisa também } \\
\text { mostraram que nenhuma metodologia é } \\
\text { capaz de abarcar os vários processos em } \\
\text { uma sistemática de dimensionamento, } \\
\text { distribuição e alocação de profissionais. }\end{array}$ \\
\hline $\begin{array}{l}\text { Isidro-Filho e } \\
\text { Serrano } \\
(2016)\end{array}$ & $\begin{array}{l}\text { Realização de pesquisa para o } \\
\text { desenvolvimento e aplicação de } \\
\text { metodologia quanti-qualitativa em } \\
\text { um órgão público. }\end{array}$ & $\begin{array}{l}\text { Estudo com } \\
\text { abordagem } \\
\text { qualitativa e } \\
\text { quantitativa }\end{array}$ & $\begin{array}{l}\text { 1- Metodologia desenvolvida e aplicada em } \\
\text { unidade piloto de um órgão público; } \\
\text { 2- Definição de variáveis transversais à } \\
\text { todas as unidades; } \\
\text { 3- A metodologia precisou retirar algumas } \\
\text { variáveis importantes por falta de controle } \\
\text { de informações pela instituição. }\end{array}$ \\
\hline
\end{tabular}

Fonte: elaborado pela autora.

A análise desses onze estudos evidenciou que parte dos modelos adotados para dimensionar a força de trabalho basearam-se em diversas teorias para a construção de métodos que se adequassem à realidade encontrada. Os demais usaram métodos de previsão de pessoal já difundidos, como: Método Gaidzinski; Modelo de Programação Inteira; Modelos de Teoria de Filas. Esses métodos foram amplamente explorados pela revisão bibliográfica realizada por Vianna et al (2013).

O método desenvolvido por Gaidzinski tem como foco o dimensionamento da força de trabalho de enfermagem para unidades hospitalares e está ancorado em cinco fases: 
identificação do perfil dos usuários e grau de complexidade da assistência; horas de assistência necessárias, conforme regulação da categoria; identificação do percentual por especialidade, de acordo com a dependência assistencial; levantamento da jornada de trabalho efetiva; e identificação dos índices de absenteísmo e ausências (BONFIM et al, 2012; FUGULIN et al, 2012; VIANNA et al, 2013). De acordo com esses autores, a partir do levantamento desse conjunto de informações, é aplicado um modelo matemático para se calcular o número de profissionais de enfermagem.

Segundo Vianna et al (2013), o modelo de Programação Inteira para dimensionar força de trabalho busca o aproveitamento ótimo das disponibilidades, considerando os limites impostos no processo produtivo, e exige o estabelecimento de parâmetros de produtividade e índices de uso dos serviços. De acordo com esses autores, esse método requer que se conheça o "tempo gasto na execução de cada tarefa realizada pelo profissional", portanto, sua utilidade é maior para dimensionar força de trabalho que desempenham atividades invariáveis e pouca quantidade (VIANNA et al, 2013, p. 938).

O método da Teoria de Filas dimensiona a força de trabalho considerando a "taxa de utilização dos serviços, a dinâmica do atendimento ao cliente e o tempo de permanência na fila", de acordo com Vianna et al (2013, p. 936). Esses autores afirmaram que esse método é adequado para definição de quadros de pessoal em centrais de atendimento.

Esses métodos não se mostram adequados ao contexto do órgão pesquisado. Logo, por meio de um termo de cooperação com a Universidade de Brasília, foi desenvolvido um método de dimensionamento próprio para a instituição, cuja fórmula matemática considera um conjunto de variáveis relativas à força de trabalho (quantidade de servidores, jornada de trabalho, desligamentos, admissões, dentre outras) e os indicadores de resultados dos processos de trabalho das áreas. Além do método matemático, também foi incorporada uma etapa qualitativa 
na metodologia para que fosse possível identificar os perfis requeridos por cada processo de trabalho.

Após examinar os artigos nacionais e internacionais acerca do tema DFT, foram identificadas informações associadas ao processo de dimensionamento, apontadas nos estudos que fizeram parte da pesquisa bibliográfica como insumos (inputs) críticos e essenciais na implantação de um processo de DFT. O tópico a seguir é dedicado à explicitação dessas informações.

\subsection{GESTÃO DAS INFORMAÇÕES PARA O DFT}

Nos últimos anos, houve um grande aumento no volume de registros de informações, que passaram a apoiar a tomada de decisão não somente referente aos processos fins das organizações, mas também aos processos de gestão (COSTA, 2011). Ter um grande número de informações disponíveis sem que sejam confiáveis não agrega valor à tomada de decisão nas organizações, por isso é necessário conquistar "um equilíbrio entre quantidade de informação produzida e sua qualidade" (COSTA, 2011, p. 51).

A informação torna-se ainda mais importante quando, por exemplo, subsidia a tomada de decisões estratégicas relacionadas à previsão de produção e construção de cenários, nos quais históricos de informações são necessários (COSTA, 2011; SOHONI; JOHNSON; BAILEY, 2004).

A necessidade de tomar decisões em curto espaço de tempo é recorrente no meio organizacional atual. Isso requer das organizações planejamento sustentado, baseado em informações de qualidade (COSTA, 2011). Ocorre que "na maioria dos sistemas, a qualidade dos dados é totalmente negligenciada e, pior ainda, quem os usa muitas vezes pensa que, pelo facto da informação aparecer num ecrã de computador, está totalmente correta" (COSTA, 2011, 
p. 28). Nesse sentido, Arts, Keizer e Scheffer (2002) afirmaram que o dado para ser útil precisa ser de boa qualidade.

Em se tratando do processo de DFT, a necessidade de informações de boa qualidade é essencial. Corroborando essa afirmativa, Pereira et al (2011, p. 1601) argumentam que "informações coletados, registrados, classificados, organizados, armazenados e disponíveis para consulta" permitem analisar produção, resultados e auxiliam na tomada de decisão gerencial.

As demandas informacionais necessárias ao processo de DFT são definidas a partir da metodologia que se pretende adotar (CLACK et al, 2001). Assim, a partir da análise dos artigos que compuseram a amostra da pesquisa bibliográfica, foram identificados conjuntos de informações apontados em cada estudo como sendo elementos essenciais para o processo de DFT nas organizações. O Quadro 3, a seguir, apresenta esses blocos de informações e os autores das pesquisas científicas.

Quadro 3 - Inputs/informações apontadas como necessárias nos estudos de DFT

(Continua)

\begin{tabular}{|c|c|}
\hline INFORMAÇÕES/INPUTS & AUTORES \\
\hline $\begin{array}{l}\text { Recursos recebidos; produção, mão de obra disponível, esforço e níveis de } \\
\text { pessoal necessários. }\end{array}$ & Clack et al. (2001) \\
\hline $\begin{array}{l}\text { Produção regular; produção flutuante ou variável; informações da força de } \\
\text { trabalho (quantitativo, férias, horas de trabalho, formação/treinamento). }\end{array}$ & $\begin{array}{l}\text { Sohoni, Johnson e Bailey } \\
\text { (2004) }\end{array}$ \\
\hline $\begin{array}{l}\text { Usuários dos serviços; horas de trabalho requeridas considerando a missão da } \\
\text { instituição; estrutura organizacional; estrutura física, complexidade do serviço; } \\
\text { política de pessoal; material e finanças; legislação; padrão de serviço pretendido; } \\
\text { categorias de profissionais necessárias; ausências; jornada efetiva de trabalho } \\
\text { dedicada a produção; padrões de produção; produtividade. }\end{array}$ & Nicola e Anselmi (2005) \\
\hline $\begin{array}{l}\text { Carga de trabalho (volume de produção); perfil profissional; jornada de trabalho; } \\
\text { tempo efetivo de produção; ausências; treinamentos. }\end{array}$ & $\begin{array}{l}\text { Dal Ben e Gaidzinsk } \\
\text { (2007) }\end{array}$ \\
\hline $\begin{array}{l}\text { Demandas regular, demanda irregular, dias parados (feriados, finais de semana), } \\
\text { horas de trabalho requeridas para execução das demandas, horas disponíveis } \\
\text { contratadas, horas extras máximas permitidas, custo de horas extras, salários } \\
\text { pagos, políticas de substituição, políticas de treinamento, horas de treinamento, } \\
\text { custos com recrutamento e seleção, número de empregados, recrutamentos, } \\
\text { demissões, substituições, promoções, política de empregados temporários. }\end{array}$ & Li, Chen e Cai (2007) \\
\hline Índice de segurança técnico, tempo efetivo de trabalho, carga de trabalho. & Pereira et al. (2011) \\
\hline $\begin{array}{l}\text { Informações de cada empregado ao longo dos últimos } 9 \text { anos: horas de trabalho, } \\
\text { idade, antiguidade, filhos, etc., fluxos internos e externos de desperdício, fluxos } \\
\text { de entrada. }\end{array}$ & Guerry (2011) \\
\hline
\end{tabular}

Fonte: elaborado pela autora. 
Quadro 3 - Inputs/informações apontadas como necessárias nos estudos de DFT

(Conclusão)

\begin{tabular}{|l|l|}
\hline \multicolumn{1}{|c|}{ INFORMAÇÕES/INPUTS } & \multicolumn{1}{|c|}{ AUTORES } \\
\hline $\begin{array}{l}\text { Demanda planejada, turnos de trabalho, tipo de serviço, tempo requerido para } \\
\text { execução do serviço, requisitos técnicos para realizaçâo da atividade. }\end{array}$ & $\begin{array}{l}\text { Ivannikova e } \\
\text { Kryshkevych (2013) }\end{array}$ \\
\hline $\begin{array}{l}\text { Produtividade, rotatividade, tipo de serviço, determinantes demográficos, } \\
\text { informações socioeconômicas, epidemiológicas, demográficas (taxa de } \\
\text { mortalidade, migrações, envelhecimento), demandas por serviços, quantitativo } \\
\text { populacional. }\end{array}$ & Vianna et al. (2013) \\
\hline $\begin{array}{l}\text { População demandante; número de profissionais; horas de trabalho por semana } \\
\text { e ano; horas demandadas, força de trabalho existente, tempo de execução das } \\
\text { atividades, complexidade da atividade, custos. }\end{array}$ & $\begin{array}{l}\text { Griffiths e Preshaw } \\
(2014)\end{array}$ \\
\hline $\begin{array}{l}\text { Demanda, planejamento do trabalho, habilidades exigida em cada tarefa; } \\
\text { disponibilidade de funcionários; horas de trabalho por tarefa e por dia; número } \\
\text { mínimo de pessoas ao mesmo tempo para realização das tarefas; nível de de } \\
\text { experiência dos empregados para determinada tarefa; perfil dos empregados; } \\
\text { custo dos empregados; máximo de horas que um trabalhador pode gastar em } \\
\text { horas para realizar uma tarefa (respeitando a segurança e ergonomia); horas do } \\
\text { empregado disponível (respeitada legislação); restrições legais. }\end{array}$ & $\begin{array}{l}\text { Ladier, Alpan e Penz } \\
\text { (2014) }\end{array}$ \\
\hline
\end{tabular}

Fonte: elaborado pela autora.

Essas informações são relativas aos seguintes aspectos organizacionais: estratégia, estrutura, processos, pessoas, legislação (Figura 1). As informações demográficas referidas por Vianna et al (2013) foram utilizadas como insumos quando o objetivo do estudo foi dimensionar categorias profissionais para o atendimento de demandas relativas aos serviços de saúde de um país, por exemplo. Como o recorte dessa pesquisa é o ambiente organizacional, essa categoria não será explorada. 


\section{Estratégia}

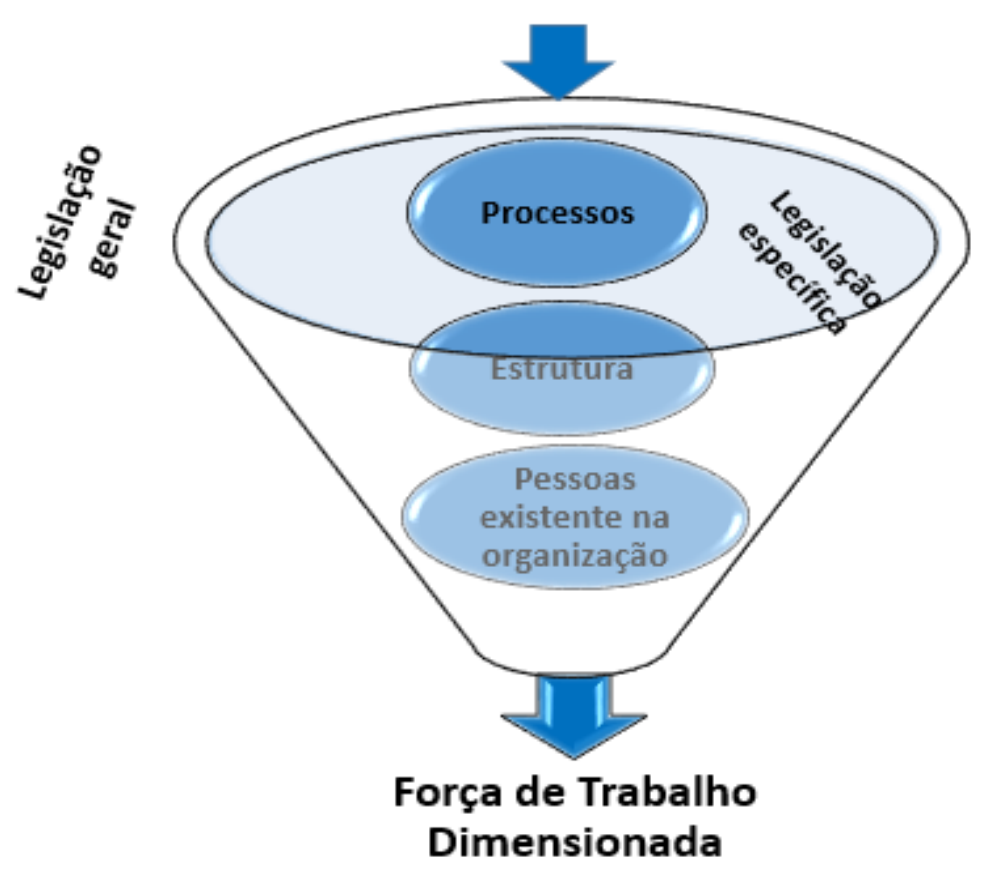

Figura 1 - Aspectos organizacionais que fornecem inputs/informações para o processo de DFT Fonte: elaborado pela autora.

Com relação à estratégia, Mintzberg, Ahlstrand e Lampel (2000, p. 17) afirmaram que se trata de um padrão, "consistência em comportamento ao longo do tempo". De forma pragmática, Fernandino e Oliveira (2010) e Galbraith (2012) afirmaram que estratégia também pode ser definida como a direção; as metas e os objetivos que serão perseguidos; os produtos e serviços que serão ofertados; e que postura será adotada na relação com os clientes.

À luz da afirmativa desses autores sobre o papel exercido pela estratégia no contexto organizacional, percebe-se que o conjunto de informações ou inputs apontados nos estudos relativos à DFT, considerados necessários à condução de processos dessa natureza, parte se origina da estratégia assumida pela organização para um dado período de tempo e parte é decorrente dessa estratégia (estrutura, processos e pessoas). Nesse sentido, Vituri et al, (2011) afirmaram que metodologias de dimensionamento precisam considerar peculiaridades institucionais e, principalmente, as estratégias organizacionais definidas. 
No que concerne à estrutura organizacional, Mintzberg (2012, p. 12) conceitua como sendo a "soma total das maneiras pelas quais o trabalho é dividido em tarefas distintas e, depois, como a coordenação é realizada entre essas tarefas”. Nesse sentido, os elementos da estrutura precisam ser escolhidos para o alcance da coerência ou harmonia interna, além da integração básica com a condição da organização (MINTZBERG, 2012). De acordo com esse autor, a definição da estrutura organizacional é influenciada por fatores situacionais (ambiente, porte da organização, tecnologia, processos produtivos) e estratégias de crescimento adotadas para atingir objetivos de crescimento e expansão. Assim, "a otimização da estrutura irá variar de acordo com os fatores situacionais ou contingenciais da organização" (FERNANDINO; OLIVEIRA, 2010, p. 1080).

A relação entre as pessoas e a estrutura organizacional é condição essencial para o êxito das instituições, considerando que a adequação da estrutura aos objetivos organizacionais e ao ambiente não são suficientes para o cumprimento da estratégia se o arranjo criado for incompatível com a força de trabalho disponível (VASCONCELLOS; HEMSLEY, 1997). Consonante com a afirmativa desses autores, estudos empíricos relativos a dimensionamento de pessoal afirmaram que a estrutura é uma das variáveis essenciais a ser considerada para identificação de quantitativos e perfis da força de trabalho necessário para cumprimento da missão institucional (NICOLA; ANSELMI, 2005; PAIXÃO et al, 2015).

O terceiro conjunto de inputs informacionais apontado na literatura como essencial para o processo de dimensionamento é relativo aos processos de trabalho da organização. Esse aspecto será mais explorado, considerando o objeto de estudo dessa pesquisa.

Processos de trabalho são os meios pelos quais produtos e serviços são criados e entregues aos clientes (ABPMP, 2013, p.46). Na perspectiva de análise de Galbraith (2012), os processos são referentes aos fluxos de informação e à comunicação que perpassam toda a 
organização por meio das decisões e ações relativas ao planejamento, ao orçamento, à mensuração de desempenho e às ligações entre as várias unidades organizacionais.

Processo de trabalho sempre foi um tema de interesse das organizações produtivas e objeto de diversas pesquisas (PAIM et al, 2009). Com o movimento da reengenharia de processos de negócio, ocorrido no final de 1980 a início de 1990, foi ampliada a disseminação do conceito de processos de trabalho, embora a frustação com os resultados alcançados com a reengenharia colaborou com a deterioração desse termo (PAIM et al, 2009; RIBEIRO, 2009). Outro marco importante para a literatura e práticas de processos foi a criação e difusão do "Sistema Toyota de Produção". Esse movimento, também conhecido como modelo de melhoria contínua ou TQM (Total Quality Management), foi iniciado na década de 1970 no Japão e disseminado para outros países a partir da década de 1980. O diferencial desse modelo é a gestão da qualidade aplicada a todas as etapas dos processos organizacionais (PAIM et al, 2009; RIBEIRO, 2009). A partir da década de 1990, uma nova abordagem de processos foi difundida a partir do conceito de Business Process Management (BPM). Essa nova abordagem entende que os processos de negócio precisam ser monitorados, ajustados e otimizados de forma contínua para a adaptação ao ambiente.

Nos dias atuais o que se verifica é uma "crescente demanda das organizações por incorporarem tarefas que as permitam responder a mudanças internas e externas" (PAIM et al, 2009, p. 24) e uma busca crescente por integração e aperfeiçoamento dos processos de trabalho, com vistas à otimização dos recursos e ao alcance dos objetivos e das metas estratégicos (RIBEIRO, 2009).

Em resumo, a melhoria de processos de trabalho é a condição básica para que as instituições consigam responder às mudanças frequentes no contexto de sua atuação e, com isso, manterem-se competitivas (PAIM et al, 2009). No setor público, a melhoria de processo é essencial para o desempenho das instituições e a geração de valor público. Como os recursos 
são escassos e a demanda da população por serviços de qualidade é crescente, o uso de tecnologias para otimização dos processos de trabalho é fundamental para produção de bens e serviços.

No contexto do DFT, conforme se verifica no Quadro 4, a literatura aponta um rol de informações relativos aos processos de produção organizacionais que contempla: tipo de serviço que será ofertado, recursos e custos envolvidos, demanda, usuários, padrão de serviço, produção, atividades desenvolvidas, tempo requerido de execução, produtividade. Essas informações funcionam como inputs ou insumos informacionais para o processo de dimensionamento.

Quadro 4 - Informações relativas aos processos utilizados como insumos/inputs no DFT

\begin{tabular}{|c|c|}
\hline INFORMAÇÕES/INPUTS & AUTORES \\
\hline Tipo de serviço & Vianna et al (2013); Ivannikova e Kryshkevych (2013) \\
\hline Recursos de entrada & Clack et al (2001); Guerry (2011) \\
\hline Custos & Griffiths e Preshaw (2014) \\
\hline Demanda (planejada, regular, irregular) & $\begin{array}{l}\text { Li, Chen e Cai (2007); Ivannikova e Kryshkevych (2013); Vianna et } \\
\text { al (2013); Ladier, Alpan e Penz (2014); Paixão et al. (2015) }\end{array}$ \\
\hline Usuários dos serviços & Nicola e Anselmi (2005); Griffiths e Preshaw (2014) \\
\hline Padrão de serviço pretendido & Nicola e Anselmi (2005) \\
\hline $\begin{array}{l}\text { Produção (regular, produção flutuante } \\
\text { ou variável) }\end{array}$ & $\begin{array}{l}\text { Clack et al. (2001); Sohoni, Johnson e Bailey (2004) } \\
\text { Nicola e Anselmi (2005); Dal Ben e Gaidzinsk (2007); Paixão et al. } \\
(2015)\end{array}$ \\
\hline Atividades e sua complexidade & $\begin{array}{l}\text { Nicola e Anselmi (2005); Cruz et al. (2014); Griffiths e Preshaw } \\
\text { (2014); Paixão et al. (2015) }\end{array}$ \\
\hline $\begin{array}{l}\text { Tempo requerido para execução das } \\
\text { atividades }\end{array}$ & $\begin{array}{l}\text { Nicola e Anselmi (2005); Li, Chen e Cai (2007); Ivannikova e } \\
\text { Kryshkevych (2013); Griffiths e Preshaw (2014); Ladier, Alpan e } \\
\text { Penz (2014); Cruz et al. (2014); Paixão et al. (2015) }\end{array}$ \\
\hline Tempo efetivo de produção & Dal Ben; Gaidzinsk (2007) \\
\hline $\begin{array}{l}\text { Requisitos técnicos e habilidades } \\
\text { exigidas para realização da atividade }\end{array}$ & Ivannikova e Kryshkevych (2013); Ladier, Alpan e Penz (2014) \\
\hline Produtividade & Nicola e Anselmi (2005); Vianna et al (2013); Paixão et al. (2015) \\
\hline $\begin{array}{l}\text { Fluxos internos e externos de } \\
\text { desperdício }\end{array}$ & Guerry (2011) \\
\hline $\begin{array}{l}\text { Planejamento do trabalho; } \\
\text { Número mínimo de pessoas ao mesmo } \\
\text { tempo para realização das tarefas; } \\
\text { Nível de experiência dos empregados } \\
\text { para determinada tarefa. }\end{array}$ & Ladier, Alpan e Penz (2014) \\
\hline
\end{tabular}

Fonte: elaborado pela autora. 
Percebe-se que há maior consenso entre alguns autores sobre a importância de três aspectos dos processos de trabalho, considerados insumos informacionais importantes para o dimensionamento: demanda, produção e tempo requerido para execução das atividades de produção. O presente projeto tem como foco de estudo os insumos informacionais relativos à produção, especificamente as informações concernentes aos processos produtivos (Figura 2), considerando que esses são elementos centrais na metodologia utilizada no processo de DFT em implantação no órgão pesquisado.

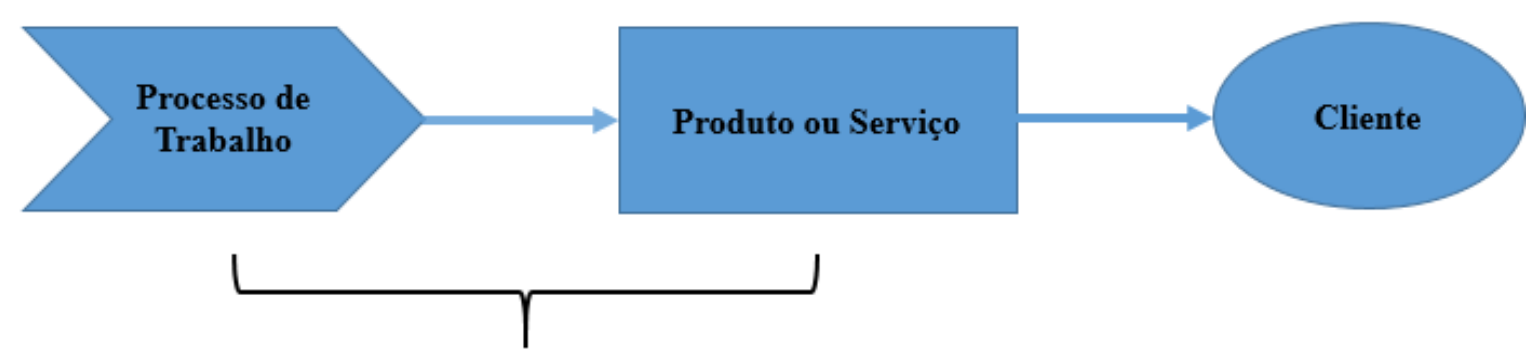

\section{Informações para o \\ DFT}

Figura 2 - Objeto da pesquisa: práticas de gestão de informação relativas aos processos de trabalho no contexto do DFT

Fonte: elaborado pela autora.

O quarto conjunto de informações apontado na literatura como insumo para o processo de dimensionamento é relativo à força de trabalho da organização ou às pessoas. Esse tema, já explorado no tópico 2.1 desse projeto, fornece um conjunto de inputs essenciais a esse processo.

No modelo de desenho organizacional proposto por Galbraith (2012), a categoria pessoas refere-se às políticas de pessoal que servem de base para os processos organizacionais relativos à identificação, ao recrutamento, à seleção, à contratação, ao desenvolvimento, à promoção dos trabalhadores que são necessários pela estratégia, à estrutura e às competências para o alcance dos objetivos estratégicos estabelecidos. 
Os estudos analisados apontam inputs informacionais relativos à gestão de pessoas que precisam estar disponíveis para realização do processo de DFT: política de pessoal, força de trabalho existente, categorias, perfis, férias, horas de trabalho contratadas, jornadas de trabalho; formação, ausências, capacidade produtiva efetiva, novos ingressos, demissões, promoções, movimentações, custos de mão de obra e faixa etária (CLACK et al., 2001; SOHONI; JOHNSON; BAILEY, 2004; NICOLA; ANSELMI, 2005; DAL BEN; GAIDZINSK, 2007; LI; CHEN; CAI, 2007; GUERRY, 2011; VIANNA et al, 2013; GRIFFITHS; PRESHAW, 2014; LADIER; ALPAN; PENZ, 2014; PAIXÃO et al, 2015).

O último aspecto que fornece insumos informacionais ao processo de dimensionamento é relativo à legislação que estabelece as regras formais de gestão de pessoas. No setor público, contexto desse estudo, a legislação impõe uma série de regras aos processos de gestão de pessoas. Nesse sentido, Chenso et al (2004, p. 84) afirmaram que nas instituições públicas a substituição de força de trabalho e novas contratações de profissionais "obedecem à legislação do serviço público, o que torna os processos mais demorados e complexos".

No contexto brasileiro, no que tange à legislação que versa sobre contratação de pessoal, por exemplo, Fernandino e Oliveira (2010) afirmaram que essa leva a processos de recrutamento e seleção ineficientes e ineficazes, uma vez que dificultam sobremaneira a entrada dos perfis desejados, restando às instituições investir no desenvolvimento de sua força de trabalho. Essa prática, dependo da complexidade das atividades a serem desempenhadas, acaba exigindo um tempo maior de preparação dos trabalhadores, para operação adequada dos processos de trabalho.

No âmbito da Administração Pública Federal, "parte das políticas relevantes à gestão de pessoas é formulada e coordenada de maneira centralizada, o teor da legislação e dos controles definirá os parâmetros legais e a estratégia comum para orientação das organizações públicas na consecução dos objetivos de governo" (FONSECA et al, 2013, p. 1453). 
Os estudos analisados apontam que considerar os insumos informacionais relativos à legislação (internas e externas) de gestão de pessoas da instituição na qual o dimensionamento será realizado é condição para o êxito do processo (NICOLA; ANSELMI, 2005; LADIER; ALPAN; PENZ, 2014).

Percebe-se que, à semelhança do processo de transformação proposto por Slack et al (2008), Figura 3, e do modelo de sistema, no qual as entradas são processadas para geração das saídas (BEAL, 2004), o processo de DFT, a partir de uma metodologia predefinida, promove a transformação dos inputs, relativos aos cinco aspectos explorados nesse tópico, em outputs, ofertando à organização um conjunto de informações que auxilia na tomada de decisão relativa à gestão de pessoas.

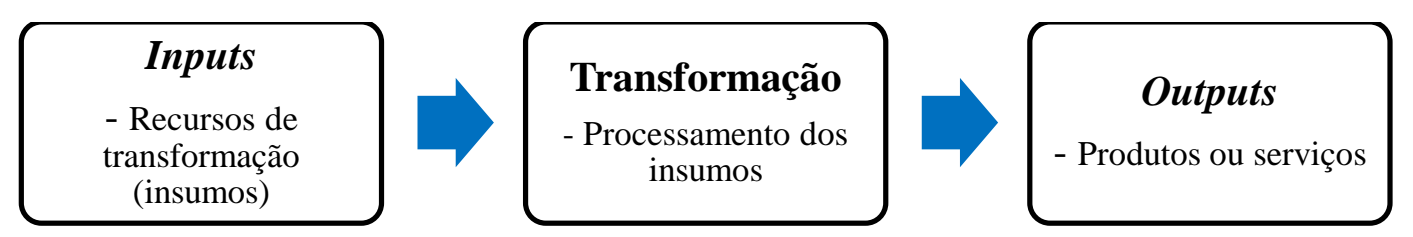

Figura 3 - Processo de transformação de inputs em outputs Fonte: Adaptado de Slack et al., 2008.

A propriedade dos resultados gerados pelo processo de dimensionamento é decorrente da qualidade dos insumos utilizados. Essa preocupação com os insumos utilizados nos processos de dimensionamento de pessoal foi expressada na literatura, por exemplo, por Clack et al (2001) ao afirmar que as informações definidas para o modelo precisam estar disponíveis e corretas, uma vez que metodologias de dimensionamento usam informações centrais, cujos registros precisam ser reais.

Considerando que a informação se apresenta como elemento essencial ao processo de dimensionamento da força de trabalho, para que os insumos informacionais utilizados no processo de DFT estejam disponíveis e confiáveis, é necessário que essas informações sejam identificadas e geridas pela organização. Diante disso, para melhor analisar o objeto dessa pesquisa, fez-se necessário recorrer à Ciência da Informação para definição de conceitos e 
explicitação, com base nessa literatura, de como esse insumo precisa ser gerido no contexto organizacional para dar suporte à tomada de decisão gerencial.

A informação é um elemento essencial para tomada de decisão organizacional (MORESI, 2000; ANGELONI, 2003; MONTEIRO; VALENTIM, 2008).

De acordo com Angeloni (2003, p.17), dado, informação e conhecimento "formam um sistema hierárquico de difícil delimitação. O que é um dado para um indivíduo pode ser informação e/ou conhecimento para outro". Didaticamente, a literatura acaba por conceituar esses três termos, mesmo compreendendo a dificuldade de delimitação e separação precisa desses na prática. Os dados são os insumos para a geração da informação (MORESI, 2000; ANGELONI, 2003). São "elementos brutos, sem significado, desvinculado da realidade" (ANGELONI, 2003, p. 18). Essa autora acrescenta que a qualidade da decisão está diretamente relacionada à qualidade do dado utilizado e da informação. A geração da informação ocorre a partir do processamento dos dados. Corroborando essa afirmativa, Angeloni (2003) e Beal (2004) conceituam informação como sendo informações dotados de significado. Moresi (2000, p. 15) adota um conceito mais abrangente ao afirmar que informações são "estruturas significantes com a competência de gerar conhecimento no indivíduo ou em sua organização”. O conhecimento pode ser compreendido como a informação processada e em uso pelo indivíduo (MORESI, 2000; ANGELONI, 2003). Assim, “o conhecimento não pode ser desvinculado do indivíduo; ele está estritamente relacionado com a percepção do mesmo, que codifica, decodifica, distorce e usa a informação de acordo com suas características pessoais, ou seja, de acordo com seus modelos mentais" (ANGELONI, 2003, p. 18).

Selecionar as informações que precisam ser monitoradas em função de sua relevância para a tomada de decisão gerencial é um desafio para as organizações, considerando o contexto atual de grande produção de informações. Para Choo (2006, p. 100) "as necessidades de informação não surgem plenamente formadas, mas crescem e evoluem com o tempo". 
A tomada de decisão exige que o gestor tenha acesso a um conjunto de informações relativas ao ambiente (interno e externo) e ao histórico de decisões anteriores e seus resultados (VALENTIM et al, 2003). Para que seja acessível, a informação precisa ser organizada e gerida (MARCHIORI, 2002). Nesse sentido, Marchiori (2002) afirma que identificar a demanda por informação é a etapa inicial de qualquer processo de Gestão da Informação (GI). Uma vez identificada essa demanda, inicia-se uma série de ações com foco no atendimento das necessidades informacionais da organização (MARCHIORI, 2002; VALENTIM et al, 2003).

As informações apontadas como essenciais ao processo de tomada de decisão, deixam de ser recursos comuns e assumem papel estratégico e vital no contexto organizacional (CARVALHO, 2001). Assim, sua gestão passa a ser decisiva para o êxito no processo decisório gerencial.

O processo de GI consiste na identificação das demandas informacionais, organização, tratamento e disseminação para o uso (MARCHIORI, 2002; VALENTIM et al, 2003; BARBOSA, 2008; SOUZA et al, 2011; MACEDO; BARBOSA, 2013; VALENTIM, 2013). Consoante com esses autores, Borges (2014, p. 88) afirma que "gestão da informação compreende ferramenta capaz de planejar, organizar, dirigir e controlar informações que alimentarão a tomada de decisão e possibilitará a solução de questões de maneira estratégica e oportuna”.

Nessa mesma perspectiva, Davenport (1998) afirma que o processo de GI é composto por quatro etapas (Figura 4):

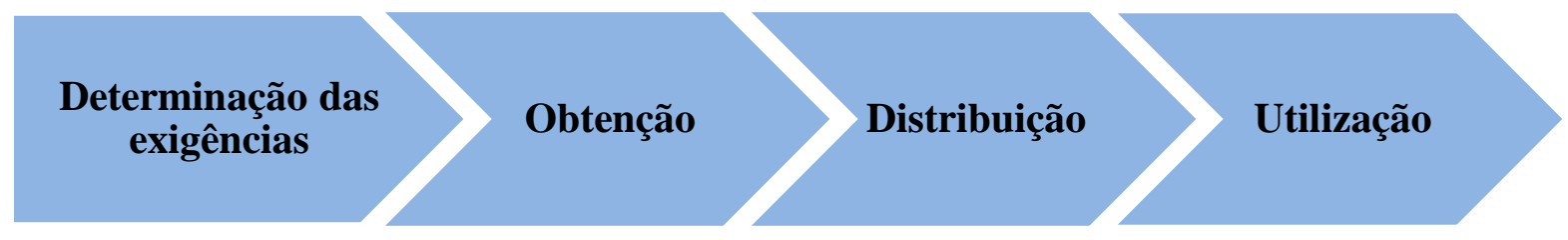

Figura 4 - Processo genérico de gerenciamento da informação Fonte: Davenport (1998, p. 175). 
Conhecer os dados necessários, os fatores fundamentais para o êxito organizacional e quais informações são essenciais para o monitoramento desses fatores é um primeiro passo para definir as exigências informacionais (DAVENPORT, 1998). Segundo esse autor, é preciso acompanhar os gerentes para compreender as rotinas administrativas e suas necessidades informacionais. Uma vez que essas estejam definidas, começa-se a etapa de obtenção de informação (atividade ininterrupta), que contempla as seguintes subatividades: exploração ou busca de informações nas fontes identificadas, classificação e criação de grupos de informações, formatação e estruturação (DAVENPORT, 1998; LIMA, 2006). Para esses autores, as duas últimas etapas do processo podem ser definidas assim: distribuição - está relacionada à forma como a informação é formatada e disponibilizada aos usuários; utilização - é a etapa final do processo de GI, ou seja, todas as etapas iniciais foram percorridas e a informação está preparada para uso.

Semelhante ao Davenport (1998), Choo (2006) também propõe um modelo para gerir a informação organizacional que perpassa pela elaboração de processos que contemplem a identificação das necessidades, busca e disponibilização da informação para uso. Trata-se de um ciclo (Figura 5) contendo seis etapas indissociáveis: (i) identificação das demandas informacionais; (ii) aquisição da informação; (iii) organização e armazenamento da informação; (iv) geração de produtos e serviços informacionais; (v) distribuição da informação; e (vi) utilização da informação (CHOO, 2006, p. 404). De acordo com esse autor, com a implementação dessas seis etapas, alcança-se o comportamento adaptativo, que se refere ao aproveitamento dos recursos e capacidades informacionais necessários “à seleção e à execução de ações dirigidas para os objetivos" e, também, condições de adaptação às condições ambientais. 


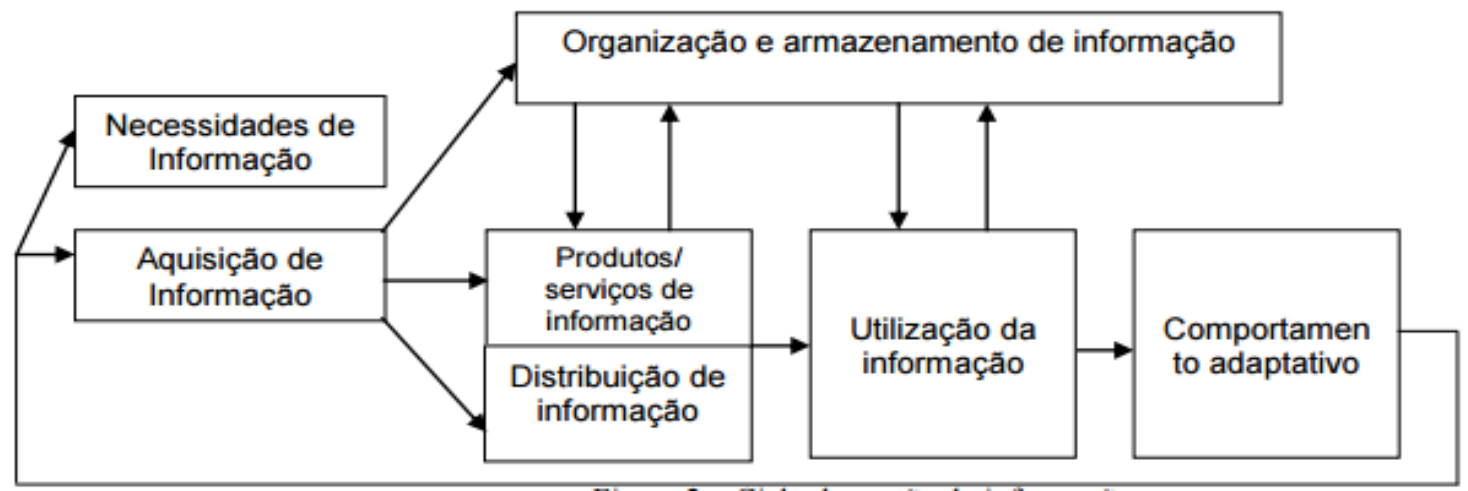

Figura 5 - Processo cíclico de GI organizacional Fonte: Choo (2006, p. 404).

Na literatura nacional, um dos modelos para GI no ambiente organizacional foi proposto por Beal (2004), que acrescenta uma etapa diferente aos modelos propostos por Davenport (1998) e Choo (2006): o descarte. Para essa autora, o fluxo informacional (Figura 6) é composto por sete etapas: (i) identificação das necessidades e requisitos informacionais: refere-se ao mapeamento das necessidades e dos requisitos para que sejam gerados os produtos informacionais adequados à aplicação "na melhoria de produtos ou processos" organizacionais; (ii) obtenção: ação de criação, captura em diferentes fontes e formatos, para servir de insumo aos processos da organização; (iii) tratamento: consiste na "organização, formatação, estruturação, classificação, análise, síntese e apresentação", requeridas pelo processo que irá utilizar as informações como insumo; (iv) distribuição: essa etapa refere-se à ação de levar a informação correta a "quem precisa dela": (v) uso: é a etapa mais importante, portanto, todo o esforço nas etapas anteriores somente fará sentido se houver o consumo da informação para melhorar os resultados organizacionais; (vi) armazenamento: etapa necessária para "assegurar a conservação dos informações e informações, permitindo seu uso e reuso dentro" do ambiente organizacional; (vii) descarte: concerne à necessidade de avaliação constante dos repositórios de informação para identificar o que poderá ser descartado em função da perda de utilidade ou defasagem (BEAL, 2004, p. 30). 


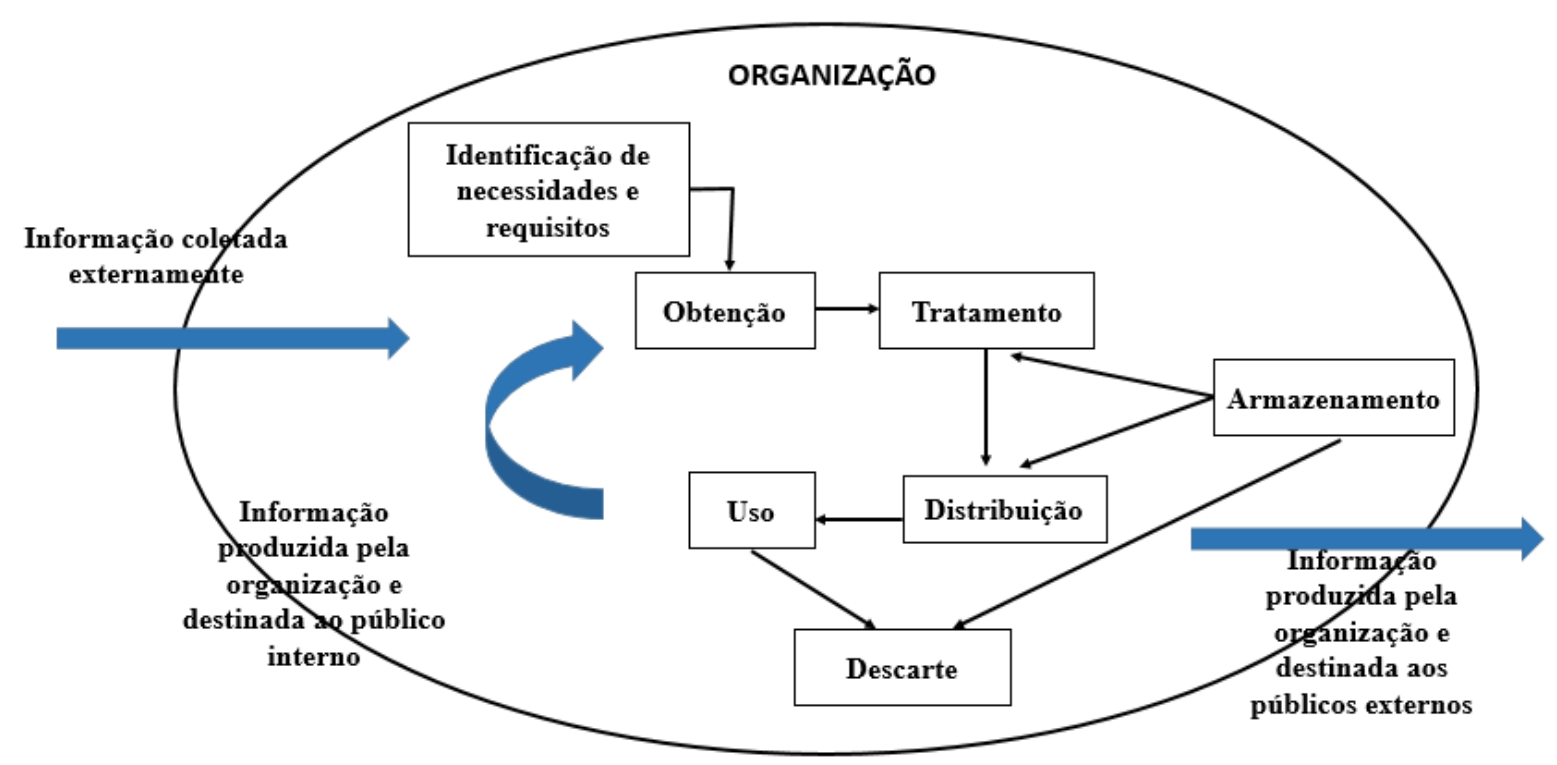

Figura 6 - Fluxo da informação nas organizações Fonte: Beal (2004, p. 29).

Um aspecto essencial no processo de GI é a preocupação com a qualidade da informação em cada uma das fases. A qualidade é um elemento que distingue a informação e a confere utilidade para uso (NASCIMENTO; TOMAÉL, 2013).

A qualidade da informação é um "conceito multidimensional” (PAIM et al, 1996; MORESI, 2000). Segundo Moresi (2000, p. 21), esse conceito "se realiza por meio de um conjunto de atributos ou características". Paim et al (1996, p. 112), por sua vez, afirma que, embora esse tema seja discutido desde a década de 1970, ainda "não há consenso na literatura sobre definições teóricas e operacionais da qualidade da informação”.

Para se desviar do senso comum, a proposta é analisar a qualidade da informação a partir de três dimensões: transcendente, intrínseca, contingencial (PAIM et al, 1996; OLETO, 2006). Segundo esses autores, a perspectiva transcendente refere-se ao "[...] reconhecimento do valor da informação como absoluto e universalmente aceitável”, além de atemporal; a dimensão intrínseca aborda aspectos relacionados à validade, à confiabilidade, à precisão, à completeza, à novidade, à atualidade, ao significado no tempo e à abrangência. A ótica contingencial ou prática da qualidade da informação tem como foco o usuário e sua "proposição central é a de 
que o valor ou a qualidade da informação depende do usuário e do contexto em que é considerada" (PAIM et al, 1996, p. 114). Esses autores afirmaram que classificar a qualidade da informação nessas três dimensões tem como objetivo destacar os predicados de "responsabilidade do provedor da informação, evitando o excessivo subjetivismo de definições usuais de qualidade da informação" (PAIM et al, 1996, p. 115).

Ressaltada a importância da qualidade da informação e a necessidade de estabelecimento de critérios que minimamente reduzam o senso comum e a subjetividade na avaliação da informação para uso, percebe-se que o processo de GI apresenta-se com ferramenta gerencial com potencial para garantir aspectos essenciais que favoreçam a percepção do usuário quanto à qualidade da informação e a sua capacidade de subsidiar a tomada de decisão na organização.

A GI é um tema explorado nessa pesquisa porque fornece embasamento teórico e metodológico para pesquisa e análise das necessidades informacionais associadas ao processo de DFT, bem como apresenta um conjunto de práticas de gestão da informação que, se adotado pelas organizações, favorece a definição das necessidades de informação, obtenção, distribuição e utilização. Práticas de gestão da informação referem-se à capacidade das organizações de gerir de forma efetiva seus recursos informacionais por todo o ciclo de vida da informação (MARCHAND; KETTINGER; ROLINS, 2000; KETTINGER, MARCHAND, 2011; BARBOSA; NASSIF, 2012).

O processo de DFT decorre da necessidade das organizações tomarem as melhores decisões acerca do planejamento e alocação de sua mão de obra, considerando os objetivos traçados. Nesse sentido, há a necessidade de análise de uma grande quantidade de informações que alimentam esse processo e geram um conjunto de outputs (saídas), resultados informacionais que subsidiam a tomada de decisão gerencial acerca do quadro de pessoal. 
A implantação de um processo de dimensionamento demanda das instituições gestão das informações requeridas pela metodologia adotada. Se essas informações não se encontram organizadas, armazenadas e recuperáveis no momento da implantação do processo, este pode ser fragilizado ou inviabilizado.

No capítulo a seguir, são apresentados os métodos, as técnicas e os procedimentos adotados, considerando o objeto de estudo e os objetivos almejados nesta pesquisa. 


\section{MÉTODOS, PROCEDIMENTOS E TÉCNICAS DE PESQUISA}

Neste capítulo são caracterizados a organização, o locus da pesquisa, os métodos, as técnicas, os procedimentos e as escolhas realizadas com relação à coleta e à análise das informações do estudo em questão.

\subsection{CARACTERIZAÇÃO DA ORGANIZAÇÃO}

A Administração Pública Federal (APF) é composta por um conjunto de órgãos e entidades que são responsáveis pela prestação de serviço de responsabilidade da União. Os Ministérios integram essa estrutura estatal e são ligados diretamente ao poder central. São estruturas por meio das quais o Governo Federal viabiliza sua agenda.

O Ministério da Saúde (MS), órgão onde foi aplicado esse estudo, foi criado em 1953, mas somente a partir de 1988, com a criação Sistema Único de Saúde (SUS) pela Constituição Federal, esse órgão passou a ocupar a função de coordenador federal desse Sistema, que representa uma política de grande impacto na vida de toda população brasileira.

Conforme consta no Decreto $n^{\circ}$ 8.065, de 07 de agosto de 2013 (BRASIL, 2013a), alterado pelo Decreto ${ }^{\circ}$ 8.490, de 13 de julho de 2015, o MS possui uma estrutura com sete secretarias, conforme se verifica na Figura 7. A força de trabalho do órgão é composta por cerca de 75 mil servidores ativos e o recurso orçamentário executado anualmente é de aproximadamente 70 bilhões. 


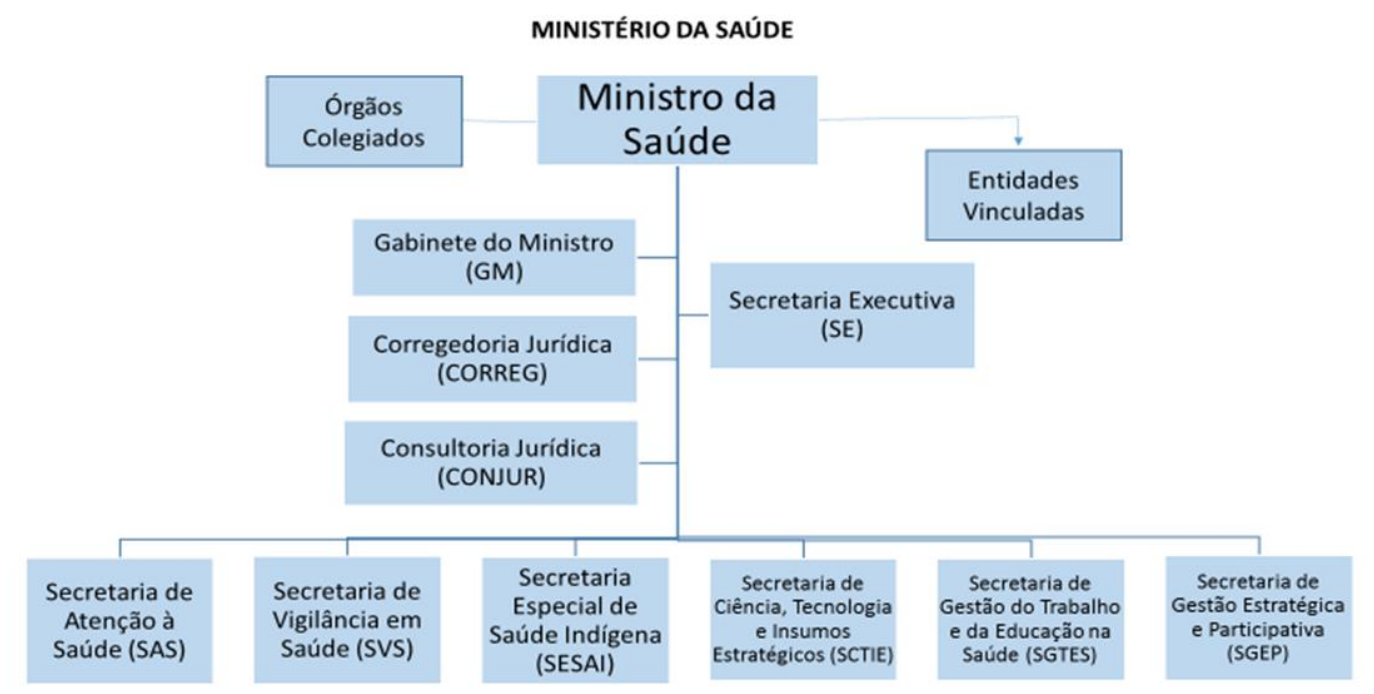

Figura 7 - Estrutura organizacional do Ministério da Saúde Fonte: site do Ministério da Saúde, 2016.

O quadro de trabalhadores desse órgão foi formado ao longo do tempo pela incorporação de servidores oriundos de órgãos da seguridade social extintos, concursos públicos, processos seletivos, prestadores de serviços e outras formas de contratações. Ocorre que não há atualmente um estudo consistente com critérios e parâmetros claros da real necessidade quantitativa e qualitativa de trabalhadores que esse órgão precisa para viabilizar seus processos de trabalho, alcançar os resultados pretendidos e aperfeiçoar a prestação de serviços públicos.

Na perspectiva de estruturação de um processo de DFT, capaz de gerar informações consistentes para a tomada de decisão da gestão acerca da formação dos quadros de trabalhadores do MS, foi iniciado em 2014 o Projeto de Estudo e Pesquisa para Dimensionamento da Força de Trabalho no Ministério da Saúde, cujo objetivo foi desenvolver uma metodologia de dimensionamento levando em consideração as peculiaridades das áreas, de forma a permitir ao órgão conhecer sua real necessidade de pessoal.

A etapa inicial do projeto de DFT consistiu na realização de um piloto no Fundo Nacional de Saúde (FNS). Essa unidade administrativa é responsável pela gestão financeira de todo recurso destinado ao Sistema Único de Saúde na esfera federal. Essa unidade possui cerca 
de 296 trabalhadores alocados nos seus processos de trabalho. Nesse locus foi desenvolvida a fase de pesquisa e desenvolvimento da primeira versão da metodologia de dimensionamento.

$\mathrm{Na}$ etapa seguinte, a metodologia passou por alguns ajustes e foi aplicada em duas outras unidades do MS: na Coordenação-Geral de Gestão de Pessoas (CGESP), que possui 298 trabalhadores, e no Núcleo Estadual do Ministério da Saúde no Ceará (NEMS/CE), com 162 trabalhadores.

A metodologia desenvolvida e aplicada nessas áreas tem como elemento central os processos de trabalho, considerando que todas as demais informações são analisadas a partir desses. Dessa forma, a gestão das informações relativas aos processos de trabalho, objeto de estudo dessa pesquisa, é essencial para o êxito do processo de DFT. Um ponto crítico para gerir essas informações é seu grande volume, em decorrência do porte da instituição e da diversidade dos processos. Por exemplo, nessas três áreas onde a metodologia foi aplicada foram identificados 214 processos de trabalho.

Portanto, considerando que o dimensionamento é um processo que ocorre de forma continua nas organizações, isso requer que a gestão das informações de processos de trabalho (obtenção, distribuição, uso e reuso) seja realizada para que a instituição possa de fato implantar o processo de DFT de forma exitosa. Esse é o desafio que se apresenta para o órgão locus dessa pesquisa.

\subsection{CARACTERIZAÇÃO DA PESQUISA}

Esta pesquisa buscou realizar um estudo empírico com o Ministério da Saúde para avaliar a presença de práticas de gestão da informação de processos de trabalho no contexto do Dimensionamento de Força de Trabalho (DFT). 
O estudo pode ser caracterizado como pesquisa-diagnóstico. Segundo Roesch (2006), essa tipologia de pesquisa é utilizada quando se deseja explorar o ambiente organizacional e definir o problema objeto de investigação.

Quanto ao método, essa pesquisa pode ser classificada como um estudo de caso, com delineamento descritivo e abordagem qualitativa. Essa escolha metodológica é adequada à proposta do Mestrado Profissional, uma vez que possibilita analisar um caso específico e prático e, principalmente, porque atende aos objetivos propostos nesse estudo. Segundo Minayo (2012), como método de pesquisa, o estudo de caso deve ser utilizado para entender uma unidade com profundidade, podendo se tratar de fenômeno individual, de grupo, organizacional, social, político, entre outros.

De acordo com Paula (2005), a administração por ser uma ciência social aplicada e que necessita do uso de métodos e técnicas de pesquisa qualitativos, pois, estes possibilitam analisar com profundidade a complexidade dos fenômenos examinados. Nesse mesmo sentido, Yin (2005, p. 20) afirma que a estratégia do estudo de caso é adotada quando se deseja "compreender fenômenos sociais complexos" e quando há o interesse de investigar em profundidade fenômenos em contextos reais, como "processos organizacionais e administrativos", em que as fronteiras entre o objeto de estudo e contexto não estão nitidamente delimitadas.

De acordo com Yin (2005), no estudo de caso incentiva-se a coleta de informações em várias fontes para corroborar um mesmo fenômeno. Dessa forma, foram realizados pesquisa documental e grupos focais com pesquisadores envolvidos no projeto de dimensionamento, com gestores-chave do órgão e com especialistas em processos e em tecnologia da informação. 


\subsection{CARACTERIZAÇÃO DOS INSTRUMENTOS DE PESQUISA}

Considerando o objeto de estudo, a natureza qualitativa, o caminho de investigação escolhido na primeira etapa da pesquisa foi a realização de entrevistas coletivas com seis atoreschave no desenvolvimento e aplicação da metodologia de dimensionamento de força de trabalho no MS. Para a coleta dos informações foi construído e validado pelo orientador da pesquisa um roteiro de entrevista contendo seis questões (Apêndice I), abordando as quatro etapas do processo de gestão da informação propostas por Davenport (1998): determinação das exigências informacionais, obtenção das informações, distribuição das informações e o uso dessas informações. Também foi perguntado aos entrevistados quais seriam os atores-chave que precisariam ser ouvidos sobre a disponibilidade das informações de processos de trabalho para o DFT. O objetivo dessa primeira parte da pesquisa foi identificar a presença de práticas de GI no contexto do DFT, na perspectiva do usuário da informação, que são os pesquisadores da Universidade de Brasília e membros do Comitê Técnico do DFT envolvidos na implantação do processo de dimensionamento.

A segunda parte da pesquisa procurou identificar a disponibilidade das informações de processos. Para alcançar esse objetivo, conforme recomendado pelos entrevistados da primeira parte da pesquisa, foi realizada entrevista coletiva com seis especialistas em processos que são membros do escritório de processos do Ministério da Saúde. Para coletar as informações, foi desenvolvido um roteiro de entrevista, validado pelo orientador da pesquisa, contendo cinco questões (Apêndice II) relativas à existência de cadeia de valor, ao mapeamento de processos, às informações de processos disponíveis, ao acesso às informações de processos mapeados e à integração do sistema de processos com outras bases do órgão.

Entrevista coletiva (ou entrevista em grupo) é uma técnica que "permite entrevistar um grupo de pessoas", possibilitando a amplificação do objeto da entrevista e possui algumas características como, por exemplo: (i) baixo custo; e (ii) riqueza de informações, porque 
estimula os entrevistados a se auxiliarem para relembrar fatos e irem além do que ocorreria em uma entrevista individual (FLICK, 2009, p.181).

$\mathrm{Na}$ terceira parte da pesquisa, conforme orientado pelos entrevistados da primeira parte desse estudo, foi realizada entrevista com dois especialistas em tecnologia da informação para identificar a existência no órgão de práticas de GI relativas à distribuição e à obtenção de informações de processos, exigidas no contexto do DFT. Para realização das entrevistas foi construído um roteiro, validado pelo orientador da pesquisa, contendo sete questões.

Como fonte de informações secundários, a quarta parte da pesquisa foi constituída de análise documental, cujo objetivo foi coletar informações acerca das necessidades e requisitos informacionais relativos aos processos de trabalho, bem como evidências das práticas de GI no contexto do órgão pesquisado. Para a realização de pesquisa documental, foi construído um formulário no aplicativo Excel para conferir sistematização à análise dos conteúdos (Apêndice III). Esse formulário foi dividido em três blocos: (i) identificação dos documentos: nome, formato, autoria, ano, natureza, objetivo e número de páginas; (ii) práticas relativas à gestão da informação de processos no contexto do dimensionamento: questão relativa a cada objetivo específico, prática identificada, evidência da prática no órgão, frequência em que aparece e documento; e (iii) práticas relativas à gestão da informação de processos - perspectiva da tecnologia da informação: questão direcionadora, resposta, evidência e documento.

A pesquisa documental, geralmente, é utilizada como fonte complementar a entrevistas ou algum outro método de coleta de informações (ROESCH, 2006). Análise documental seguiu os passos recomendados por essa autora, que são: acesso, verificação de autenticidade, compreensão dos documentos, análise das informações e utilização das informações.

Os documentos institucionais autorizados pela instituição para a realização da pesquisa documental foram: 23 Atas de Reunião do Projeto de Dimensionamento de Força de Trabalho; 02 Relatórios Executivos do Dimensionamento da Força de Trabalho; 01 Relatório de 
Desenvolvimento da Metodologia de DFT; 01 Relatório de Aplicação da Metodologia de DFT no FNS; 01 Relatório de Aplicação da Metodologia na CGESP; 01 Relatório de Aplicação da Metodologia no NEMS/CE; 01 Relatório Executivo da Gestão 2011-2014 do Departamento de Informática do SUS; 01 Plano Diretor de Tecnologia da Informação 2016 do MS.

No tópico a seguir serão apresentados os sujeitos entrevistados nas três primeiras etapas da pesquisa.

\subsection{PARTICIPANTES DA PESQUISA}

Adota-se nessa pesquisa o termo "participantes” para se referir aos indivíduos que foram entrevistados. De acordo com Günter (2003, p. 4), “em pesquisas fora do laboratório, termos como respondente, entrevistado ou participante são mais adequados”.

Considerando os objetivos propostos nessa pesquisa, são três os grupos de participantes desse estudo:

i. Grupo 1: constituído por seis entrevistados: 04 pesquisadores da Universidade de Brasília envolvidos no Projeto de Pesquisa de Dimensionamento da Força de Trabalho do Ministério da Saúde; e 02 servidores representantes do Comitê Técnico instituído pelo órgão para acompanhamento da execução desse Projeto. A escolha dos atores que compuseram esse grupo foi decorrente do papel central que eles exerceram ou exercem na implantação do processo de DFT no Órgão. Esses entrevistados podem ser classificados com os usuários das informações dos processos de trabalho, no contexto do DFT, considerando que são os atuais demandantes dessas informações.

ii. Grupo 2: a entrevista com esse grupo foi decorrente da recomendação do Grupo 1, ao ser perguntado sobre que atores-chaves poderiam apontar a 
situação atual da informação de processos de trabalho no âmbito do MS. Atendendo o indicativo, foi realizada entrevista coletiva com seis especialistas em gestão de processos, do escritório de processos do MS: 01 Coordenador e 05 analistas técnicos.

iii. Grupo 3: também decorrente da recomendação do Grupo 1, foram realizadas duas entrevistas com especialistas em TI. Um é gestor do DATASUS e outro desenvolve projetos estratégicos em tecnologia da informação para o MS. O primeiro foi escolhido pelo critério de acessibilidade, papel central que exerce na tomada de decisão sobre sistemas internos e pelo amplo conhecimento acerca da estrutura tecnológica do Órgão. A escolha do segundo entrevistado foi pelo critério de acessibilidade e devido ao conhecimento que possui sobre os recursos informacionais e de tecnologia da informação disponíveis na instituição.

Dessa forma, percebe-se que os entrevistados foram escolhidos em função do seu amplo conhecimento acerca de determinada perspectiva do objeto estudado. O Quadro 5 a seguir apresenta o perfil dos participantes da pesquisa.

Quadro 5 - Participantes da pesquisa

(Continua)

\begin{tabular}{|c|c|c|c|c|}
\hline \multicolumn{5}{|c|}{ ENTREVISTADOS } \\
\hline Grupo & Denominação & Perfil & Gênero & $\begin{array}{c}\text { Duração da } \\
\text { entrevista }\end{array}$ \\
\hline \multirow{6}{*}{1} & Entrevistado 1 & $\begin{array}{l}\text { Doutorando da Universidade de Brasília e } \\
\text { pesquisadores do Projeto de DFT }\end{array}$ & \multirow{6}{*}{$\begin{array}{c}03 \\
\text { masculinos e } \\
03 \text { femininos }\end{array}$} & \multirow{6}{*}{$\begin{array}{c}\text { 1h } 37 \mathrm{~min} \\
19 \mathrm{~s} ; \text { e } 42 \mathrm{~min} \\
11 \mathrm{~s}\end{array}$} \\
\hline & Entrevistado 2 & $\begin{array}{l}\text { Doutorando da Universidade de Brasília e } \\
\text { pesquisadores do Projeto de DFT }\end{array}$ & & \\
\hline & Entrevistado 3 & $\begin{array}{l}\text { Mestrando da Universidade de Brasília e } \\
\text { pesquisadores do Projeto de DFT }\end{array}$ & & \\
\hline & Entrevistado 4 & $\begin{array}{l}\text { Mestrando da Universidade de Brasília e } \\
\text { pesquisadores do Projeto de DFT }\end{array}$ & & \\
\hline & Entrevistado 5 & $\begin{array}{c}\text { Servidor do Ministério da Saúde e membro do } \\
\text { Comitê Técnico do DFT }\end{array}$ & & \\
\hline & Entrevistado 6 & $\begin{array}{l}\text { Servidor do Ministério da Saúde e membro do } \\
\text { Comitê Técnico do DFT }\end{array}$ & & \\
\hline
\end{tabular}

Fonte: informações da pesquisa. 
Quadro 5 - Participantes da pesquisa

(Conclusão)

\begin{tabular}{|c|c|c|c|c|}
\hline \multicolumn{5}{|c|}{ ENTREVISTADOS } \\
\hline Grupo & Denominação & Perfil & Gênero & $\begin{array}{l}\text { Duração da } \\
\text { entrevista }\end{array}$ \\
\hline \multirow{6}{*}{2} & Entrevistado 7 & $\begin{array}{l}\text { Servidor, gestor, especialista em processos, membro } \\
\text { do escritório de processos do Ministério da Saúde }\end{array}$ & \multirow{6}{*}{$\begin{array}{l}01 \text { masculino } \\
\text { e } 05 \\
\text { femininos }\end{array}$} & \multirow{6}{*}{ 1h $10 \min 10 \mathrm{~s}$} \\
\hline & Entrevistado 8 & $\begin{array}{c}\text { Servidor, Coordenador Substituto, especialista em } \\
\text { processos, membro do escritório de processos do } \\
\text { Ministério da Saúde }\end{array}$ & & \\
\hline & Entrevistado 9 & $\begin{array}{l}\text { Servidor, especialista em processos, membro do } \\
\text { escritório de processos do Ministério da Saúde }\end{array}$ & & \\
\hline & $\begin{array}{l}\text { Entrevistado } \\
10\end{array}$ & $\begin{array}{l}\text { Servidor, especialista em processos, membro do } \\
\text { escritório de processos do Ministério da Saúde }\end{array}$ & & \\
\hline & $\begin{array}{c}\text { Entrevistado } \\
11\end{array}$ & $\begin{array}{l}\text { Servidor, especialista em processos, membro do } \\
\text { escritório de processos do Ministério da Saúde }\end{array}$ & & \\
\hline & $\begin{array}{l}\text { Entrevistado } \\
12\end{array}$ & $\begin{array}{l}\text { Servidor, especialista em processos, membro do } \\
\text { escritório de processos do Ministério da Saúde }\end{array}$ & & \\
\hline \multirow[t]{2}{*}{3} & $\begin{array}{l}\text { Entrevistado } \\
13\end{array}$ & $\begin{array}{l}\text { Especialista em tecnologia da informação, consultor } \\
\text { em sistemas de informação }\end{array}$ & Masculino & $36 \min 43 \mathrm{~s}$ \\
\hline & $\begin{array}{l}\text { Entrevistado } \\
14\end{array}$ & $\begin{array}{l}\text { Servidor, gestor, especialista em tecnologia da } \\
\text { informação }\end{array}$ & Masculino & $18 \min 08 \mathrm{~s}$ \\
\hline
\end{tabular}

No tópico a seguir estão descritos os procedimentos de coleta de informações e as técnicas de análise que foram empregadas no estudo.

\subsection{PROCEDIMENTOS DE COLETAS E ANÁLISE DE INFORMAÇÕES}

As informações dessa pesquisa foram coletadas por meio de aplicação de entrevistas junto aos pesquisadores da Universidade de Brasília envolvidos no Projeto de Estudo e Pesquisa para Dimensionamento da Força de Trabalho no Ministério da Saúde, membros do Comitê Técnico do DFT (nomeado de Grupo 1), especialistas em processos do escritório de processos do MS (nomeado de Grupo 2), especialistas em TI (nomeado de Grupo 3). Foram entrevistados 14 atores presencialmente, entre os meses julho a novembro de 2016. A coleta de informações 
foi iniciada após autorização formal do MS para realização de entrevistas e acesso aos documentos de interesse da pesquisa.

Acrescenta-se que as entrevistas foram precedidas de uma introdução para apresentação do pesquisador, exposição da pesquisa e seus objetivos. Também foi solicitado aos entrevistados a leitura e assinatura de Termo de Consentimento Livre e Esclarecido (Apêndice V). O contato com os entrevistados, para convite, ocorreu por meio de contato telefônico e mensagens eletrônicas. Foi solicitada permissão para gravação de todos os áudios das entrevistas, para possibilitar a transcrição posterior das respostas.

Considerando a disponibilidade de agenda dos participantes do Grupo 1, primeiro foi realizada a entrevista coletiva com quatro dos atores desse grupo e posteriormente foram realizadas entrevistas com os dois outros atores juntos. O roteiro de entrevista foi estruturado a partir de categorias específicas relacionadas as quatro etapas do processo de GI (DAVENPORT, 1998), de forma a captar percepções, opiniões e esclarecimentos dos entrevistados acerca do processo de DFT, as informações de processos de trabalho necessárias, bem como a presença de práticas de GI apontadas na literatura no contexto do DFT. O roteiro pode ser observado ao final desse trabalho, nos apêndices.

As entrevistas com o Grupo 2 foram realizadas em um mesmo momento (entrevista em grupo ou coletiva) no espaço físico de realização de reuniões do escritório de processos do MS. Para essa entrevista com os seis atores, foi elaborado um roteiro de entrevista, também disponível nos apêndices, contendo cinco perguntas com objetivo de capturar como ocorre a gestão de processos do órgão, as disponibilidades das informações requerida na metodologia de DFT e a existência de integração das bases de informações de processos de trabalho com outros sistemas do órgão.

Como técnica complementar, foram selecionados os documentos com potencial de contribuição para a pesquisa, separadas cópias eletrônicas. Para conferir sistematização à 
análise documental, foi elaborado um formulário eletrônico no aplicativo Excel para realizar os registros das evidências.

A análise de informações foi realizada com a aplicação de técnica de análise de conteúdo. Essa técnica possibilita realizar "inferência de conhecimentos relativos às condições de produção (ou, eventualmente, de recepção), inferência esta que recorre a indicadores (quantitativos ou não) " e é composta pelas seguintes fases: “1) a pré-análise; 2) a exploração do material; 3) o tratamento dos resultados, a inferência e a interpretação" (BARDIN, 1977, p.38). Dessa forma, a análise dos informações observou o seguinte: (i) transcrição das entrevistas e pré-análise dos informações brutos coletados; (ii) identificação dos insumos informacionais relativos a processos no contexto do DFT do órgão; (iii) classificação dos informações nas quatro categorias predefinidas dos processos de GI (DAVENPORT, 1998), com auxílio de uma planilha do aplicativo Excel: determinação das exigências informacionais, obtenção das informações, distribuição das informações e uso da informações; (iv) identificação das práticas de GI relativas a processos no contexto do DFT, a partir de vinte e cinco práticas identificadas na literatura base da pesquisa, conforme Quadro 6; (v) verificação do atendimento das práticas pelo órgão pesquisado; e, por fim, (vi) interpretação dos informações a partir do referencial teórico adotado. 
Quadro 6 - Práticas associadas às etapas do processo de GI

(Continua)

\begin{tabular}{|c|c|}
\hline \multicolumn{2}{|r|}{ ETAPAS DO PROCESSO GI E SUAS PRÁTICAS } \\
\hline Etapas & Práticas \\
\hline \multirow{6}{*}{$\begin{array}{l}\text { Determinação de exigências } \\
\text { informacionais }\end{array}$} & 1. Clareza dos objetivos a serem alcançados (DAVENPORT, 1998) \\
\hline & $\begin{array}{l}\text { 2. Compreensão do contexto dos processos administrativos e suas necessidades } \\
\text { informacionais (DAVENPORT, 1998; BEAL, 2004) }\end{array}$ \\
\hline & $\begin{array}{l}\text { 3. Clareza das informações-chave para os usuários (DAVENPORT, 1998; } \\
\text { KETTINGER, MARCHAND, 2011) }\end{array}$ \\
\hline & $\begin{array}{l}\text { 4. Avaliação periódica da necessidade de readequação das exigências de } \\
\text { informação (DAVENPORT, 1998; BEAL, 2004) }\end{array}$ \\
\hline & 5. Definição clara dos limites das informações (escopo) (DAVENPORT, 1998) \\
\hline & $\begin{array}{l}\text { 6. Clareza das fontes de informação (DAVENPORT, 1998; BEAL, 2004; } \\
\text { KETTINGER, MARCHAND, 2011) }\end{array}$ \\
\hline \multirow{10}{*}{ Obtenção das informações } & $\begin{array}{l}\text { 7. Exploração do ambiente informacional por meio de abordagens } \\
\text { automatizada e humana (DAVENPORT, 1998) }\end{array}$ \\
\hline & $\begin{array}{l}\text { 8. A gestão reconhece a necessidade de investir sistemas que possibilitem a } \\
\text { filtragem de informações e geração de informações para os usuários } \\
\text { (DAVENPORT, 1998) }\end{array}$ \\
\hline & $\begin{array}{l}\text { 9. Fontes de informações atualizadas, confiáveis e disponíveis (DAVENPORT, } \\
\text { 1998; KETTINGER, MARCHAND, 2011) }\end{array}$ \\
\hline & $\begin{array}{l}\text { 10. Base de informações integrada que armazena e distribui as informações } \\
\text { (DAVENPORT, 1998; MARCHAND; KETTINGER; ROLINS, 2000); } \\
\text { KETTINGER, MARCHAND, 2011) }\end{array}$ \\
\hline & 11. Coleta e distribuição eletrônica de informações (DAVENPORT, 1998) \\
\hline & $\begin{array}{l}\text { 12. Equipes capacitadas e em quantitativos suficientes para geração e análise } \\
\text { das informações necessárias (DAVENPORT, 1998; MARCHAND; } \\
\text { KETTINGER; ROLINS, 2000; KETTINGER; MARCHAND, 2011) }\end{array}$ \\
\hline & $\begin{array}{l}\text { 13. Diretriz clara de rotinas a serem adotadas por cada produtor das } \\
\text { informações para classificação, interpretação e armazenamento do conteúdo } \\
\text { informacional gerado (DAVENPORT, 1998; MARCHAND; KETTINGER; } \\
\text { ROLINS, 2000; BEAL, 2004; KETTINGER; MARCHAND, 2011) }\end{array}$ \\
\hline & $\begin{array}{l}\text { 14. Estrutura de fornecimento das informações que favorece a autonomia do } \\
\text { usuário (DAVENPORT, 1998) }\end{array}$ \\
\hline & $\begin{array}{l}\text { 15. Informações categorizadas, classificadas em formatos que facilitam } \\
\text { compreensão pelo usuário (DAVENPORT, 1998; KETTINGER; } \\
\text { MARCHAND, 2011) }\end{array}$ \\
\hline & $\begin{array}{l}\text { 16. Informações produzidas para atender demandas específicas dos usuários } \\
\text { (DAVENPORT, 1998) }\end{array}$ \\
\hline \multirow{5}{*}{ Distribuição das informações } & $\begin{array}{l}\text { 17. A estrutura política favorece a distribuição da informação (DAVENPORT, } \\
\text { 1998) }\end{array}$ \\
\hline & $\begin{array}{l}\text { 18. Existe estratégia de distribuição de informação bem definida (por demanda, } \\
\text { por oferta programada ou mista) (DAVENPORT, 1998; BEAL, 2004) }\end{array}$ \\
\hline & $\begin{array}{l}\text { 19. Há arquitetura de informações que direciona a informação ao usuário dela } \\
\text { (DAVENPORT, 1998) }\end{array}$ \\
\hline & $\begin{array}{l}\text { 20. Há repositório eletrônico que integra as diversas bases de informações e } \\
\text { distribui as informações (DAVENPORT, 1998) }\end{array}$ \\
\hline & $\begin{array}{l}\text { 21. Os meios de distribuição das informações são automatizados } \\
\text { (DAVENPORT, 1998) }\end{array}$ \\
\hline
\end{tabular}

Fonte: Davenport, 1998; Beal, 2004; Marchand, Kettinger, Rolins, 2000; Kettinger, Marchand, 2011. 
Quadro 6 - Práticas associadas às etapas do processo de GI

(Conclusão)

\begin{tabular}{|c|l|}
\hline \multicolumn{2}{|c|}{ ETAPAS DO PROCESSO GI E SUAS PRÁTICAS } \\
\hline \multicolumn{1}{|c|}{ Etapas } & \multicolumn{1}{c|}{ Práticas } \\
\hline \multirow{5}{*}{ Uso das informações } & $\begin{array}{l}\text { 22 A instituição estimula e reconhece o uso das informações } \\
\text { (DAVENPORT, 1998) }\end{array}$ \\
\cline { 2 - 2 } & $\begin{array}{l}\text { 23. A frequência de uso da informação é conhecida pelo gerador do dado } \\
\text { (DAVENPORT, 1998) }\end{array}$ \\
\cline { 2 - 3 } & $\begin{array}{l}\text { 24. A instituição faz uso dessas informações nas avaliações de desempenho } \\
\text { (DAVENPORT, 1998; KETTINGER; MARCHAND, 2011) }\end{array}$ \\
\cline { 2 - 2 } & $\begin{array}{l}\text { 25. Há reuniões frequentes nas quais se faz uso das informações } \\
\text { (DAVENPORT, 1998) }\end{array}$ \\
\hline
\end{tabular}

Fonte: Davenport, 1998; Beal, 2004; Marchand, Kettinger, Rolins, 2000; Kettinger, Marchand, 2011.

Para verificar o quanto das práticas de GI são adotadas no contexto do processo de DFT, no órgão pesquisado, foram estabelecidos quatro critérios para essa análise: adota, adota parcialmente, não adota, não identificado. No Quadro 7, estão descritos os critérios usados para esse agrupamento. Considerando que as entrevistas são as informações primárias do estudo, a análise documental será considerada somente para confirmar ou não determinada constatação das informações coletadas com os entrevistados.

Quadro 7 - Critérios utilizados para sintetizar os resultados da pesquisa

(Continua)

\begin{tabular}{|l|l|}
\hline CRITÉRIOS & \multicolumn{1}{c|}{ DEFINIÇÃO } \\
\hline \multirow{5}{*}{ Adota } & $\begin{array}{l}\text { (i). Quando há a manifestação de ao menos um entrevistado afirmando a adoção da prática } \\
\text { pelo órgão e não há manifestação de não adoção; } \\
\text { (ii). Quando a metade dos entrevistados afirma que há adoção da prática pelo órgão; } \\
\text { (iii). Quando as manifestações de adoção e não adoção são numericamente equivalentes } \\
\text { e a análise documental confirma a adoção; } \\
\text { (iv). Quando há concordância pela adoção da prática em dois grupos de informantes; } \\
\text { (v). Quando não ocorre manifestação dos entrevistados e a análise documental confirma } \\
\text { a adoção da prática. }\end{array}$ \\
\hline \multirow{5}{*}{ Adota } \\
parcialmente
\end{tabular}

Fonte: elaborado pela autora. 
Quadro 7 - Critérios utilizados para sintetizar os resultados da pesquisa

(Conclusão)

\begin{tabular}{|l|l|}
\hline CRITÉRIOS & \multicolumn{1}{c|}{ DEFINIÇÃO } \\
\hline \multirow{5}{*}{ Não adota } & $\begin{array}{l}\text { (i). Quando não há manifestação dos entrevistados de que a prática é adotada pelo órgão; } \\
\text { (ii). Quando há manifestação de adoção e de não adoção da prática, mas a manifestação } \\
\text { de não adoção é percentualmente superior; } \\
\text { (iii). Quando as manifestações de adoção e não adoção são numericamente equivalentes } \\
\text { e a análise documental confirma a não adoção; } \\
\text { (iv). Quando há concordância pela não adoção da prática em dois grupos de informantes. } \\
\text { (v). Quando não ocorre manifestação dos entrevistados e a análise documental confirma } \\
\text { a não adoção das práticas. }\end{array}$ \\
\hline $\begin{array}{l}\text { Não } \\
\text { identificado }\end{array}$ & Quando não há manifestação dos entrevistados sobre a prática. \\
\hline
\end{tabular}

Fonte: elaborado pela autora.

O capítulo a seguir é dedicado à apresentação e à discussão dos achados desta pesquisa. 


\section{RESULTADOS E DISCUSSÕES}

Conforme apresentado no capítulo anterior, no período de 2015 a 2016, a metodologia de DFT foi aplicada em três unidades do MS: Fundo Nacional de Saúde (FNS), CoordenaçãoGeral de Gestão de Pessoas do MS (CGESP) e Núcleo Estadual do Ministério da Saúde no Ceará (NEMS/CE). Durante essa fase, 06 pesquisadores da Universidade de Brasília e 05 membros do Comitê Técnico de Dimensionamento participaram das atividades do Projeto de Estudo e Pesquisa para Dimensionamento da Força de Trabalho no Ministério da Saúde. Em momentos específicos, participaram também representantes do Departamento de Informática do SUS (DATASUS) e da Coordenação de Inovação de Processos e de Estruturas Organizacionais (CODIPE), considerando as competências relativas à tecnologia da informação e ao escritório de processos, respectivamente, que essas duas áreas gerenciam, que são essenciais para a implantação do processo de dimensionamento no Ministério da Saúde. Os resultados do trabalho realizado foram documentados por meio de relatórios, atas, instrumentos de suporte à aplicação da metodologia e mapeamento do processo de DFT.

Considerando o objeto da pesquisa, foram realizadas entrevistas com três grupos de sujeitos: pesquisadores e membros do Comitê Técnico do DFT do MS, especialistas em processos do escritório de processos e especialistas em tecnologia da informação, totalizando 14 entrevistados, conforme especificado no tópico sujeitos da pesquisa, com a finalidade de realizar as coletas de informações. Além disso, foram analisados dois conjuntos de documentos: relativos ao DFT (relatórios, atas, e documentos de suporte ao processo de DFT) e relativos à TI (relatório de gestão do 2011-2015 do DATASUS e o Plano Diretor de Tecnologia de Informação 2016 do MS - PDTI). Os resultados das entrevistas e das análises dos documentos são apresentados e discutidos a seguir.

A apresentação dos resultados está organizada da seguinte forma: primeiramente são apresentadas as informações de processos de trabalho requeridas pela metodologia de DFT; a 
segunda parte é composta por quatro seções referentes às categorias de análise: (i) Categoria 1

- determinação de exigências informacionais; (ii) Categoria 2 - obtenção das informações; (iii)

Categoria 3 - distribuição das informações; e (iv) Categoria 4- uso das informações. Nessas seções constam os resultados da verificação da manifestação das práticas de GI no contexto do DFT, no que tange a informações de processos de trabalho, e identificada se essas práticas são adotas pelo órgão pesquisado.

\subsection{QUANTO ÀS INFORMAÇÕES RELATIVAS A PROCESSOS REQUERIDAS PELO DFT}

As informações coletadas evidenciaram que a construção da metodologia de DFT do órgão foi precedida de ampla pesquisa na literatura científica sobre o tema e que a construção do modelo a ser adotado passou por análise detalhada do contexto interno da instituição, considerando suas limitações e potencialidades. Isso pode ser verificado nas falas dos entrevistados a seguir.

Durante o desenvolvimento da metodologia, nas primeiras versões, inclusive, a gente tinha duas perspectivas utilizadas para definir quais os requisitos/necessidades de informação: uma do ponto de vista teórico de quais as metodologias disponíveis e quais informações elas utilizavam, não só na literatura científica, mas também em casos práticos que foram observados, como requisitos do ponto de vista de premissas que o projeto tinha em relação quais tipos de informações que a gente teria acesso (ENTREVISTADO 1).

A gente viu o que o Ministério tem e daí buscamos na literatura "isso aqui que o Ministério tem é uma boa variável; essa outra medida que o Ministério tem é uma boa variável também" e aí montar a partir disso, né. Então, assim, a gente pegou o que o Ministério tem e usou a literatura como filtro, né, ao invés de buscar "ah, na literatura diz que tem que ter isso" porque aí depende "ah, o Ministério tem capacidade de fazer isso ou não?". Então, é um problema maior que a gente tem passado. O que o Ministério tem e como a gente pode trabalhar com o que o Ministério tem (ENTREVISTADO 4).

Após essa pesquisa inicial, foi iniciado o projeto piloto no FNS que possibilitou uma imersão no contexto dessa unidade, ocasionado a explicitação de algumas limitações de disponibilidades informacionais, conforme se verifica na fala do entrevistado 4 a seguir e, consequentemente, necessitando adequar a metodologia à realidade institucional. 
Então, considerando até a nossa primeira etapa de levantamento de informações, isso incluía, preferencialmente, também documentações que nos trouxessem informações sobre os processos das áreas. Então, assim, até como sendo base para a nossa metodologia, que são os processos e as entregas das áreas. Só que, claro, é uma dificuldade que a gente enfrentou, uma delas, porque as áreas em geral não são bem estruturadas, não tem mapeamento formalizado, né, os processos. Então, é um levantamento que a gente, muitas vezes, teve que começar desde o início, né, através do grupo focal, perguntando [...]. Para adaptar ao contexto, né. Inclusive é uma questão que se deve prezar muito, né. Não vamos só recorrer à literatura e utilizar o modelo, não, tem que fazer uma adaptação antes, até em termos do que o Ministério tem condições de oferecer (ENTREVISTADO 4).

Decorridas as fases de prototipação, experimentação e ajustes, previstas no método de estudo, pesquisa e desenvolvimento da metodologia de dimensionamento para o Ministério da Saúde, de acordo com os entrevistados e pesquisa documental, foram definidas as etapas do processo de dimensionamento da força de trabalho do órgão (Figura 8) e quais os requisitos informacionais de entrada para que os resultados oferecessem à gestão o quantitativo de pessoal necessário e os perfis profissionais requeridos, considerando os processos de trabalho das áreas e os resultados de produção de cada um deles. As exigências de informações relativas a processos de trabalho definidas foram: (i) processos de trabalho e suas etapas; (ii) indicadores de resultado dos processos de trabalho (produção) mensais e com histórico mínimo de 2 anos; (iii) percentual de tempo (esforço) dedicado para a execução dos processos; (iv) nível de informatização do processo de trabalho; (v) nível de complexidade do processo de trabalho; e (vi) valor agregado do processo de trabalho.

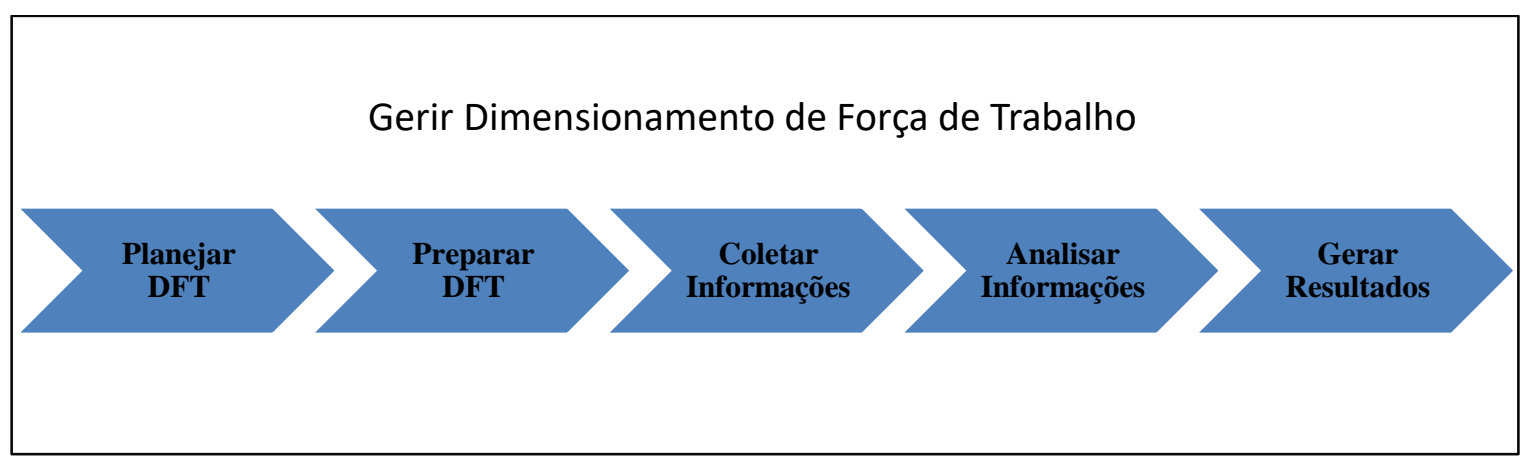

Figura 8 - Processo de DFT do Ministério da Saúde

Fonte: Documentação do processo DFT mapeado pelo escritório de processo do órgão. 
Recorrendo à literatura (CLACK et al., 2001; SOHONI; JOHNSON; BAILEY, 2004; NICOLA; ANSELMI, 2005; DAL BEN; GAIDZINSK, 2007; CRUZ et al, 2014; GRIFFITHS; PRESHAW, 2014; PAIXÃO et al, 2015) percebe-se que a metodologia de dimensionamento do órgão contempla cinco insumos informacionais relativos aos processos de trabalho que são apontados como importantes para dimensionar força de trabalho: produção, tempo, complexidade dos processos, nível de informatização e valor agregado. Dois outros insumos informacionais relativos a processos, que são recorrentemente apontados como importantes por alguns autores (NICOLA; ANSELMI, 2005; LI; CHEN; CAI, 2007; IVANNIKOVA; KRYSHKEVYCH, 2013; VIANNA et al, 2013; LADIER; ALPAN; PENZ, 2014; GRIFFITHS; PRESHAW, 2014; CRUZ et al, 2014; PAIXÃO et al, 2015), não foram contemplados na metodologia: demanda e tempo requerido para a execução das atividades. Em relação à demanda, o entrevistado 1 argumentou que houve necessidade de adaptação da metodologia ao contexto do órgão, considerando que as unidades, geralmente, não tinham clareza de sua demanda e, portanto, foi estabelecido um histórico de informações de dois anos para se conhecer a produção dos processos de trabalho e, com isso, estabelecer uma previsão de produção futura, conforme se verifica na fala a seguir.

No nível maior, onde a organização está mais preparada para fazer o dimensionamento, ela tem alguma forma de determinação de meta de produção. Então ela sabe no futuro, ela estima no futuro quanto daquele processo ela tem que executar e se existe algum aspecto contextual que vai fazer aquele processo aumentar ou diminuir e aí a aplicação do índice de produtividade sobre essa meta me permitiria dizer se eu vou precisar de mais pessoas ou não. Teria que considerar várias outras variáveis relacionadas, não só a parte de produtividade, mas parte de gestão de pessoas, mas ela tem um impacto direto nessa estimativa. Mas esse é o primeiro ponto. Como na nossa experiência a maioria das unidades não fazem um planejamento nesse nível de detalhe porque as vezes nem o foco de planejamento da própria área ou da própria organização porque muitas vezes isso é mais característica de unidade finalística do que de gestão, a gente utiliza a ideia da série histórica e tendências históricas como uma forma de previsão de cenários. Essa é uma técnica utilizada em outros casos onde não é possível determinar metas ou estimativas certeiras. Então, a análise do histórico permite tentar estabelecer uma tendência de como aquele processo vai se comportar no futuro e dessa forma fazer a prospecção de cenários para o dimensionamento. Nessa lógica, é por isso que existe essa necessidade, esse requisito da série histórica de informações. Independentemente de você trabalhar com metas de produtividade ou não, é necessário ter uma série histórica para estabelecer índices de produtividade do processo (ENTREVISTADO 1). 
Com relação ao tempo requerido para execução das atividades, as entrevistas evidenciaram que essa informação não estava disponível no órgão e que, considerando o porte da instituição, era inviável cronometrar o tempo de execução das atividades de cada processo de trabalho. Dessa forma a variável tempo, tratada na metodologia como esforço, foi medido por meio da identificação do percentual de tempo dedicado pelas equipes para geração da produção. As falas a seguir dos entrevistados explicam a escolha feita.

Esforço é um indicador de tempo né, que pode ser percentual ou índice absolutos que não afeta o potencial de análise. Porque de certa forma uma coisa vai ser ajustada a outra. Então as duas perguntas são: qual a sua jornada de trabalho e qual o percentual? Porque eu consigo transformar isso em horas absolutas, mas da mesma forma eu posso só perguntar as horas e depois somar e calcular o percentual a partir disso. Então se é percentual ou horas absolutas não faz diferença (ENTREVISTADO 1).

A adoção de percentual foi uma opção para que o indivíduo identificasse mais ou menos o tempo que ele dedicava para aquele resultado. O percentual ficou mais fácil para as pessoas informarem. Isso porque senão o indivíduo teria que somar suas horas por semana, por mês para definir o quantitativo de horas que ele se dedicava para contribuir com determinado resultado. Isso seria muito difícil. Usando percentual já foi considerado difícil (ENTREVISTADO 2).

Às pessoas a gente pergunta como é que elas fazem com $100 \%$ do tempo produtivo delas dentro da organização, como é a distribuição em relação às entregas da área. $\mathrm{E}$ aí num tempo maior para que ela possa contemplar todas as entregas em certo período para que possam contemplar sazonalidade. E essa informação é feita com base na percepção das pessoas (ENTREVISTADO 5).

Considerando os relatos apresentados, percebe-se que a definição das variáveis da metodologia relativa aos processos de trabalho levou em consideração potenciais informações disponíveis no órgão e, também, formas mais modernas de gestão do trabalho, considerando que modelos mecanicistas, como a cronoatividade, são pouco aderentes ao ambiente da instituição, onde os processos de trabalho são mais fluidos e menos rotineiros, diferenciado sobremaneira de um ambiente fabril. 


\subsection{QUANTO À DETERMINAÇÃO DAS EXIGÊNCIAS INFORMACIONAIS}

Nesta Categoria 1 são apresentadas e discutidas as informações oriundas das entrevistas realizadas com o Grupo 1, composto por integrantes da equipe de desenvolvimento do Projeto de Dimensionamento de Força de Trabalho no Ministério da Saúde no período de 2015 a 2016, e com o Grupo 2 (especialistas em processos). Buscou-se com as entrevistas identificar práticas de GI relativas às informações de processos no contexto do DFT, a partir de um rol de práticas identificadas na literatura base da pesquisa, e verificar se essas práticas são adotadas no órgão pesquisado.

A análise das informações evidenciou que as seis práticas de GI apontadas na literatura, na categoria determinação de exigências informacionais, estão presentes no contexto do processo de DFT: 1. Clareza dos objetivos a serem alcançados; 2. Compreensão do contexto dos processos administrativos e suas necessidades informacionais; 3. Clareza das informaçõeschave para os usuários; 4. Avaliação periódica da necessidade de readequação das exigências de informação; 5. Definição clara dos limites das informações (escopo); e 6. Clareza das fontes de informação.

Além dessas, foi identificada uma outra prática: identificação das possibilidades e restrições de informações do contexto. Esta pode ser definida como a verificação de quais informações podem ser acessadas e a partir disso se estabelece o que irá ser considerado no processo e, também, quais as restrições, dificuldades de geração da informação, que muitas vezes inviabiliza o uso de determinada variável, sendo sugerida a sua substituição. Percebe-se que o campo influencia na escolha das variáveis, que não são fruto somente de modelos predefinidos. Essa parece ser uma prática própria da estruturação do processo de dimensionamento ou de processos em que se aplica uma metodologia de prototipação, experimentação e validação. 
Após a verificação da presença das práticas da Categoria 1 no contexto do DFT, conforme previsto nos objetivos específicos da pesquisa, procedeu-se a análise para verificar a adoção dessas práticas pelo órgão pesquisado. Dessa forma, na sequência são apresentados os resultados e discussões das entrevistas realizadas com o Grupo 1 sobre as práticas, os achados a partir da análise documental, a manifestação dos entrevistados especialistas em processos (Grupo 2) e a discussão com base na literatura.

\subsubsection{Resultados e Discussões - Categoria 1}

Com relação à prática clareza dos objetivos a serem alcançados, as entrevistas coletivas revelaram que pelo próprio foco teórico-metodológico do tema dimensionamento de força de trabalho é possível compreender o que se pretende com um processo dessa natureza, embora algumas interfaces com outros processos organizacionais sejam necessárias, conforme pode ser observado na fala do entrevistado a seguir:

\footnotetext{
Então, o dimensionamento tem esse foco específico na quantidade de pessoas. Ele não entra em aspectos de infraestrutura ou outros aspectos que devem ser objeto de outros tipos de dimensionamento, planejamento da operacional que conversam com o dimensionamento. Então ele é uma ferramenta específica da área de gestão de pessoas. Digo gestão de pessoas como tema e não como área dentro da estrutura organizacional. Mas ele é uma ferramenta de gestão de pessoas que precisa conversar com planejamentos operacionais, planejamentos estratégicos e demais ferramentas de gestão de outras áreas temáticas de gestão (ENTREVISTADO 1).
}

Com relação a esse ponto, a pesquisa documental evidenciou que tanto o Termo de Execução Descentralizada n 52/2014 celebrado entre o Ministério da Saúde e a Universidade de Brasília, como os relatórios produzidos no âmbito do projeto apresentavam explicitamente o objetivo a ser alcançado: desenvolver e implementar uma metodologia de dimensionamento da força de trabalho do Ministério da Saúde que fosse capaz de evidenciar o quantitativo de pessoal necessário e os perfis profissionais para desenvolver os processos de trabalho.

Recorrendo à teoria base dessa pesquisa, verifica-se que ter clareza dos objetivos a serem alcançados e compreensão do processo gerencial que fará uso das informações é 
essencial para a definição adequada do conjunto de informações que deverão ser geradas (DAVENPORT, 1998). Nesse mesmo sentido, Beal (2004) afirma que o esforço para definir os requisitos informacionais não é tarefa fácil, mas é recompensado com a percepção de que a informação é útil para o destinatário dela. Percebe-se que, conforme recomenda a literatura, havia clareza dos objetivos a serem alcançados pelo processo de dimensionamento e, portanto, essa prática de GI foi atendida no contexto analisado.

Em relação à prática compreensão do contexto dos processos administrativos e suas necessidades informacionais, conforme se verifica na fala a seguir, houve uma exploração inicial do ambiente organizacional que subsidiou a estruturação da metodologia:

A gente viu o que o Ministério tem e daí buscamos na literatura "isso aqui que o
Ministério tem é uma boa variável; essa outra medida que o Ministério tem é uma boa
variável também" e aí montar a partir disso, né. Então, assim, a gente pegou o que o
Ministério tem e usou a literatura como filtro, né, ao invés de buscar "ah, na literatura
diz que tem que ter isso" porque aí depende "ah, o Ministério tem capacidade de fazer
isso ou não?". Então, é um problema maior que a gente tem passado. O que o
Ministério tem e como a gente pode trabalhar com o que o Ministério tem
(ENTREVISTADO 4).

Percebe-se que durante o processo de construção da metodologia alguns fatores, como

a falta de clareza das próprias áreas acerca de seus processos de trabalho, influenciaram nas escolhas das etapas de condução dos trabalhos, de acordo com a fala a seguir:

Para adaptar ao contexto, né. Inclusive é uma questão que se deve prezar muito, né. Não vamos só recorrer à literatura e utilizar o modelo, não, tem que fazer uma adaptação antes, até em termos do que o Ministério tem condições de oferecer. [...] então, considerando até a nossa primeira etapa de levantamento de informações, isso incluía, preferencialmente, também documentações que nos trouxessem informações sobre os processos das áreas. Então, assim, até como sendo base para a nossa metodologia, que são os processos e as entregas das áreas. Só que, claro, é uma dificuldade que a gente enfrentou, uma delas, porque as áreas em geral não são bem estruturadas, não tem mapeamento formalizado, né, os processos. Então, é um levantamento que a gente, muitas vezes, teve que começar desde o início, né, através do grupo focal, perguntando[...] o ideal era que isso já tivesse muito bem preparado para que a gente conseguisse alinhar o dimensionamento ao que estaria sendo feito aqui em termos de gestão de processos, o que acabou não acontecendo, né. Então, nesse sentido foi mais uma questão de levantar informação, buscar quais eram os processos e as entregas do que achar isso pronto e sistematizado já (ENTREVISTADO 3). 
Nesse mesmo sentido, o entrevistado 5, conforme abaixo, argumenta que essa falta de clareza por parte dos gestores sobre os seus fluxos de trabalho foi um ponto crítico que impactou a implantação do DFT nas áreas analisadas, ao mesmo tempo em que provocou nessas unidades uma reflexão sobre seus processos de trabalho e seus resultados.

\begin{abstract}
A gente verificou também que durante o dimensionamento, nesse início do processo mesmo em que a gente foi entrevistar os gestores das áreas e realizar os grupos focais, muitas vezes os próprios gestores não tem clareza do que eles estão fazendo, de quais são seus processos de trabalho. Então, isso também provoca uma reflexão da área. Então seria interessante que os gestores tivessem clareza de quais são suas entregas, quais são seus processos (ENTREVISTADO 5).
\end{abstract}

Os relatos das entrevistas com os especialistas em processos, que fazem parte do escritório de processos do órgão, demonstram que a compreensão do contexto dos processos administrativos e suas necessidades informacionais demanda uma análise detalhada da documentação dos processos de trabalho mapeados. Porém, foi relatado que esse trabalho de mapeamento ainda abrange poucas unidades na organização, não permitindo ter uma visão de todos os processos do órgão. Principalmente porque, conforme a seguir, a cadeia de valor da instituição e de suas secretarias não estão definidas, o que dificulta a compreensão dos processos gerenciais, finalísticos e de suporte de todas as unidades da instituição.

Porque normalmente quando você vai fazer a cadeia, você identifica que eles não conhecem os seus próprios processos...nem os processos. Não sabem se existem, quais os processos existem. Então, eu acho que é um tema ainda que falta maturidade, né (ENTREVISTADO 10).

A pesquisa documental apontou que em reunião com a equipe alocada no projeto foi orientado que essa deveria se apropriar "ao máximo de informações acerca do funcionamento do MS, das áreas visitadas e seus processos de trabalho para evitar demonstração de desconhecimento" do contexto das unidades (Ata de Reunião no 4, p. 1; Ata de Reunião no 6, p.1). Nessa mesma Ata de $n^{\circ}$, consta que havia certa assimetria de informações na equipe de desenvolvimento do projeto com relação à concepção do projeto, estrutura do órgão e composição da força de trabalho. 
Essas evidências apontam para uma situação já mencionada por Davenport (1998) e Beal (2004) que é a dificuldade de se conhecer a fundo o contexto dos processos de trabalho sem que haja uma imersão nas áreas da organização. Em se tratando de um órgão do porte do Ministério da Saúde, com uma grande quantidade, diversidade e complexidade de processos de trabalho, essa dificuldade é elevada. A complexidade dos processos de trabalho inclusive foi mencionada no $1^{\circ}$ Relatório Executivo do Comitê Técnico do DFT, no qual foi citado como ponto crítico ao bom andamento dos trabalhos. Outro fator complicador é a baixa cultura de gestão de processos, a baixa automação e a gestão da produção das unidades.

Quanto à prática clareza das informações-chave para os usuários é importante destacar que os usuários no contexto do DFT são os condutores do processo (pesquisadores da UnB e áreas do Ministério da Saúde responsáveis pela implementação do dimensionamento) que precisam ter acesso às informações essenciais para condução dos trabalhos.

O entrevistado 1 afirmou que os usuários da informação tinham clareza das informações-chave e que, inclusive, o rol de informações de processos necessário e o nível de detalhamento fez parte das premissas de construção da metodologia de DFT. Isso pode ser confirmado na fala seguinte:

\footnotetext{
Uma das premissas que a gente não entraria nesse nível de detalhamento que a gente focaria na verdade nos resultados que cada processo gera, ou seja, um produto, um serviço, um resultado de gestão e isso seria o ponto base de mensuração dessa unidade de tempo ao invés de entrar necessariamente no processo (ENTREVISTADO 1).
}

Por outro lado, o entrevistado 5 destacou, conforme a seguir, que essa clareza não era compartilhada pelos produtores das informações de processos, necessitando de alinhamento conceitual acerca das terminologias adotadas no âmbito do processo de DFT, demonstrando pouca aproximação com o tema gestão de processos. Isso evidencia que, embora haja um escritório de processo no órgão e esse seja um tema importante para gestão das unidades, o diálogo e prática acerca da gestão de processos não faz parte do cotidiano das unidades. 
Existe também uma falta de clareza que a gente percebeu até acerca dos conceitos do que é um processo. Eles não sabiam, por exemplo, a diferença entre um processo, entrega e atividade. Muitas das equipes, por exemplo, achavam que as atividades eram as entregas finais dos processos. E não como parte de um processo maior que tinha uma entrega. Então isso, no início do processo de dimensionamento isso foi muito difícil com as áreas até que a gente conseguisse definir quais eram as entregas de cada processo (ENTREVISTADO 5).

As informações da pesquisa documental corroboram a afirmação do entrevistado 5, uma vez que constam nas Atas $n^{\circ} 4$ e $n^{\circ} 6$ que havia necessidade de ajuste no fluxo de coleta de informações e nas terminologias utilizadas nos instrumentos, porque os produtores das informações estavam com dificuldade de compreender o que os usuários estavam demandando. Essa falta de compreensão dos produtores da informação foi recorrente no âmbito do projeto piloto, de acordo com a pesquisa documental, não sendo observada na aplicação da metodologia em outras áreas. Isso sugere que a incorporação de uma etapa de capacitação na metodologia pode ter esclarecido às unidades produtoras as necessidades informacionais do processo de DFT.

Sobre essa dificuldade de o produtor da informação ter clareza do que realmente o usuário necessita, Davenport (1998) afirma que o produtor precisa buscar compreender qual o problema a ser resolvido, para que a informação produzida de fato consiga auxiliar em sua resolução. Nesse mesmo sentido, Marchiori (2002), Valentim e Cervantes (2003) afirmam que a compreensão de quais informações são necessárias é o primeiro passo para que a organização inicie ações com foco no atendimento dessas necessidades informacionais. Corroborando o disposto na literatura, a partir dos relatos dos entrevistados e da análise documental, percebe-se que a dificuldade de compreensão dos produtores da informação foi sendo superada com a capacitação no processo de DFT.

Já em relação à prática avaliação periódica da necessidade de readequação das exigências de informação, de acordo com os entrevistados, no decorrer da implantação do processo de DFT, algumas necessidades informacionais relativas aos processos de trabalho foram agregadas à metodologia e, também, outras foram revistas para que se obtivessem 
informações de melhor qualidade. Então, essa prática de avaliar a necessidade de readequação das exigências de informação foi constatada, conforme se verifica na fala a seguir:

\begin{abstract}
Algumas outras premissas surgiram ao longo do tempo, que não foram no início, mas durante a aplicação na prática nós começamos a perceber algumas necessidades de adequação, como por exemplo, cada processo ser ter somente uma entrega, somente um produto [...] A ideia inicial, na primeira versão, era perguntar o tempo por entrega, para uma entrega. A gente percebeu que isso não era viável porque uma mesma entrega pode ter diferentes níveis de complexidade e isso acontece para a maioria dos processos. [...] então, a ideia de usar percentual e de novo uma estratégia de ter acesso a uma informação mais fácil e uma informação que tem uma estimativa mais correta (ENTREVISTADO 1).
\end{abstract}

A pesquisa documental evidenciou que pela própria natureza inovadora do projeto de desenvolvimento e implantação de uma metodologia de dimensionamento e a adoção do método Design Science já indicava a necessidade prototipação, experimentação e validação. Percebe-se que no projeto piloto foram percorridas essas fases e, portanto, verificada e testada a pertinência das variáveis para o locus no qual ocorria a aplicação da metodologia.

Com relação à prática definição clara dos limites das informações (escopo), sob a perspectiva do usuário havia clareza das informações. O entrevistado 1, fala a seguir, argumenta que havia uma delimitação das informações referentes aos processos de trabalho requeridas pela metodologia de DFT.

Precisa conhecer os processos que ela executa e quais entregas que cada um desses processos têm no final [...] então, inicialmente ela teria uma identificação mínima nos processos, não um mapeamento, uma vez que a proposta da metodologia não era analisar atividade, mas sim o processo como um todo, mas haveria necessidade de ter a identificação desses processos e quais os resultados que eles geravam. Então, qual o produto final daquele processo essa seria a unidade que eu utilizaria para medir o tempo (ENTREVISTADO 1).

A pesquisa documental evidenciou que havia uma definição dos limites (escopo) das informações e que essas eram referentes aos processos das áreas e seus resultados (produção). No entanto, nos registros documentais foi percebido também que o conceito de processo adotado na metodologia gerou algumas dúvidas nos produtores das informações, que não sabiam exatamente quais informações deveriam considerar no cálculo dos indicadores de 
produção. Foi verificado nos registros que essas dúvidas foram sanadas pelos pesquisadores e membros do comitê técnico.

Como o conceito de processo de trabalho pode mudar a depender da metodologia adotada e do referencial assumido, uma ação de capacitação em processo poderia dirimir as dúvidas existentes e evitar atrasos no cronograma por falta de compreensão dos limites (das fronteiras) a serem observadas na produção da informação. No entanto, não se observou na pesquisa documental a realização de tal ação.

A clareza das fontes de informação é uma prática apontada na literatura como importante para o processo de GI e há o reconhecimento disso no contexto do DFT, de acordo com a fala do entrevistado 6. Ocorre que, de acordo com os entrevistados 1 e 5, nem sempre essa identificação das fontes pode ser feita a priori, em função de que as áreas não tinham os processos identificados antes de começar a aplicação da metodologia de DFT. Dessa forma, muitas das fontes foram definidas à medida que a metodologia de dimensionamento foi aplicada, como pode ser confirmado nas falas seguintes.

Então é importante que as fontes de informações sejam bem definidas e não fique a cargo das equipes. Indicando onde, de fato, essas informações estão. É claro que em alguns processos as informações de produção não estarão em sistemas, mas o máximo que se puderem usar esses sistemas oficiais como fonte de informação, mais bem ancorado estará o dimensionamento. Isso é o ideal. Até porque, por causa do dimensionamento, o sujeito acaba tendo que qualificar a informação para inserir naquele sistema (ENTREVISTADO 6).

Não foram travadas as fontes informações porque, no início do projeto, muitas áreas não tinham clareza das entregas e somente depois da definição dos processos e entregas é que se verificam onde essas informações poderão ser obtidas. Em um segundo ciclo de dimensionamento isso poderia ser feito. As informações de produção vieram de diferentes fontes: sistemas, planilhas, documentos Word, dentre outros. E sempre essas informações foram apuradas e declaradas pelas áreas que estavam passando pelo dimensionamento (ENTREVISTADO 1).

Também porque os gestores no momento podem não ter clareza dessas fontes. Mas, no momento de levantamento das informações da área, são identificados os documentos da área, principais processos, etapas desses processos, entregas e os sistemas de coleta, onde essas informações poderão ser obtidas. Isso é declarado pelo gestor. Nem sempre essas informações estão disponíveis em sistemas, muitas vezes são planilhas, arquivos, espaços que se tem na rede, documentos em Word, processos físicos, listas de presença, enfim. Existe uma série de fontes de informação a depender da entrega. O acesso a essas fontes se dá pelas áreas (ENTREVISTADO 5). 
A fonte de informação que foi definida na concepção da metodologia foi a variável esforço, conforme fala do entrevistado 1. Essa definição, de acordo com a pesquisa documental, foi devido à constatação de que essa informação não estava disponível na instituição, que não iria ser adotado o método de cronoatividade, por ser uma forma mecanicista de mensuração de tempo de dedicação dos trabalhadores às atividades laborais e, também, porque era inviável, considerando o porte da organização. Assim, foi feita a escolha de coletar essa informação diretamente com o trabalhador por meio da declaração de percentual de tempo dedicado à produção dos resultados do(s) processo(s) nos quais suas atividades eram exercidas.

Então, foi dessa forma que surgiu também que o tempo fosse declarado e não medido numa coleta primária necessariamente (ENTREVISTADO 1).

Com relação à identificação das fontes de informação disponíveis, a pesquisa documental indica que houve uma tentativa dos pesquisadores e técnicos em fazer um levantamento dos sistemas da organização que pudessem ser potenciais fontes de informação de resultados de processos, que poderiam ser utilizados no contexto do DFT. No entanto, não obtiveram êxito porque a unidade de tecnologia de informação, que gerencia os bancos de informações, considerou inviável fazer esse levantamento.

Recorrendo à literatura base dessa pesquisa, percebe-se que o mapeamento da informação disponível, diferentemente do que foi sugerido pela área de tecnologia da informação do órgão, de acordo com Davenport (1998) e Beal (2004), é uma importante ação para conduzir o usuário às fontes de informação de que necessita. Segundo essa autora, esse mapeamento aumenta consideravelmente a chance dessas informações serem utilizadas e reutilizadas eficientemente e que, além disso, algumas disfunções, como informações dispersas, divergentes, excessivas e em duplicidade podem ser evitadas.

A análise das evidências demonstrou que a determinação das exigências informacionais foi antecedida da prática de identificação das possibilidades e restrições de informações do 
contexto. A identificação das possibilidades consiste na verificação de que informações podem ser acessadas e a partir disso se estabelece o que irá ser considerado no processo. Percebe-se que o campo influencia na escolha das variáveis, que não são fruto somente de modelos predefinidos. As restrições são dificuldades de geração da informação que, muitas vezes, inviabiliza o uso de determinada variável, sendo sugerida a sua substituição. O que se percebe na fala dos entrevistados, conforme a seguir, é que embora tenham sido definidos requisitos mínimos, as disponibilidades e as limitações do ambiente interno influenciaram na definição do conjunto de informações que a metodologia considerou.

Durante o desenvolvimento da metodologia, nas primeiras versões, inclusive, a gente tinha duas perspectivas utilizadas para definir quais os requisitos/necessidades de informação: uma do ponto de vista teórico de quais as metodologias disponíveis e quais informações elas utilizavam, não só na literatura científica, mas também em casos práticos que foram observados, como requisitos do ponto de vista de premissas que o projeto tinha em relação quais tipos de informações que a gente teria acesso (ENTREVISTADO 1).

A gente viu o que o Ministério tem e daí buscamos na literatura "isso aqui que o Ministério tem é uma boa variável; essa outra medida que o Ministério tem é uma boa variável também" e aí montar a partir disso, né. Então, assim, a gente pegou o que o Ministério tem e usou a literatura como filtro, né, ao invés de buscar "ah, na literatura diz que tem que ter isso" porque aí depende "ah, o Ministério tem capacidade de fazer isso ou não? ". Então, é um problema maior que a gente tem passado. O que o Ministério tem e como a gente pode trabalhar com o que o Ministério tem. (ENTREVISTADO 4).

De acordo com a literatura sobre o tema dimensionamento, a definição das demandas informacionais para um processo de dimensionamento é norteada pela metodologia a ser adotada (CLACK et al., 2001). Dessa forma, percebe-se que a construção de uma metodologia própria para o órgão não poderia desconsiderar aspectos que pudessem inviabilizar a implementação desse processo nas unidades. Acrescenta-se que a pesquisa documental evidencia esforços da equipe de desenvolvimento do projeto de DFT, na fase de prototipação, para superar limitações de disponibilidade acerca das informações referentes a processos de trabalho que se enquadra em requisitos mínimos, como produção, por exemplo, para se conseguir gerar os resultados do dimensionamento de forma satisfatória. 
Considerando as quatro categorias de resultados possíveis (adota, adota parcialmente, não adota, não identificado) e os critérios usados para esse agrupamento, no Quadro 8, a seguir são sintetizados os achados da pesquisa referentes à Categoria 1.

Quadro 8 - Síntese das informações sobre a adoção das práticas referentes à Categoria 1

\begin{tabular}{|c|c|c|c|c|c|}
\hline \multicolumn{6}{|c|}{ CATEGORIA 1: DETERMINAÇÃO DE EXIGÊNCIAS INFORMACIONAIS } \\
\hline \multirow{2}{*}{ Práticas } & \multicolumn{3}{|c|}{$\begin{array}{l}\text { Adoção das práticas de acordo com } \\
\text { os entrevistados do Grupo } 1\end{array}$} & \multirow[t]{2}{*}{$\begin{array}{c}\text { Análise } \\
\text { documental }\end{array}$} & \multirow{2}{*}{ Resultados } \\
\hline & Adota & $\begin{array}{c}\text { Não } \\
\text { adota }\end{array}$ & $\begin{array}{c}\text { Sem } \\
\text { manifestação }\end{array}$ & & \\
\hline $\begin{array}{l}\text { 1. Clareza dos objetivos a serem } \\
\text { alcançados }\end{array}$ & $17 \%$ & - & $83 \%$ & Adota & Adota \\
\hline $\begin{array}{l}\text { 2. Compreensão do contexto dos processos } \\
\text { administrativos e suas necessidades } \\
\text { informacionais }\end{array}$ & $33 \%$ & $17 \%$ & $50 \%$ & Não adota & $\begin{array}{c}\text { Adota } \\
\text { parcialmente }\end{array}$ \\
\hline $\begin{array}{l}\text { 3. Clareza das informações-chave para os } \\
\text { usuários }\end{array}$ & $50 \%$ & $17 \%$ & $33 \%$ & Adota & Adota \\
\hline $\begin{array}{l}\text { 4. Avaliação periódica da necessidade de } \\
\text { readequação das exigências de informação }\end{array}$ & $17 \%$ & - & $83 \%$ & Adota & Adota \\
\hline $\begin{array}{l}\text { 5. Definição clara dos limites das } \\
\text { informações (escopo) }\end{array}$ & $50 \%$ & $17 \%$ & $33 \%$ & Adota & Adota \\
\hline 6. Clareza das fontes de informação & - & $33 \%$ & $67 \%$ & Não adota & Não adota \\
\hline $\begin{array}{l}7 \text { - Identificação das possibilidades e } \\
\text { restrições de informações do contexto } \\
\text { (identificada na pesquisa) }\end{array}$ & $33 \%$ & - & $67 \%$ & Adota & Adota \\
\hline
\end{tabular}

Fonte: informações da pesquisa.

Com relação à adoção das práticas de GI relativas às informações de processos no contexto do DFT pelo órgão pesquisado, os resultados das entrevistas com o Grupo 1 demonstraram o seguinte: $17 \%$ dos entrevistados afirmaram que houve adoção da prática 1; $33 \%$ dos entrevistados confirmaram a adoção da prática 2; $50 \%$ dos entrevistados reconheceram a adoção da prática 3; $17 \%$ dos entrevistados apontaram a adoção da prática $4 ; 50 \%$ dos entrevistados reconheceram a adoção da prática 5; não houve manifestação de adoção da prática 6; 33\% dos entrevistados apontaram a presença da prática identificação das possibilidades e restrições de informações do contexto. 
Os resultados da pesquisa documental, por sua vez, não confirmaram a adoção das práticas 2 e 6 . Esta última foi apontada pelos entrevistados como importante, porém as tentativas de identificar as práticas a priori foram esvaziadas em função de que o órgão não tinha essa informação mapeada e disponível. Dessa forma, a cada aplicação da metodologia de dimensionamento, são levantados os processos das áreas e, posteriormente, verificado onde as informações de resultados desses processos podem ser localizadas, se em alguma ferramenta informatizada ou em meio físico.

Os resultados das entrevistas demonstraram baixa manifestação dos entrevistados acerca da adoção ou não das práticas pelo órgão pesquisado (cinco práticas). No entanto, a partir dos critérios estabelecidos para consolidar os resultados foi possível perceber que, das sete práticas, três são adotas pelo órgão, três são adotadas parcialmente e uma não foi constatada adoção no contexto pesquisado. A partir dos relatos dos especialistas em processo, é possível compreender o grau de dificuldade de adoção da prática 2 na integra (compreensão do contexto dos processos administrativos e suas necessidades informacionais), considerando que não estão disponíveis na instituição documentações relativas às cadeias de valor das unidades e que os mapeamentos de processos e o controle de indicadores de produção ainda são incipientes. Esse cenário sugere que há no órgão uma baixa cultura de gestão das informações de processos e de resultados.

\subsection{QUANTO À OBTENÇÃO DAS INFORMAÇÕES}

A Categoria 2 contempla os resultados e discussão das informações coletados por meio das entrevistas realizadas com o Grupo 1 (integrantes da equipe de desenvolvimento do Projeto de Dimensionamento de Força de Trabalho no Ministério da Saúde no período de 2015 a 2016), Grupo 2 (especialistas em processos) e Grupo 3 (especialistas em TI). Primeiramente as informações foram analisadas com o objetivo de identificar práticas de GI relativas às informações de processos no contexto do DFT, tomando por base um conjunto de práticas 
apontadas na literatura base desse estudo. Na sequência, foi verificada a adoção dessas práticas pela instituição locus da pesquisa.

As informações evidenciaram que as dez práticas apontadas na literatura, na categoria obtenção das informações, estão presentes no contexto do processo de DFT: 7. Exploração do ambiente informacional por meio de abordagens automatizada e humana; 8 . A gestão reconhece a necessidade de investir sistemas que possibilitem a filtragem de informações e geração de informações para os usuários; 9. Fontes de informações atualizadas, confiáveis e disponíveis; 10. Base de informações integrada que armazena e distribui as informações; 11 . Coleta e distribuição eletrônica de informações; 12. Equipes capacitadas e em quantitativos suficientes para geração e análise das informações necessárias; 13. Diretriz clara de rotinas a serem adotadas por cada produtor das informações para classificação, interpretação e armazenamento do conteúdo informacional gerado; 14 . Estrutura de fornecimento das informações que favorece a autonomia do usuário; 15. Informações categorizadas, classificadas em formatos que facilitam compreensão pelo usuário; 16. Informações produzidas para atender demandas específicas dos usuários. Não foram encontradas outras práticas no contexto pesquisado.

Realizada a verificação das práticas relativas à obtenção das informações, conforme previsto nos objetivos específicos desse estudo, foram buscadas nas falas dos entrevistados evidências de adoção das práticas no contexto do órgão pesquisado. Assim, a seguir são apresentados os resultados dessas análises, os achados nos documentos analisados e as discussões à luz da literatura base.

\subsubsection{Resultados e Discussões - Categoria 2}

Com relação à prática exploração do ambiente informacional por meio de abordagens automatizada e humana, o entrevistado 3, fala a seguir, argumentou que há predominância de exploração do ambiente informacional por meio de ação dos profissionais alocados diretamente 
nos processos de trabalho e que foi verificada certa dificuldade na geração das informações por ser um trabalho manual. O pesquisador 4 , por outro lado, afirma em seu relato que a exploração do que existe de informação na instituição contemplou abordagens automatizadas e humanas, uma vez que foram realizadas buscas em sistemas e, também, levantamento a partir do esforço dos indivíduos de cada processo de trabalho.

[...] elas apontam muito "tá, eu até posso levantar essa informação mensal para até 2 anos atrás, mas eu não tenho um sistema que me ajude a fazer isso, o trabalho é manual. Eu vou levar um tempo muito maior e você precisa em 1 semana. Infelizmente, eu não consigo" (ENTREVISTADO 3).

Depende muito da área, né, que aí, sei lá, onde o TCU já passou antes ou onde já tem alguma cultura mais forte, tem um sistema específico para tal coisa [...] mas temos alguns casos em que a pessoa vai ter que abrir o armário dela e contar os processos. Então, eu diria que depende muito... (ENTREVISTADO 4).

Os achados da pesquisa documental evidenciam que a exploração informacional para identificação de potenciais fontes de informação de processos para o DFT ocorreu de forma mista, com abordagens humanas e automatizadas. Isso corrobora o disposto na literatura (DAVENPORT, 1998; BEAL, 2004; CHOO, 2006) que orienta que as buscas precisam ocorrer por meio dessas duas abordagens, em função de que há nas organizações informações estruturadas e não estruturadas. Estas podem estar dispersas no ambiente, diretamente com os indivíduos ou em papéis, embora representem importante ativo informacional institucional, sendo sua identificação importante para que possam ser geridas.

Quanto à prática a gestão reconhece a necessidade de investir sistemas que possibilitem a filtragem de informações e geração de informações para os usuários, de acordo com o entrevistado 3, relato a seguir, o reconhecimento da necessidade de investir em ferramentas informatizadas para controle das informações de processos é muito dependente do perfil de cada gestor, que não foi percebido como sendo uma orientação institucional e sim uma iniciativa do gerente de cada área. Por outro lado, os especialistas em TI entrevistados 
afirmaram, falas a seguir, que há esse reconhecimento por parte da gestão. O entrevistado 14 afirmou que se trata, inclusive, de "uma diretriz de gestão".

\begin{abstract}
Até tem a ver com o perfil do gestor que está na área, né, porque se não me lembro (...) a gente passou por uma área que... parece que o esforço da área aumentou muito de um ano para o outro, a quantidade de entregas, mas não, simplesmente informatizou muitos dos processos. Então, é uma visão até do gestor que, às vezes, está lá na área e identifica que a informatização é.... por exemplo, desenvolver sistema, ampliar as funcionalidades do que já tem seria uma boa alternativa (ENTREVISTADO 3).

Eu acho que a gestão percebeu a importância do processo de negócio da gestão de informação, isso é o mais importante do que um instrumento. Porque, como eu sempre costumo dizer, a TI é o catalisador da inovação, ela não é inovação, nunca vai ser inovação [...] E aí o instrumento que vai ser usado pode não ser um só, pode ser vários instrumentos, desde que viabilizem a integração e o fluxo da informação aqui dentro (ENTREVISTADO 13).
\end{abstract}

Embora os especialistas em TI manifestem a presença dessa prática, não houve evidência nos documentos analisados. Isso sugere que essa diretriz de gestão não está suficientemente disseminada em todos os níveis da instituição. Portanto, é necessário que haja a difusão dessa orientação, considerando que as informações das entrevistas do Grupo 1 e 2 evidenciaram que a automação dos processos de trabalho, que possibilitem filtragem de informações e geração de informações de resultados, está restrita a algumas áreas e ocorre, geralmente, em função de determinado perfil de gestor. Ao analisar esses resultados, percebese que parte da gestão ainda não percebeu que gerir as informações de suas unidades é estratégico para a tomada de decisão. Essa situação corrobora a afirmação de Moresi (2000) de que as organizações ainda precisam aceitar que a informação é um dos recursos de maior valor institucional e, dessa forma, requer reconhecimento do valor das informações e dos sistemas necessários para sua efetiva gestão.

Sobre a prática fontes de informações atualizadas, confiáveis e disponíveis, os relatos dos entrevistados, falas a seguir, são de que ela não está presente na instituição e que se percebe que o dimensionamento de força de trabalho tem funcionado como um indutor da organização das informações acerca dos processos de trabalho. Foi relatado que as informações de resultados não estavam disponíveis prontamente para coleta e envio à equipe de dimensionamento. 
Eu diria que quase o processo de dimensionamento induz a área a promover a gestão de sua informação. Pelo menos é um pouco o que a gente está sentindo lá na secretaria onde eu estou agora, onde a gente tem a perspectiva de realizar o dimensionamento. O que está se buscando é uma tentativa de qualificar a informação para quando ocorrer o dimensionamento (ENTREVISTADO 6).

Ocorre que, como já foi dito, nenhuma das áreas dimensionadas tinham todas as informações disponíveis. Algumas áreas tinham algumas. Mas nenhuma tinha as informações prontamente. Muitas passaram a produzir as informações especificamente para atender ao dimensionamento de força de trabalho (ENTREVISTADO 1).

Nem sempre essas informações estão disponíveis ... tinha áreas que não tinham informação nenhuma. E elas tiveram que gerar as informações (ENTREVISTADO 5).

Quanto à confiabilidade das fontes de informação, os entrevistados 1, 2 e 3 afirmaram, falas a seguir, que parte das informações foram declaradas e que a equipe de dimensionamento não teve acesso direto às fontes. Ademais havia sempre um ou mais intermediário entre o produtor da informação e o receptor.

Até porque a informação declarada, independente de quem seja ou de onde eu estou, tem um risco de viés. E, então, se fosse possível separar esses atores e a equipe que estão dimensionando tivesse acesso à informação na fonte e não só à informação declara, isso seria a melhor forma de fazer, o ideal para minimizar a influência desses atores na informação. (...). Então, o membro pesquisador fazia a requisição da informação ao gestor, que era um coordenador-geral, que passava para outro gestor, um coordenador, que passava para o executor do processo que fazia a coleta. Então, com esse caminho feito há a vários riscos e possibilidade de a informação perder qualidade, sofrer alteração e gerar vários problemas (ENTREVISTADO 1).

Em um caso de um indicador, por exemplo, que a gente mensurou um indicador e, quando foi confirmar, a área mudou o indicador por mais duas vezes até chegar ao valor final. (ENTREVISTADO 2).

Muitas vezes, essa falta de gestão de maturidade da informação impacta no resultado, porque, claro, seria muito mais robusto e confiável se tivesse maior confiabilidade, né (ENTREVISTADO 3).

Quanto à informação de esforço, que se refere ao tempo dedicado pelos trabalhadores à produção dos resultados de cada processo, de acordo com os relatos a seguir, como essa informação não estava disponível na instituição, optou-se por coletá-la diretamente com os trabalhadores por meio de aplicação de um questionário.

Essa informação de esforço não existe hoje na organização (ENTREVISTADO 5).

Essa informação está sendo coleta a partir do dimensionamento (ENTREVISTADO $6)$. 
De novo, para a maioria das organizações não existe esse tipo de controle. Primeiro porque nem sempre $100 \%$ das atividades são executadas dentro de um sistema. Segundo porque não necessariamente uma pessoa só abre o sistema quando ela vai executar a atividade e só fecha quando ela para de executar a atividade. Existem várias dificuldades operacionais de utilizar esses tipos de indicadores. De novo seria o cenário ideal se tivéssemos indicadores dessa forma (ENTREVISTADO 1).

O tempo médio para execução de um processo poderia ser definido no momento do mapeamento dos processos pelo escritório de processo do órgão. Ocorre que os especialistas em processos entrevistados afirmaram, falas a seguir, que a metodologia atual usada pelo escritório não prevê o levantamento dessa informação. Embora considerem importante a identificação dessa informação no mapeamento de processos, dois dos entrevistados manifestaram que a identificação do tempo médio para execução das atividades dos processos fazia parte da metodologia e foi suprimido durante atualização realizada em 2016 por uma consultoria contratada pela instituição.

\begin{abstract}
Não, para a pesquisa, para que o pessoal está precisando de dimensionamento, se já tivesse processo mapeado com o tempo que gasta com cada atividade para fazer o produto final, ia ser ótimo, porque não tem. Quando a gente chega na área, a área não faz a menor ideia, o pessoal chuta quanto tempo eles gastam (ENTREVISTADO 8).

Eu não concordo de forma alguma de ter tirado, porque apesar de toda essa complexidade para medir - que é complexo mesmo para medir -, mas seria um dado que com o tempo ele ia ficando mais exato (ENTREVISTADO 7).
\end{abstract}

Não concordo de ter retirado. No processo é uma das coisas mais relevante que tem (ENTREVISTADO 10).

Os especialistas em TI, falas seguintes, reconhecem que há dificuldade de suprir as necessidades de informações dos usuários, considerando que nem sempre essas informações são facilmente recuperadas ou estão sistematizadas. Ademais, alguns sistemas internos possuem algumas limitações de acesso.

Em primeiro lugar, nós temos um caminho entre aquele que gostaria de ter a informação e a informação. Esse caminho passa pela LAI, Lei de Acesso à Informação, que hoje existe, qualquer cidadão brasileiro pode solicitar qualquer tipo de informação. Só que essa informação está armazenada na base de informações do Ministério da Saúde de diversas formas: em base de informações, em documentos, que a gente chama de informação não estruturada; toda informação que está em base de informações a gente chama de informação estruturada e as que não estão, a gente chama de desestruturadas, digamos assim. Por exemplo, esse documento que assinei 
Aí, tem várias palavras aí, vários textos e tudo mais, eles não estão estruturados. Eu, enquanto ser humano e você, enquanto ser humano, entende, mas o computador teria que analisar isso para saber o que está aí dentro, então a informação não está estruturada, entendeu? Então, nós temos esse caminho para percorrer. Então, hoje quando um usuário pede uma informação, né, de $100 \%$ do nosso universo observável, digamos assim, nós temos um pequeno percentual onde eu consigo rapidamente ter acesso a esse dado (ENTREVISTADO 13).

Vamos lá, depende. Porque tem a questão do desenvolvimento do sistema de gestão interno e o desenvolvimento de sistemas de saúde que são fora do Ministério. Então, do ponto de vista interno, depende do sistema; há sistema para alteração de informações que não vai existir esse fomento de qualquer um entrar e está alterando as informações; muitos deles também até de visualização, tem o controle de acesso à informação. Então, considerando que o dado não for público, não for sensível, pode até ter nesse sentido, em relação ao portal. Vamos lá: a página de Cadastro Nacional de Estabelecimento de Saúde, onde qualquer cidadão pode entrar lá e ver um estabelecimento, onde fica, quais são os profissionais... essas informações são públicas, então ele é incentivado sim que qualquer um pode entrar. Agora, algumas informações sensíveis, isso não é fomentado (ENTREVISTADO 14).

A pesquisa documental corrobora a fala dos especialistas em TI, uma vez que evidencia uma limitação na disponibilidade de informações, ou porque não eram controladas ou por dificuldades na extração. Essa dificuldade de acesso às informações provocou impacto no cronograma de implantação do processo e foi salientado que isso, também, poderia provocar, inclusive, impacto no grau de exatidão dos resultados do dimensionamento de determinadas áreas.

Os achados da pesquisa sugerem a falta de uma ação de mapeamento das informações, que possibilite identificar as informações relevantes para os vários atores. Como se trata de informações de processos de trabalho, o DFT do órgão necessita realizar buscas em diversas fontes, evidenciando considerável grau de complexidade. De acordo com Marchiori (2002, p. 73), as necessidades de informação estão "cada vez mais complexas e dependentes de diferentes e múltiplas fontes", exigindo avaliação criteriosa e permanente. Em situação dessa natureza, Beal (2004) recomenda ser feito o mapeamento das fontes de informação. Essa ferramenta é essencial para apontar as fontes disponíveis, a forma de captura segura e as rotinas necessárias para mantê-las atualizadas e confiáveis.

As informações evidenciaram que não há uma base de informações integrada que armazena e distribui as informações (prática 10) de processo para o dimensionamento. Os 
entrevistados 3 e 1 afirmaram que as informações estão dispersas em vários formatos e nem sempre são confiáveis. Esse último entrevistado sinalizou ainda que há toda uma estrutura de TI na instituição que permitiria a integração das diversas bases de informações, embora alguns aspectos, por exemplo, culturais, precisem ser equalizados para que esse potencial transforme em uma prática no órgão.

Normalmente a informação está bem espalhada mesmo, né. Uma controla pela planilha de Excel, outro já tem no sistema, um nível de informatização mais alto. E, às vezes, é ali no controle que se faz muito insipiente, mas se tem alguma informação para dá, por mais que às vezes ela não seja a mais fidedigna possível. Pode, muitas vezes, essa falta de gestão, maturidade da informação impacta no resultado porque, claro, seria muito mais robusto e confiável se tivesse maior confiabilidade, né. (ENTREVISTADO 3).

Se houvesse uma base de informações integrada, não se trabalharia com informação declarada eliminaria o viés (ENTREVISTADO 1).

Mas o fato de existir uma área que cuida de várias bases de informações pode indicar um potencial de desenvolvimento de bases de informações unificadas e substituir a informação declarada, de quem está envolvida na execução. Isso seria um processo superinteressante de se ter acesso à informação. Mas aí entra vários aspectos culturais e estruturais da organização se isso é passível de ser feito ou não (ENTREVISTADO $1)$.

Com relação à base na qual estão armazenados os processos mapeados, de acordo com os especialistas em processos 1 e 6, não há integração com outros sistemas do órgão, conforme os relatos a seguir:

\footnotetext{
Não. Eu acho que a ferramenta permite, só que hoje nós temos um sistema específico para cuidar da estrutura (ENTREVISTADO 7).

Não, ele é um software que fica abrigado no servidor no DATASUS, no qual nós possuímos licenças. Aí, ele fica abrigado no servidor. Inclusive, o Publisher, que é a parte que publiciza, a gente tira de um servidor, no qual é abrigado na fase de mapeamento, e passa para esse outro para ficar publicado, né (ENTREVISTADO 12).
}

Os especialistas em TI, por sua vez, relataram que há uma grande fragmentação nas bases de informações da instituição, que há esforços no sentido de integrar essas bases de informações, porém são muitas as dificuldades enfrentadas, principalmente, em função de fatores, como, por exemplo, sistemas desenvolvidos de forma isolada, em linguagem diferente e muito antigos. 
Algumas não. Não por dificuldade do próprio negócio, por questões relacionadas a legado. Tem coisas que foram construídas há 15 anos, 15 anos para TI é uma eternidade. Então, tem coisas que... e também pela forma como são feitas. Existe um termo que a gente usa na TI, nossos termos normalmente vêm do inglês, que a gente chama de sistema stand alone, então eles são sozinhos e aí isso é ruim hoje em dia, principalmente hoje em dia quando a gente está falando de internet das coisas, por exemplo, quando a gente está falando de APIs, de fazer coisas que não se conversam. Mas isso é hoje, há 5/10 anos não era assim. Então, eu tenho um sistema de 5 anos atrás que tem 5/6 milhões de registros [...]. Então, nós temos um desafio futuro, de integrar essas bases de informações todas e isso não é só um problema, má vontade, não é isso. É porque é legado, é difícil. Por exemplo, o DATASUS estava fazendo uma iniciativa, não sei o status atual, que era integrar, de fazer a identificação única da pessoa, do paciente, digamos assim, quando ele entra no sistema até o final. Quando ele entra no negócio? Quando ele nasce e de lá para cá ele passa por diversas coisas no nosso sistema de saúde: ele é vacinado, ele faz algumas cirurgias, ele recebe alguma coisa do SUS, porque todo mundo usa o SUS, né, mesmo que ele não aceite, ele usa, né, e depois ele morre. Têm sistemas de informação que gera tudo isso, só que são separados. Como é que eu vou saber que aquele cara está em todos eles? É difícil fazer isso, porque não tem uma chave única, não é um CPF que tem todo mundo, não; tem gente que não tem CPF, mas é uma pessoa que está lá no SUS, como é que eu vou saber que aquele cara é um? Então, o DATASUS estava com uma iniciativa muito interessante de fazer integração disso aí tudo, né. Então, tem coisas que sim, estão integradas e tem outras que não, por conta dessa dificuldade que te falei (ENTREVISTADO 13).

Você foi direto no ponto principal, mais problemático dentro do Ministério da Saúde hoje. Pela cultura de muitos anos de cada gestor fazer o seu, cada área não conversar com a outra, por si só não era a área de TI que ia fazer com que elas conversassem. Então, teria que nascer de cima para baixo. Então, existem, na sua grande maioria, as bases separadas, certo, que são construídas, como eu falei, sem ter comunicação com outras, mas há exceção. Então, a exceção é de alguns processos de negócio que dependem de outras áreas que eles se conversem, certo? Aí tipo, a tela do sistema que vai cadastrar o recebimento daquele paciente, ele tem que identificar o estabelecimento de saúde, ele não cadastra um novo estabelecimento de saúde, ele vai lá na tabela de outro setor, do DRAC, por exemplo, que tem a tabela de cadastro, ele só faz a consulta lá e aproveita o dado. Então, só quando essas áreas têm uma sinergia, elas se conversam, é que consegue adiantar o processo de trabalho, que não haja uma construção nova, que não tenha um novo cadastro ou outra tabela, entendeu. Então, quando isso acontece, quando não tem essa comunicação, é custo, é tempo, é retrabalho, é tudo. Então, resumindo: o mote principal hoje do Ministério no comitê de TI e tudo mais é não se desenvolver mais sistema, fragmentação, e os que têm integrarem e mais ainda, se continuar vários sistemas e tentar centralizar em aplicações mais estratégicas, que possa alimentar tudo ali. Porque no cuidado à saúde do cidadão ele entra pela atenção básica e vai caminhando e não precisa ter um sistema para cada atendimento dele, entendeu? (ENTREVISTADO 14).

A pesquisa documental corrobora a afirmativa dos especialistas em TI, considerando que evidencia a existência de áreas formais e informais dispersas no órgão que desenvolvem atividades relacionadas a TI. Algumas dessas estruturas atuam em complementação com o DATASUS, mas outras não. Isso traz repercussões práticas como o baixo controle de aspectos relativos a padrões tecnológicos e a metodologias de tratamento de informações e informações. 
informações e impedem "o processo de padronização das ferramentas e cadastros informatizados" (PDTI 2016, p. 52). O diagnóstico dessa situação foi realizado pela primeira vez em 2002 e, segundo o PDTI 2016, ainda persiste atualmente.

Essas evidências sugerem fragilidades no processo de integração das informações disponíveis no órgão, ocasionado pela proliferação de sistemas em diferentes áreas e com padrões distintos. Essa situação não favorece o acesso às informações de processos de trabalho que são utilizadas no contexto do DFT. Esse panorama das bases de informações, explicitado pelos entrevistados, contraria o disposto na literatura, que assevera que as organizações precisam garantir aos usuários o acesso eficiente às informações úteis à tomada de decisão e que isso requer que as diferentes bases de informações sejam integradas para permitir que as buscas sejam completas, ou seja, em toda a organização (DAVENPORT, 1998). A integração das bases de informações, além de potencializar o uso das informações existentes, evita novas coletas de uma mesma informação em diferentes fontes de informações, possibilita a reutilização de informações e facilita sua atualização (MARCHAND; KETTINGER; ROLINS, 2000).

Com relação à prática coleta e distribuição eletrônica de informações, três entrevistados evidenciaram que não há um alto nível de informatização dos processos no órgão e que isso é uma barreira para a aplicação da metodologia do dimensionamento. $\mathrm{O}$ entrevistado 4 argumenta que alguns processos são automatizados, principalmente, nas áreas em que o Tribunal de Contas da União fez alguma exigência. Os entrevistados 4 e 5 acrescentam que algumas informações não são controladas ao menos por planilhas eletrônicas, havendo necessidade de contagem por meio físico no momento que são demandadas as informações.

Se for fazer uma análise a grande maioria não tem um alto nível de informatização, está mais para o lado do médio e do baixo porque não se desenvolveu, não tem ainda as bases de informações, por exemplo, informatizadas, ou os processos não são automatizados o suficiente. Se isso tivesse muito bem organizado, a gente ia conseguir rodar mais rápido, claro, porque seria quase granular a informação do tipo que a gente precisa e que é um esforço muito grande para as áreas (ENTREVISTADO 3). 
Depende muito da área, né, que aí, sei lá, onde o TCU já passou antes ou onde já tem alguma cultura mais forte "ah, tem um sistema específico para tal coisa" ou "Ah, tal processo é todo feito no sistema" ou "maior parte é feita no sistema". Mas temos alguns casos em que a pessoa vai ter que abrir o armário dela e contar os processos. Então, eu diria que depende muito... (ENTREVISTADO 4).

Nem sempre essas informações estão disponíveis em sistemas, muitas vezes são planilhas, arquivos, espaços que se tem na rede, documentos em Word, processos físicos, listas de presença, enfim (ENTREVISTADO 5).

Com relação a essa prática, o entrevistado 13 argumenta, fala a seguir, que a área de TI ainda é muita reativa e, geralmente, trabalha por demanda, embora seja guardiã de um grande conjunto de informações que poderiam estar disponíveis para uso por diversos atores da organização. O entrevistado 14 afirma que algumas informações são disponibilizadas para os usuários, mas que outras não, em decorrência da sua classificação e que, portanto, a distribuição das informações pode ocorrer por demanda ou por oferta.

Como falei agora há pouco, nós somos ainda muito reativos, eu acho que a gente espera demais. E nós enquanto guardiões da informação e do dado, fazendo aquela diferenciação de dado, informação e conhecimento, nós temos a visão do todo. Se temos a visão do todo, de tudo que temos aqui, é função sim da TI ter um olhar crítico e te ajudar a resolver. Quando eu digo que nós somos reativos, eu digo assim: nós temos aqui um conjunto enorme de informações e você vem com uma necessidade, eu não para fazer uma avaliação para saber qual a melhor forma de atender, eu vou e simplesmente faço mais um sistema; aí faço mais um sistema, outro sistema e eles não se conversam, não são integrados e aí quando a gente fala de integração, a gente fala de integração daquele requisito não funcional "ah, está integrado com o sistema de login" a pessoa só loga uma vez, mas e a informação? O que interessa para o cara? Será que o CNES está integrado com outro sistema qualquer que me informe se a equipe de saúde da família existe naquele local? Não sei. Então, eu acho que essa avaliação falta para a gente. Falando gente assim enquanto cidadão brasileiro e pessoa que trabalhou aqui e se sente como participe das coisas aqui (ENTREVISTADO 13).

\begin{abstract}
Alguns dados para a tomada de decisão do gestor municipal e estadual são publicados em uma ferramenta de tabulação de informações, que é o TABWIN/TABNET. Então, esses gestores podem ir lá, é self-service, eles vão lá, puxa essa informação e até mesmo cria um arquivo $c s v$ para levar para dentro da instituição deles e fazer os cruzamentos que precisa. Já existem outros dados, como eu tinha falado antes, que não, não são assim; até porque tem que ter uma classificação da informação, né, então é nesse cenário. Então, tem de tudo (ENTREVISTADO 14).
\end{abstract}

A pesquisa documental evidenciou que parte das informações de processos de trabalho ainda está em formatos não estruturados, dificultando a distribuição por meio eletrônico. Dessa forma, para que essa prática seja aperfeiçoada no âmbito do DFT, é necessário, após o mapeamento das fontes, construir uma estratégia de captura dessas informações, de maneira 
que sua atualização, distribuição e armazenamento sejam realizados de maneira adequada, proporcionando facilidade de acesso ao usuário, conforme recomenda a literatura (DAVENPORT, 1998; BEAL, 2004).

Com relação à prática equipes capacitadas e em quantitativos suficientes para geração e análise das informações necessárias, as evidencias demostram escassez de pessoal para a função de geração das informações para o processo de DFT. Ademais, há uma tendência de essa atividade ficar concentrada em um único executor, como se verifica nas falas dos entrevistados 3 e 4, a seguir. Este último alerta em sua fala para outro aspecto relativo às equipes, que é o interesse e a disposição em colaborar.

\footnotetext{
Em algumas áreas, uma pessoa centralizava a atividade porque está acostumada a trabalhar com isso, então preenche; em outras, se separava, quem é responsável pelo processo " $\mathrm{x}$ " tente buscar as informações de resultado das entregas (ENTREVISTADO 3).
}

Se eu bem me lembro, tinha uma pessoa específica que pegava todas as entregas ou ela pegava a maioria das entregas e algumas que eram 1 pessoa ou 2 pessoas só que faziam, ela pedia... em outro caso... são bem divididas as áreas e cada área ficou responsável pelas entregas que ela ia pegar, né [...]. Eu acho que o que pesa mais não é a capacidade contributiva, intelectual, qualquer coisa assim, mas a abertura mesmo. Porque mesmo em algumas áreas que, às vezes, as pessoas tinham um pouco mais de dificuldade, quando elas estavam afins, andava bem mais fácil (ENTREVISTADO 4).

Com relação a esse aspecto, a análise documental também evidenciou a dependência dos usuários em relação ao produtor da informação e a concentração da geração da informação em determinados trabalhadores, que nem sempre estão disponíveis para fornecer as informações demandada no tempo requerido. Esse problema é, geralmente, decorrente da baixa automação dos processos de trabalho, que foi constatada pelas informações da pesquisa. Essa automação poderia facilitar o acesso à informação diretamente pelo usuário, podendo otimizar o número de trabalhadores envolvidos na atividade de geração dessas informações.

Com relação ao aspecto comportamental, apontado pelo entrevistado 4, conforme recomenda Beal (2004), uma ação da organização que estimule o compartilhamento de informações úteis poderá eliminar barreiras desfavoráveis à troca de informações para os 
processos de negócios, coibir os "feudos informacionais" e minimizar as dificuldades de obtenção de informações.

Sobre a prática diretriz clara de rotinas a ser adotada por cada produtor das informações para classificação, interpretação e armazenamento do conteúdo informacional gerado, não houve manifestação dos entrevistados dos Grupos 1, 2 e 3 em relação a essa prática. No entanto, a pesquisa documental apontou que houve capacitação de equipes das áreas nas quais a metodologia de DFT foi aplicada para que esses atores pudessem atuar na localização e coleta das informações necessárias ao processo de DFT. Não houve evidência em relação às orientações de procedimentos de armazenamento. Embora essa seja considerada uma prática de GI importante no contexto organizacional, como o processo de dimensionamento ainda é recente na instituição (iniciado em janeiro de 2015, conforme pesquisa documental), foi possível perceber pelos relatos dos entrevistados, a seguir, que ainda não se encontra definida a periodicidade de aplicação da metodologia. Portanto, isso sugere que a definição dos procedimentos de armazenamento das informações do processo de DFT ainda não está estruturada.

\begin{abstract}
Se por exemplo a informação eu consigo coletar todas as informações mês a mês é possível eu realizar o dimensionamento mês a mês. Então o dimensionamento depende da frequência de coleta de informações. Então, depende da estratégia da organização em relação ao dimensionamento (ENTREVISADO 1).

Hoje eu diria que o dimensionamento, quando ele é aplicado em uma organização como a nossa, por exemplo, ele vai provocar um olhar, trazer à luz um olhar para seus processos de trabalho e pensar em priorizar isso. E daí eu acho que em um segundo momento de reaplicação e tal, talvez já traga um diagnóstico um pouco mais estruturado. Porque realmente a gestão da informação é zero e sem gestão da informação ele fica difícil, fica deficitário (ENTREVISTADO 6).
\end{abstract}

A literatura aponta que os procedimentos de armazenamento adequados são essenciais para que as informações sejam facilmente recuperadas, distribuídas e acessadas rapidamente pelos gestores dos processos de negócio, de forma a subsidiar a tomada de decisão organizacional (DAVENPORT, 1998; MARCHAND; KETTINGER; ROLINS, 2000; BEAL, 2004). 
Já com relação à estrutura de fornecimento das informações que favorece a autonomia do usuário, os relatos evidenciaram que há uma dependência em relação aos produtores da informação. Os usuários não possuem acesso direto às informações e, em alguns casos, há a figura de mais de um intermediário até a entrega dessas informações aos destinatários. Isso pode ser verificado nas falas a seguir:

\begin{abstract}
Então, a obtenção das informações é bem dependente do controle de indicadores das próprias áreas. Então, se a unidade tem um sistema que controla o quantitativo de entregas e o tempo necessário para execução, então dá para coletar no sistema. Embora a coleta também seja feita pelas próprias áreas e não pela equipe de dimensionamento...se fosse possível separar esses atores, e a equipe que estão dimensionando tivesse acesso à informação na fonte e não só à informação declara, isso seria a melhor forma de fazer, o ideal para minimizar a influência desses atores na informação. Inclusive a gente percebe na prática que tem mais de um intermediário nesse processo (ENTREVISTADO 1).

Em geral as áreas ficam responsáveis por levantar, por exemplo, os dados de resultado e quantitativo ao longo do tempo e de preferência mensal dos últimos 2 anos (ENTREVISTADO 3).
\end{abstract}

Existem uma série de fontes de informação a depender da entrega. O acesso a essas fontes se dá pelas áreas (ENTREVISTADO 5).

Essa dependência das áreas para a obtenção das informações de processos poderia ser superada se houvesse na instituição uma base de informações com todos os processos que foram mapeados. Nesse sentido, os entrevistados 8 e 12, membros do escritório de processos, argumentam que as iniciativas de mapeamento de processos não contemplam toda instituição, mas que as informações dos mapeamentos finalizados pelo escritório estão disponibilizadas na intranet. Foi relatado que, como os arquivos são grandes, o acesso ao formato $p d f$ dos documentos também pode se dar por meio de um link disponibilizado pelo escritório de processos.

Então, todos esses processos podem ser disponibilizados pela própria ferramenta que a gente desenha. É uma plataforma do próprio sistema (ENTREVISTADO 8).

O ARIS tem uma plataforma chamada Publisher que disponibiliza esses processos. A gente coloca o link em um servidor próprio, coloca o link na intranet, e tem acesso todo o Ministério (ENTREVISTADO 12). 
No entanto, a fala do entrevistado 7, corroborada pelo entrevistado 10, a seguir, demonstra que há exceção com relação à publicação dos processos mapeados. Há processos que, embora mapeados, não são disponibilizados, publicados na intranet, conforme afirmaram os entrevistados 8 e 12, em função da confidencialidade e por ser uma informação sensível, que poderia ter uso indevido. Um exemplo citado é o caso do processo de compras de insumos estratégicos para o Sistema Único de Saúde (SUS).

\begin{abstract}
Mas é porque eu acho que algumas coisas que a empresa, por exemplo, não poderia ver como é feito todo o processo de compra, por exemplo do DELOG (ENTREVISTADO 7).

O processo no interesse coletivo do Ministério, que não ultrapassa as interfaces estaduais, municipais e etc., pode ser disponibilizado através de uma ferramenta. Nós já temos alguma coisa, que é do próprio ARIS, que é a publicação dos processos e manuais (ENTREVISTADO 10).
\end{abstract}

Ao serem questionados se há uma política informacional no órgão que favorece o desenvolvimento de soluções informatizadas que permitem a autonomia do usuário na busca da informação de seu interesse, geração de relatórios pelos próprios usuários, de produção dos processos de trabalho, por exemplo, os entrevistados 13 e 14 afirmaram que essa autonomia é buscada em alguns casos. Pelos relatos, foi possível perceber que a autonomia do usuário é buscada quando se trata de ferramentas utilizadas por todo o Sistema Único de Saúde (SUS), por exemplo, Cadastro Nacional de Estabelecimento de Saúde (CNES). O entrevistado 13 afirmou que, muitas vezes, existem sistemas de suporte aos processos de trabalho, mas que esses, geralmente, não geram informações de fácil compreensão pelos usuários e que há soluções informatizadas que não estão preparadas para geração de relatório. O entrevistado 14 ponderou, fala a seguir, que alguns sistemas internos não permitem o acesso diretamente pelos usuários.

Vamos lá, depende. Porque tem a questão do desenvolvimento do sistema de gestão interno e o desenvolvimento de sistemas de saúde que são fora do Ministério. Então, do ponto de vista interno, depende do sistema; há sistema para alteração de informações que não vai existir esse fomento de qualquer um entrar e está alterando os dados; muitos deles também até de visualização, tem o controle de acesso à informação. Então, considerando que o dado não for público, não for sensível, pode 
até ter nesse sentido, em relação ao portal. Vamos lá: a página de Cadastro Nacional de Estabelecimento de Saúde, onde qualquer cidadão pode entrar lá e ver um estabelecimento, onde fica, quais são os profissionais... esses dados são públicos, então ele é incentivado sim que qualquer um pode entrar. Agora, alguns dados sensíveis, isso não é fomentado (ENTREVISTADO 14).

A pesquisa documental, por sua vez, confirmou a constatação dos entrevistados quanto à dependência dos usuários em relação aos produtores das informações de processos de trabalho demandadas pelo DFT. Inclusive, há evidências nas atas de demora na geração das informações de produção porque a apuração dos resultados de alguns processos de trabalho só poderia ser gerada por determinado profissional. Percebe-se que a falta de autonomia do usuário para acessar os dados é um fator que impacta na celeridade de aplicação da metodologia de dimensionamento no órgão. A construção de estratégias para superar essa barreira é imprescindível para a fluidez do trabalho.

Com relação a essa prática, a literatura aponta que uma vez localizada a informação para solução de problemas no ambiente organizacional, essa precisa ser disponibilizada rapidamente para o acesso pelos usuários e que sistemas que permitem a filtragem das informações de interesse são recomendáveis para favorecer a autonomia dos usuários (DAVENPORT, 1998; BEAL, 2004). Nesse mesmo sentido, Paim et al (1996) afirmam que a informação só é eficaz se está disponível e acessível para subsidiar a resolução de problemas de seus usuários.

Sobre a prática informações categorizadas, classificadas em formatos que facilitam compreensão pelo usuário, os achados indicaram que as informações não estão categorizadas e classificadas de modo a atender às necessidades do processo de dimensionamento de força de trabalho. Embora sejam informações que poderiam ser utilizadas pelos gerentes no processo decisório, conforme percepção do entrevistado 3, a seguir. Esse relato é confirmado pelos entrevistados 1 e 5, que argumentam que o fato de as informações estarem dispersas, sem um padrão de categorização e formatos diferentes, faz com que o produtor das informações tenha dificuldade de geração ágil da demanda informacional. O entrevistado 5 afirma, inclusive, que 
no órgão não há gestão da informação e que isso é revelado pela dificuldade de localização da informação quando é necessária. Por outro lado, os entrevistados 13 e 14 afirmaram que as informações armazenadas são categorizadas de forma que facilita a compreensão pelas unidades demandantes e pelos usuários.

\begin{abstract}
A gente sabe que o Ministério tem um volume de informações muito alto, mas que muitas vezes ele não está organizado para o que a metodologia pede. Então, assim, é uma questão de maturidade de gestão da informação mesmo, mas que o dimensionamento vem aí para mudar, mais ou menos, esse paradigma de apenas executar o que está vindo, mas também passar a controlar essas informações e fazer a gestão, porque não é só para alimentar o dimensionamento, é, também, uma questão estratégica mesmo. (ENTREVISTADO 3).
\end{abstract}

Como ele utiliza informações de diversos pontos da organização e normalmente essas informações não estão inseridas nas ferramentas de gestão que em teoria elas deveriam estar, elas acabam centralizando no dimensionamento e o dimensionamento acaba sendo um diagnóstico da organização (ENTREVISTADO 1).

É que no MS não se tem gestão da informação. A pessoa diz que tem o dado. Mas ela tem tanta dificuldade de levantar a informação, vai buscar em tantas fontes porque não há uma cultura de sistematização e isso gera muitos problemas quando se precisa apurar os indicadores de produção para o dimensionamento (ENTREVISTADO 5).

Eu acredito que essas informações até por demanda do próprio cliente, a área demandante. Ela precisa entender de volta o que ela está armazenando ali e quando ela pede relatório de gestão e categorizações e tudo mais, pode até ser que aqueles relatórios não sejam suficientes, mas sim as informações são categorizadas de forma a ser inteligíveis, né, que a gente possa a ler de volta e tudo mais (ENTREVISTADO $13)$.

Sim, depende do usuário. Quando o usuário é um usuário mais, digamos, um pouco sofisticado e que entenda a parte de TI, a gente dá o dado bruto para ele trabalhar e a dá um dicionário lá e essa coisa toda. Agora, quando é já uma pessoa leiga que vai entrar no sistema ou então no portal, aí necessita que esse dado seja qualificado, entendeu? Precisamos apresentar de uma forma bem mais amigável (ENTREVISTADO 14).

A pesquisa documental revelou que as informações foram produzidas diretamente pelas áreas e que havia dificuldade na sua geração devido à dispersão, à pouca sistematização e aos formatos variados. Há registros nas atas de que o processamento dos resultados da aplicação da metodologia estava consumindo mais tempo que o previsto devido à falta de organização das informações no formato requerido pelo dimensionamento.

Os relatos dos entrevistados do Grupo 1 e os achados na pesquisa documental sugerem que as informações relativas a processos de trabalho não estão categorizadas, classificadas e em 
formatos que facilitam o uso pelo processo de DFT. A categorização e a classificação podem mudar ao longo do tempo, mas é necessário que se estabeleça um conjunto de regras inicialmente, como rotina de atualização, uma vez que isso estrutura e organiza a grande diversidade informacional do ambiente e facilita a rápida localização das informações pelos usuários.

Nesse mesmo sentido, a literatura afirma que a categorização e a formatação são necessárias para aperfeiçoar o gerenciamento informacional para que cada conjunto de usuários acesse de maneira eficiente aquilo que necessita no momento que precisa (DAVENPORT, 1998). Portanto, para que as informações sejam aproveitadas no ambiente organizacional, é preciso que ocorra sua organização e classificação para permitir que haja estruturação de banco de informações e de documentos, otimizando assim o acesso por diferentes caminhos ou filtros pelos interessados (BEAL, 2004).

Quanto à prática informações são produzidas para atender demandas específicas dos usuários a coleta de informações evidenciou que, embora as informações não sejam de uso exclusivo do dimensionamento, uma vez que se trata de informações de processos, demanda, produção, metas de produção, tempo para execução das atividades, complexidade e informatização desses processos, e valor agregado, não há no órgão a prática de produzir, organizar e disponibilizar essas informações para serem utilizadas como insumo em outros processos de trabalho ou para auxiliar no processo decisório. Isso pode ser verificado nas falas dos entrevistados 1,5 e 6 , a seguir.

Como já foi dito, nenhuma das áreas dimensionadas tinham todas as informações disponíveis. Algumas áreas tinham algumas. Mas nenhuma tinham as informações prontamente. Muitas passaram a produzir as informações especificamente para atender ao dimensionamento de força de trabalho. Do ponto de vista de habilidade ou de falta de habilidade (de viés da informação) seria mais interessante que as informações do dimensionamento não fossem produzidas com foco no dimensionamento (ENTREVISTADO 1).

Tinha áreas que não tinham informação nenhuma. E elas tiveram que gerar as informações (ENTREVISTADO 5). 
Isso também foi uma dificuldade porque as informações não estavam preparadas para o dimensionamento. E isso gerava um esforço da área para fornecer aquela informação, além disso ela tinha que ir atrás de uma série histórica mínima para que pudesse ter uma informação melhor para o dimensionamento (ENTREVISTADO 6).

Sobre as informações de processos, que não são exclusivas para o dimensionamento, mas que o DFT faz uso intensivo delas, os especialistas em processos afirmaram que há algumas iniciativas de mapeamento no órgão, mas que são poucas comparadas com o tamanho da instituição. Segundo os entrevistados 8 e 10, relatos a seguir, faltam direcionamento e patrocínio do nível estratégico sobre essa questão. Que hoje as bases de processos não teriam as informações requerida pelo DFT, precisariam ser produzidas.

\begin{abstract}
Não tem nem cadeia de valor, nem está definida. E no máximo o que têm são as unidades que pegam para entender um pouco de cada quadrado, mas a gente também não tem conhecimento, né, disponibilizado. [...]. Não, para a pesquisa, para que o pessoal está precisando de dimensionamento, se já tivesse processo mapeado com o tempo que gasta com cada atividade para fazer o produto final, ia ser ótimo, porque não tem. Quando a gente chega na área, a área não faz a menor ideia, o pessoal chuta quanto tempo eles gastam [...]. Resumindo: um dos maiores problemas que a gente tem é a falta de patrocínio, da descontinuidade da gestão e essa visão também, porque, às vezes, o pessoal que fica, o servidor que fica, nem acredita e eles não entendem que a gestão de processos é muito mais do que fazer o fluxo, é muito maior do que fazer manual e engavetar, do que institucionalizar aquele processo (ENTREVISTADO 8).
\end{abstract}

Eu acho que falta dentro dos objetivos estratégicos do Ministério da Saúde ter lá um objetivo que venha da alta direção determinando que isso seja uma coisa geral, estratégica. Você ter os processos documentados e organizados é uma forma de gestão (ESPECIALISTA 10).

Ao analisar a metodologia de mapeamento e modelagem de processos adotada pelo escritório, verifica-se que ela não contempla todas as necessidades de informação de processo requerida pela metodologia de dimensionamento de força de trabalho, como, por exemplo, indicadores de resultado e tempo dedicado pelas equipes para execução das atividades dos processos. Isso evidencia a necessidade de alinhamento desses dois processos para evitar retrabalho e fornecer informações robustas aos gestores, conferindo maior segurança ao processo decisório.

Com relação a essa prática, os autores afirmaram que nem sempre informações preexistentes na instituição tem o formato requerido pelos novos processos de negócio 
(DAVENPORT, 1998). Dessa forma, de acordo com esse autor, produções específicas para determinado conjunto de usuários podem ser necessárias. Embora, seja recomendado realizar ampla busca automatizada e humana para esgotar a possibilidade de que haja duplicação com a produção de informações já existentes na organização.

Considerando as quatro categorias de resultados possíveis (adota, adota parcialmente, não adota, não identificado) e os critérios usados para esse agrupamento, no Quadro 9 são sintetizados os achados da pesquisa referentes à Categoria 2. 
Quadro 9 - Síntese das informações sobre a adoção das práticas referentes à Categoria 2

(Continua)

\begin{tabular}{|c|c|c|c|c|c|c|c|c|c|c|c|c|c|c|}
\hline \multicolumn{15}{|c|}{ CATEGORIA 2: OBTENÇÃO DAS INFORMAÇÕES } \\
\hline \multirow{2}{*}{ Práticas } & \multicolumn{4}{|c|}{$\begin{array}{c}\text { Adoção das práticas de acordo com os } \\
\text { entrevistados do Grupo } 1\end{array}$} & \multicolumn{4}{|c|}{$\begin{array}{c}\text { Adoção das práticas de acordo com os } \\
\text { entrevistados do Grupo } 2\end{array}$} & \multicolumn{4}{|c|}{$\begin{array}{c}\text { Adoção das práticas de acordo com os } \\
\text { entrevistados do Grupo } 3\end{array}$} & \multirow{2}{*}{$\begin{array}{c}\text { Análise } \\
\text { documental }\end{array}$} & \multirow[t]{2}{*}{ Resultados } \\
\hline & Adota & $\begin{array}{c}\text { Adota } \\
\text { parcialmente }\end{array}$ & $\begin{array}{l}\text { Não } \\
\text { adota }\end{array}$ & \begin{tabular}{|c|} 
Não \\
identificado
\end{tabular} & Adota & $\begin{array}{c}\text { Adota } \\
\text { parcialmente }\end{array}$ & $\begin{array}{l}\text { Não } \\
\text { adota }\end{array}$ & $\begin{array}{c}\text { Não } \\
\text { identificado }\end{array}$ & Adota & $\begin{array}{c}\text { Adota } \\
\text { parcialmente }\end{array}$ & $\begin{array}{l}\text { Não } \\
\text { adota }\end{array}$ & $\begin{array}{c}\text { Não } \\
\text { identificado }\end{array}$ & & \\
\hline $\begin{array}{l}\text { 7. Exploração do } \\
\text { ambiente } \\
\text { informacional por meio } \\
\text { de abordagens } \\
\text { automatizada e humana }\end{array}$ & $17 \%$ & - & $17 \%$ & $66 \%$ & - & - & - & - & - & - & - & - & Adota & Adota \\
\hline $\begin{array}{l}\text { 8. A gestão reconhece } \\
\text { a necessidade de } \\
\text { investir sistemas que } \\
\text { possibilitem a } \\
\text { filtragem de } \\
\text { informações e geração } \\
\text { de informações para os } \\
\text { usuários }\end{array}$ & $17 \%$ & - & - & $83 \%$ & - & - & - & - & $100 \%$ & - & - & - & $\begin{array}{c}\text { Não } \\
\text { identificado }\end{array}$ & Adota \\
\hline $\begin{array}{l}\text { 9. Fontes de } \\
\text { informações } \\
\text { atualizadas, confiáveis } \\
\text { e disponíveis }\end{array}$ & - & - & $83 \%$ & $17 \%$ & - & - & $83 \%$ & $17 \%$ & - & $100 \%$ & - & - & $\begin{array}{c}\text { Não } \\
\text { identificado }\end{array}$ & Não adota \\
\hline $\begin{array}{l}\text { 10. Base de } \\
\text { informações integrada } \\
\text { que armazena e } \\
\text { distribui as } \\
\text { informações }\end{array}$ & - & - & $50 \%$ & $50 \%$ & & - & $33 \%$ & $67 \%$ & - & $100 \%$ & - & - & $\begin{array}{c}\text { Não } \\
\text { identificado }\end{array}$ & Não adota \\
\hline $\begin{array}{l}\text { 11. Coleta e } \\
\text { distribuição eletrônica } \\
\text { de informações }\end{array}$ & - & $17 \%$ & $50 \%$ & $33 \%$ & - & - & - & - & - & $100 \%$ & - & - & $\begin{array}{c}\text { Adota } \\
\text { parcialmente }\end{array}$ & $\begin{array}{c}\text { Adota } \\
\text { parcialmente }\end{array}$ \\
\hline
\end{tabular}

Fonte: Informações da pesquisa. 
Quadro 9 - Síntese das informações sobre a adoção das práticas referentes à Categoria 2

(Conclusão)

\begin{tabular}{|c|c|c|c|c|c|c|c|c|c|c|c|c|c|c|}
\hline \multicolumn{15}{|c|}{ CATEGORIA 2: OBTENÇÃO DAS INFORMAÇÕES } \\
\hline $\begin{array}{l}\text { 12. Equipes capacitadas e em } \\
\text { quantitativos suficientes para } \\
\text { geração e análise das } \\
\text { informações necessárias }\end{array}$ & - & $50 \%$ & & $50 \%$ & - & - & - & - & - & - & - & - & $\begin{array}{c}\text { Adota } \\
\text { parcialmente }\end{array}$ & $\begin{array}{c}\text { Adota } \\
\text { parcialmente }\end{array}$ \\
\hline $\begin{array}{l}\text { 13. Diretriz clara de rotinas a } \\
\text { serem adotadas por cada } \\
\text { produtor das informações para } \\
\text { classificação, interpretação e } \\
\text { armazenamento do conteúdo } \\
\text { informacional gerado }\end{array}$ & - & - & - & $100 \%$ & - & - & - & $100 \%$ & - & - & - & $100 \%$ & $\begin{array}{c}\text { Adota } \\
\text { parcialmente }\end{array}$ & $\begin{array}{c}\text { Adota } \\
\text { parcialmente }\end{array}$ \\
\hline $\begin{array}{l}\text { 14. Estrutura de fornecimento } \\
\text { das informações que favorece a } \\
\text { autonomia do usuário }\end{array}$ & - & - & $50 \%$ & $50 \%$ & $33 \%$ & $50 \%$ & - & $17 \%$ & - & $100 \%$ & - & - & Não adota & $\begin{array}{c}\text { Adota } \\
\text { parcialmente }\end{array}$ \\
\hline $\begin{array}{l}\text { 15. Informações categorizadas, } \\
\text { classificadas em formatos que } \\
\text { facilitam compreensão pelo } \\
\text { usuário }\end{array}$ & - & $17 \%$ & $33 \%$ & $50 \%$ & - & - & - & - & $100 \%$ & - & - & - & Não adota & $\begin{array}{c}\text { Adota } \\
\text { parcialmente }\end{array}$ \\
\hline $\begin{array}{l}\text { 16. Informações produzidas } \\
\text { para atender demandas } \\
\text { específicas dos usuários }\end{array}$ & $33 \%$ & - & $17 \%$ & $50 \%$ & - & - & $67 \%$ & $33 \%$ & - & - & - & - & Não adota & Não adota \\
\hline
\end{tabular}

Fonte: Informações da pesquisa. 
Com relação à adoção das práticas de GI pelo órgão pesquisado, relativas às informações de processos no contexto do DFT, os resultados das entrevistas demonstraram o seguinte: (i) prática 7: explorada somente na entrevista com o Grupo 1: 17\% afirmaram que a prática é adotada e 17\% afirmaram que não. (ii) prática 8: explorada nas entrevistas com os Grupos 1 e 3: $17 \%$ dos participantes do Grupo 1 e 100\% do Grupo 3 afirmou que a prática é adotada. (iii) prática 9: explorada nos três grupos: $83 \%$ dos entrevistados do Grupo 1 e $83 \%$ do Grupo 2 afirmaram não adoção da prática, enquanto que 100\% dos entrevistados do Grupo 3 afirmaram que adota parcialmente. (iv) prática 10: explorada nos três grupos: 50\% dos entrevistados do Grupo 1 e 33\% do Grupo 2 afirmou que a prática não é adotada no órgão; em contrapartida, 100\% do Grupo 3 afirmou que é adotada parcialmente. (v) prática 11: prática explorada nas entrevistas com os Grupos 1 e 3: 50\% dos entrevistados o Grupo 1 afirmaram que a prática não é adotada e $100 \%$ do Grupo 3 afirmou que adota parcialmente. (vi) prática 12: explorada com o Grupo 1: 50\% dos entrevistados afirmaram que a prática é adotada. (vii) prática 13: explorada nas entrevistas com os três grupos, mas sem resposta conclusiva. (viii) prática 14: explorada nos três grupos: $50 \%$ dos entrevistados do Grupo 1 afirmaram não adoção da prática, $50 \%$ do Grupo 2 e 100\% do Grupo 3 afirmaram que o órgão adota parcialmente. (ix) prática 15: explorada nas entrevistas com os Grupos 1 e 2: 17\% dos entrevistados do Grupo 1 afirmaram que há adoção parcial e 100\% do Grupo 3 afirmou que a prática é adotada na instituição. (x) prática 16: explorada nos Grupos 1 e 2, 33\% do Grupo 1 afirmaram que a prática é adotada e $67 \%$ do Grupo 2 afirmaram que não adota.

A pesquisa documental não identificou informações relativas as práticas 8, 9 e 10 . Houve evidência de adoção parcial das práticas 11, 12 e 13 e de não adoção das práticas 14, 15 e 16. Sobre essa última, os entrevistados do escritório de processos relataram hoje que seguem uma metodologia e essa não fornece as informações exigidas pela metodologia de dimensionamento. Já os entrevistados do Grupo 1 afirmaram que as informações estão sendo 
produzidas especificamente para o DFT, em função da não disponibilidade de algumas informações no formato requerido pela metodologia. Percebe-se que há um retrabalho de duas equipes sobre um mesmo objeto que são processos de trabalho. Isso requer uma reflexão da melhor forma de integrar essas duas frentes de trabalho na instituição para potencializar os resultados.

A partir dos critérios estabelecidos para consolidar os resultados foi possível perceber que das 10 práticas, da categoria 2, duas são adotas pelo órgão, cinco são adotadas parcialmente e não foram constatadas a adoção de três práticas no contexto pesquisado.

\subsection{QUANTO À DISTRIBUIÇÃO DAS INFORMAÇÕES}

Nessa terceira seção são apresentadas e discutidas as informações coletadas por meio de entrevistas com o Grupo 1, composto por integrantes da equipe de desenvolvimento do Projeto de Dimensionamento de Força de Trabalho no Ministério da Saúde no período de 2015 a 2016, e com o Grupo 3 (especialistas em TI). Buscou-se com essas entrevistas capturar a percepção dos integrantes desses dois grupos acerca de práticas de GI relativas às informações de processos no contexto do DFT, a partir de um conjunto de práticas identificadas na literatura base da pesquisa, e verificar a adoção dessas práticas no locus pesquisado.

A análise das informações mostrou que as cinco práticas de GI apontadas na literatura, na categoria distribuição das informações, são presentes no contexto do processo de DFT: 17. A estrutura política favorece a distribuição da informação; 18. Existe estratégia de distribuição de informação bem definida (por demanda, por oferta programada ou mista); 19. Há arquitetura de informações que direciona a informação ao usuário dela; 20. Há repositório eletrônico que integra as diversas bases de informações e distribui as informações; 21. Os meios de distribuição das informações são automatizados. 
Verificada a presença das práticas dessa terceira categoria no contexto do DFT, procedeu-se, conforme objetivos específicos, novamente a análise dos conteúdos das entrevistas para identificar se o órgão adota essas práticas. Assim, a seguir são apresentados os resultados dessa análise, os achados na pesquisa documental e a discussão à luz da literatura.

\subsubsection{Resultados e Discussões - Categoria 3}

Não houve manifestação dos entrevistados dos Grupo 1 e 2 acerca da existência da prática a estrutura política favorece a distribuição da informação. O entrevistado 13, Grupo 3, por sua vez, informou que há uma estrutura colegiada, que faz parte de uma estrutura de governança em TI do órgão, que analisa e aprova demandas de desenvolvimento de soluções informatizadas. Um dos critérios de aprovação de novos projetos, segundo esse entrevistado, é seu potencial de contribuição para a melhoria na disponibilização de informações úteis e, também, se a nova solução proposta pode ser integrada ao parque tecnológico existente na instituição. O entrevistado 14 afirma, fala a seguir, que culturalmente a distribuição das informações é um pouco restrita e, geralmente, é de responsabilidade da área de negócio.

\footnotetext{
Culturalmente, é um pouco restrito porque o gestor sempre fica na necessidade... por exemplo, hoje o DATASUS, área de TI dentro do Ministério da Saúde é apenas a guardiã, detentora dos dados, se responsabiliza que aqueles dados têm que estar lá, tem que está o backup, essa coisa não é qualquer um que vai acessar. Então, quando o gestor ou a área de RH ou a área de atenção básica precisa disponibilizar uma informação, eles nos demandam ou então quem está de fora tem que demandar para eles, para eles autorizarem e mandar pra gente. Mas, muitas das vezes, eles precisam classificar o que você quer dessa informação, eu não vou te dar uma informação que você identifique um paciente e saiba daquela patologia que está existindo com ele. Então, por conta disso, muitas demandas são represadas, a não ser que seja uma universidade ou é um estudo científico; eu vou te dar pra você entender realmente para fazer vigilância em saúde, esse tipo de coisa, mas eu vou descaracterizar e você não vai saber quem é a pessoa, vai ter um código lá que representa o Joãozinho. Aí dessa forma dá, entendeu? Então, é tratado dessa forma a questão da disponibilização da informação (ENTREVISTADO 14).
}

Na análise documental não foi encontra evidência da existência de política interna do órgão que estabelece regramento acerca da distribuição de informações aos diversos usuários. Essa falta de evidência, juntamente com as falas dos entrevistados do Grupo 3, sugere que não 
há na instituição um conjunto de diretrizes claras que norteia a forma como os gestores de banco de informações e os produtores das informações devam lidar com a distribuição desse ativo. A falta de diretriz faz com que cada detentor da informação adote critérios próprios, subjetivos para restringir ou disponibilizar acesso ao conteúdo informacional produzido. Constata-se que uma etapa importante do processo de GI, segundo a literatura, precisa de definição institucional. A distribuição faz a ligação de gestores e funcionários com as informações de que precisam para solução de problemas organizacionais (DAVENPORT, 1998; BEAL, 2004). Dessa forma, conforme recomenda Valentim et al (2003), é necessário que a organização defina políticas e programas com foco na organização e tratamento das informações, para que essas sejam eficazes para quem precisa delas.

De acordo com as informações da pesquisa, percebe-se que não há uma estratégia de distribuição de informação bem definida (por demanda, por oferta programada ou mista). No caso específico das informações necessárias ao dimensionamento, a distribuição para o usuário ocorre por demanda, geralmente, encaminhada ao escritório de processos e às demais unidades que executam os processos de trabalho e estão passando pelo DFT. A afirmação do entrevistado 1, a seguir, corrobora essa percepção.

Ocorre que, como já foi dito, nenhuma das áreas dimensionadas tinham todas as informações disponíveis. Algumas áreas tinham algumas. Mas nenhuma tinham as informações prontamente (ENTREVISTADO 1).

Os entrevistados 1 e 2 acrescentam que existe no órgão uma área que trabalha com ferramenta de Business Intelligence (BI) e que, em reunião realizada com essa equipe, foi percebido que essa área pode ter acesso a várias bases de informações. Ocorre que, como as fontes ainda estão sendo definidas pelas áreas executoras dos processos de trabalho, foi feita a opção por primeiro definir e validar com os produtores da informação, para posteriormente realizar a demanda à equipe de BI, para integrar e distribuir. No entanto, esses dois 
pesquisadores reconhecem que o fato de haver uma estrutura tecnológica com potencial de busca em várias bases pode ser um fator positivo para melhorar essa distribuição.

\begin{abstract}
Percebeu que essa equipe pode ter acesso a tipos de informações que são diferentes das que as áreas executoras têm. No momento de priorizar qual informação utilizar a gente priorizou utilizar a informação da área executora e não da equipe de BI. Mas por uma questão de uma facilidade de acesso e de legitimar a informação como o tínhamos que validar a informação, seria mais interessante validar a informação que eles deram que de uma área de não necessariamente ele tem essa conversa. Mas o fato de existir uma área que cuida de várias bases de informações pode indicar um potencial de desenvolvimento de bases de informações unificadas e substituir a informação declarada, de quem está envolvida na execução. Isso seria um processo superinteressante de se ter acesso à informação. Mas aí entra vários aspectos culturais e estruturais da organização se isso é passível de ser feito ou não (ENTREVISTADO $1)$.

Aí volta a questão da identificação da atual fonte. Só de se ter um BI na organização você entende que você tem uma que área que dispõe de informações e que algum momento você vai utilizar para alguma coisa. Poderia começar pelo dimensionamento (ENTREVISTADO 2).
\end{abstract}

Ao perguntar sobre as estratégias de distribuição de informação da instituição, os especialistas em TI argumentaram que tanto ocorre por demanda, como por oferta. Mas que prevalece por demanda em função de que as áreas produtoras das informações que definem se as informações poderão ser acessadas ou não. O entrevistado 14, a seguir, cita exemplo de disponibilização de informações de processos finalísticos para gestores municipais, como estratégia de oferta.

Por exemplo, alguns dados para a tomada de decisão do gestor municipal e estadual são publicados em uma ferramenta de tabulação de informações, que é o TABWIN/TABNET. Então, esses gestores podem ir lá, é self-service, eles vão lá, puxa essa informação e até mesmo cria um arquivo csv para levar para dentro da instituição deles e fazer os cruzamentos que precisa. Já existem outros dados, como eu tinha falado antes, que não, não são assim; até porque tem que ter uma classificação da informação, né, então é nesse cenário. Então, tem de tudo (ENTREVISTADO 14).

A pesquisa documental corrobora o relato dos entrevistados do Grupo 1 sobre a prática 17, evidenciando que as informações utilizadas no âmbito do DFT foram acessadas por meio de demanda. Isso sugere que, embora haja estratégias de oferta, conforme relatado pelos especialistas em TI, no caso do processo de dimensionamento que faz uso de informações relativas a processos internos e finalísticos, por lidar com a produção do órgão, ainda é 
necessário organizar o fluxo de distribuição. Considerando que as informações requeridas pela metodologia estão definidas, esse fluxo poderá ser estabelecido de forma que a informação seja ofertada para uso pelo dimensionamento. Com relação a esse assunto, a literatura afirma que cada instituição precisa analisar a melhor estratégia de distribuição de suas informações. Geralmente, uma boa estratégia combina o fornecimento programado de determinado conjunto de informações e também disponibiliza acesso dos usuários às demais, de acordo com as necessidades específicas (BEAL, 2004).

Quanto à existência de uma arquitetura de informações que direciona a informação ao usuário dela, de acordo com o entrevistado 1, fala a seguir, não há evidência dessa prática no órgão. O entrevistado 14, relato seguinte, afirma que existe uma arquitetura de informação no órgão, mas que certamente existem processos de trabalho que as informações ainda são manuais, mas que se forem digitalizadas de acordo com a arquitetura tecnológica padrão do órgão, essas poderão ser facilmente incorporadas nas bases. No entanto se estiverem em formatos distintos, será "bem mais difícil”.

\footnotetext{
Eu nem falaria que em arquitetura de informação porque a existência dessa arquitetura faria com que as informações estivessem disponíveis bastando apenas fazer os filtros, buscas nas bases de informações (ENTREVISTADO 1).

Na parte como ela é organizada dentro de um repositório de banco de informações, uma normalização para isso existe [...] na verdade, está no banco de informações único e esse banco de informações único que tem o seu servidor principal, os secundários e os backup, mas estão em tabelas diferentes. Elas ficam em uma forma de organização que a gente chama de normalização de informações que cada eixo de negócio da saúde está em uma tabela diferente que se relaciona. Mas todas elas estão em um único banco de informações. As informações estão digitalizadas, que é algum processo de negócio que é informatizado, porém, com certeza deve existir processos de negócio dentro da casa que não estão informatizados, estão ainda no processo manual (ENTREVISTADO 14).
}

A pesquisa documental evidenciou que há uma “indefinição de padrões de arquitetura de informação" e que essa situação é agravada com a existência de áreas de TI nas várias secretarias que criam suas bases de informações próprias, gerando dificuldades de padronização de linguagens. No PDTI 2016, é explicitada a preocupação com essa questão e definido um 
objetivo específico para tratar o problema, com o engajamento da alta gestão e unidades de TI desconcentradas nas secretarias do MS.

As análises dos achados da pesquisa evidenciam fragilidades na definição da arquitetura informacional e na sua gestão. A pulverização de bases de informações locais sugere que os gerentes e funcionários de áreas não têm suas demandas informacionais supridas pela unidade central e, então, lançam mão de recursos alternativos para obter as informações de que necessitam. Essa situação contraria o que se deseja de uma arquitetura de informação adequada. Uma vez que seu papel é dirigir os usuários para onde às informações estão, de maneira que essas sejam utilizadas e reutilizadas de forma eficiente e não haja duplicação de esforços em sua produção (DAVENPORT, 1998).

No caso das informações dos processos de trabalho usadas no DFT, essas são buscadas em fontes de diversos formatos, algumas, inclusive, são fruto de apurações manuais. Esse contexto se apresenta como um desafio a ser superado por meio do aperfeiçoamento da arquitetura informacional do órgão, considerando que essa tem a função de conter a ferramenta necessária para atender as necessidades de informação dos processos de negócio, de forma a subsidiar a tomada de decisão gerencial.

Quando questionados sobre a evidência da prática existência de repositório eletrônico que integra as diversas bases de informações e distribui as informações no órgão, conforme as falas a seguir, a afirmação do entrevistado 1 é de que não há e o entrevistado 5 ressaltou novamente que as informações estão muito dispersas no órgão. Às vezes, não estão disponíveis e quando estão, algumas estão em meio eletrônico, mas outras ainda são levantadas a partir de contagens em meios físicos, como processos e listas de presença, por exemplo.

Se houvesse uma base de informações integrada, não se trabalharia com informação declarada eliminaria o viés (ENTREVISTADO 1).

Nem sempre essas informações estão disponíveis em sistemas, muitas vezes são planilhas, arquivos, espaços que se tem na rede, documentos em Word, processos físicos, listas de presença, enfim (ENTREVISTADO 5). 
Embora tenha sido relatado pelo entrevistado 14 que há no órgão um banco de informações único, o relato dos entrevistados e a pesquisa documental revelam a fragmentação da informação no ambiente institucional, reforçando a necessidade de um repositório único que integre as várias informações da instituição. Trata-se de um desafio, em decorrência da necessidade de padronização, classificação das informações dispersas, em diversos formatos e, também, pela baixa automação dos processos de trabalho. Sobre essa prática, a literatura aponta que é necessário ter mecanismos voltados à consolidação das informações que se encontram dispersas na instituição, para que seja garantida a guarda e a disponibilidade eficiente aos diversos usuários (BEAL, 2004).

Quanto à prática meios de distribuição das informações são automatizados, como a maioria dos processos não estão automatizados e as fontes de informação, no contexto do DFT, ainda estão sendo definidas porque não foram mapeadas previamente, as informações evidenciam que essa ainda é uma prática incipiente no órgão. As falas dos entrevistados 1 e 3 confirmaram isso.

\footnotetext{
Às vezes elas controlam via sistema alguns processos específicos. Pela própria questão de o dimensionamento ter forçado a identificação das entregas, a área o que ela não tinha antes, ocorre que muitas vezes os sistemas que a área opera não fornece o indicador de produção que o dimensionamento requer (ENTREVISTADO 1).

Não tem ainda as bases de informações, por exemplo, informatizadas, ou os processos não são automatizados o suficiente. Se isso tivesse muito bem organizado, a gente ia conseguir rodar mais rápido (ENTREVISTADO 3).
}

A pesquisa documental corroborou a fala dos entrevistados ao evidenciar que as informações relativas a processos de trabalho foram coletadas diretamente pelos produtores das informações em sistemas de acesso somente pela própria área, contagem físicas de produção e, também, por meio de declaratório. Os documentos também revelaram que existe distribuição automatizada, mas que está restrita a alguns processos finalísticos, com uso de ferramentas modernas, como Business Intelligence. Essas evidências sugerem que há possibilidade de 
utilizar essas mesmas ferramentas para aperfeiçoar o fornecimento de informação para os processos de negócio internos. Sobre essa questão, a literatura afirma que as organizações precisam explorar diversos canais de distribuição da informação, privilegiando trocas por meio de estruturas informatizadas, que sejam flexíveis e adaptáveis às necessidades dos tomadores de decisão (BEAL, 2004).

Considerando as quatro categorias de resultados possíveis (adota, adota parcialmente, não adota, não identificado) e os critérios usados para esse agrupamento, no Quadro 10 estão sintetizados os achados da pesquisa referentes à Categoria 3. 
Quadro 10 - Síntese das informações sobre a adoção das práticas referentes à Categoria 3

\begin{tabular}{|c|c|c|c|c|c|c|c|c|c|c|}
\hline \multicolumn{11}{|c|}{ CATEGORIA 3: DISTRIBUIÇÃO DAS INFORMAÇÕES } \\
\hline \multirow{2}{*}{ Práticas } & \multicolumn{4}{|c|}{$\begin{array}{c}\text { Adoção das práticas de acordo com os } \\
\text { entrevistados do Grupo } 1\end{array}$} & \multicolumn{4}{|c|}{$\begin{array}{c}\text { Adoção das práticas de acordo com os } \\
\text { entrevistados do Grupo } 3\end{array}$} & \multirow{2}{*}{$\begin{array}{c}\text { Análise } \\
\text { documental }\end{array}$} & \multirow{2}{*}{ Resultados } \\
\hline & Adota & $\begin{array}{c}\text { Adota } \\
\text { parcialmente }\end{array}$ & $\begin{array}{c}\text { Não } \\
\text { adota }\end{array}$ & $\begin{array}{c}\text { Não } \\
\text { identificado }\end{array}$ & Adota & $\begin{array}{c}\text { Adota } \\
\text { parcialmente }\end{array}$ & $\begin{array}{c}\text { Não } \\
\text { adota }\end{array}$ & $\begin{array}{c}\text { Não } \\
\text { identificado }\end{array}$ & & \\
\hline $\begin{array}{l}\text { 17. A estrutura política favorece a } \\
\text { distribuição da informação }\end{array}$ & - & - & - & $100 \%$ & - & $100 \%$ & - & - & $\begin{array}{c}\text { Não } \\
\text { identificado } \\
\end{array}$ & $\begin{array}{c}\text { Adota } \\
\text { parcialmente }\end{array}$ \\
\hline $\begin{array}{l}\text { 18. Existe estratégia de distribuição } \\
\text { de informação bem definida (por } \\
\text { demanda, por oferta programada } \\
\text { ou mista) }\end{array}$ & - & - & $33 \%$ & $67 \%$ & - & $100 \%$ & - & - & $\begin{array}{l}\text { Adota } \\
\text { parcialmente }\end{array}$ & $\begin{array}{l}\text { Adota } \\
\text { parcialmente }\end{array}$ \\
\hline $\begin{array}{l}\text { 19. Há arquitetura de informações } \\
\text { que direciona a informação ao } \\
\text { usuário dela }\end{array}$ & - & - & $17 \%$ & $83 \%$ & $50 \%$ & $50 \%$ & - & - & Não adota & $\begin{array}{c}\text { Adota } \\
\text { parcialmente }\end{array}$ \\
\hline $\begin{array}{l}\text { 20. Há repositório eletrônico que } \\
\text { integra as diversas bases de } \\
\text { informações e distribui as } \\
\text { informações }\end{array}$ & - & - & $67 \%$ & $33 \%$ & $50 \%$ & $50 \%$ & - & - & Não adota & $\begin{array}{l}\text { Adota } \\
\text { parcialmente }\end{array}$ \\
\hline $\begin{array}{l}\text { 21. Os meios de distribuição das } \\
\text { informações são automatizados }\end{array}$ & - & - & $50 \%$ & $50 \%$ & - & $100 \%$ & - & - & Não adota & $\begin{array}{c}\text { Adota } \\
\text { parcialmente }\end{array}$ \\
\hline
\end{tabular}

Fonte: Informações da pesquisa. 
Com relação à distribuição das práticas de GI pelo órgão pesquisado, relativas às informações de processos no contexto do DFT, os resultados das entrevistas demonstram o seguinte: (i) prática 17: explorada nas entrevistas com o Grupo 1 e 3: não houve manifestação clara do Grupo 1 acerca dessa prática e 100\% do Grupo 3 afirmaram que a prática é adotada parcialmente. (ii) prática 18: explorada nas entrevistas com os Grupos 1 e 3: 33\% dos participantes do Grupo 1 afirmaram que a prática não é adotada e 100\% do Grupo 3 afirmaram que é adotada parcialmente. (iii) prática 19: explorada nas entrevistas com os Grupos 1 e 3: 17\% dos entrevistados do Grupo 1 afirmaram que a prática não é adotada e, no Grupo 3, 50\% afirmaram que é adotada parcialmente e 50\% afirmaram que é adotada. (iv) prática 20: explorada com os Grupos 1 e 3: 67\% dos entrevistados do Grupo 1 afirmaram que a prática não é adotada e, no Grupo 3, 50\% afirmaram que é adotada parcialmente e 50\% afirmaram que é adotada; (v) prática 21: prática explorada nas entrevistas com os Grupos 1 e 3: 50\% dos entrevistados o Grupo 1 afirmaram que a prática não é adotada e 100\% do Grupo 3 afirmaram que adota parcialmente.

A pesquisa documental não identificou informações relativas a prática 17 . Houve evidência de adoção parcial da prática 18 e não adoção das práticas 19, 20 e 21. Há percepção dos entrevistados do Grupo 3 é discrepante das percepções dos entrevistados do Grupo 1, que se aproximam dos achados da pesquisa documental. Isso sugere que, se as práticas existem no órgão, elas não estão documentadas e nem compartilhadas o suficiente com os usuários das informações.

A partir dos critérios estabelecidos para consolidar os resultados, foi possível perceber que, das 5 práticas da Categoria 3, todas são adotas parcialmente pelo órgão no contexto pesquisado. 


\subsection{QUANTO AO USO DAS INFORMAÇÕES}

Nessa quarta seção são apresentadas e discutidas as informações coletadas por meio de entrevistas com o Grupo 1, composto por integrantes da equipe de desenvolvimento do Projeto de Dimensionamento de Força de Trabalho no Ministério da Saúde no período de 2015 a 2016. Buscou-se com essas entrevistas capturar a percepção dos integrantes desse grupo sobre práticas de GI relativas às informações de processos no contexto do DFT, a partir de um conjunto de práticas identificadas na literatura base da pesquisa, e verificar a adoção dessas práticas na instituição pesquisada.

A análise das informações mostrou que as quatro práticas de GI apontadas na literatura, na categoria uso das informações, estão presentes no contexto do processo de DFT: 22 A instituição estimula e reconhece o uso das informações (DAVENPORT, 1998); 23. A frequência de uso da informação é conhecida pelo gerador do dado (DAVENPORT, 1998); 24. A instituição faz uso dessas informações nas avaliações de desempenho (DAVENPORT, 1998; KETTINGER; MARCHAND, 2011); e 25. Há reuniões frequentes nas quais se faz uso das informações (DAVENPORT, 1998).

Verificada a presença das práticas dessa quarta categoria no contexto do DFT, procedeuse, conforme objetivos específicos, novamente a análise das informações para identificar se o órgão adota essas práticas. Assim, a seguir são apresentados os resultados dessa análise, os achados na pesquisa documental e a discussão à luz da literatura.

\subsubsection{Resultados e Discussões - Categoria 4}

Sobre a prática a instituição estimula e reconhece o uso das informações, os achados evidenciaram que embora as informações usadas pelo dimensionamento sejam decorrentes de processos de trabalho, como gestão da produção, gestão de processos de trabalho, de maneira 
geral a organização não tem essas informações disponíveis e organizadas o suficiente para ser

utilizadas pelo DFT. Isso pode ser confirmado na fala dos entrevistados a seguir.

O dimensionamento utiliza informações que na verdade deveriam ser produto de informação de outras ferramentas de gestão. Então, o interesse da organização ela pode produzir alguma coisa específica para o dimensionamento, mas ela pode também pode ser feito de outros processos de trabalho de gestão da própria organização. A gestão de produtividade de processo ela vai tirar informação do dimensionamento depois. Digo mais normalmente os dimensionamentos, se você for olhar do ponto de vista de um planejamento de gestão, ele na verdade é uma ferramenta secundária em relação a informação. Aquela informação é de forma primária ela não deveria ser gerada para dimensionamento, mas para a própria gestão daquele processo específico. E ainda tem a vantagem de o dimensionamento vir e se apropria dessa informação para fazer seus cálculos. O que a gente percebe no MS é o inverso. O dimensionamento gera a demanda e a informação é gerada. E aí observa-se, do nosso ponto de vista, que seria interessante que já que agora você começou a produzir essa informação, que você também comece a fazer o gerenciamento dela da forma como ela deveria ter sido desde o início (ENTREVISTADO 1).

Pelas áreas que nós passamos, isso não tem sido uma preocupação tão grande, mas que a partir do dimensionamento pode ser que as pessoas enxerguem o valor de se controlar esse tipo de informação e fazer a gestão dessa informação (ENTREVISTADO 3).

A pesquisa documental evidenciou que embora haja uma grande quantidade de informações na instituição, a organização e a disponibilização dessas para uso pelo DFT consumiram muito tempo do cronograma previsto no início da aplicação da metodologia. Ademais, conforme consta em atas, nem sempre as informações de processos de trabalho disponibilizadas estavam no formato requerido, dificultando a preparação dessas para proceder ao processamento dos resultados do dimensionamento. Esse é um indicativo de há fragilidades na instituição quanto ao estímulo dos gestores e funcionários a usarem as informações de processos de trabalho para tomada de decisão, ação que independe da instalação de um processo de DFT. Processos de planejamento e de prestação de contas, por exemplo, geralmente fazem uso desse tipo de informação. Portanto, a gestão do órgão necessita estimular o uso das informações de resultados dos processos de trabalho pelas áreas de negócio, uma vez que essa ação possibilita a reflexão sobre sua eficiência e eficácia e, também, permite o fornecimento dessas informações para uso por processos institucionais (DAVENPORT, 1998; BEAL, 2004). 
Com relação à prática frequência de uso da informação é conhecida pelo gerador do dado, os achados demonstraram que, no decorrer da aplicação da metodologia de DFT nas unidades, não foi percebida cultura de monitoramento de informações de processos e seus resultados. O DFT poderá ser um indutor dessa prática, como relatado pelos entrevistados, mas, como o processo de DFT ainda é recente na instituição, não há clareza por parte dos entrevistados qual será a frequência de uso dessas informações de processo. Dessa forma, percebe-se que o gerador da informação ainda não tem essa definição, porque depende da frequência de aplicação da metodologia em sua respectiva área. Embora, conforme já afirmado, trata-se de informações que deveriam ser de uso recorrente na gestão dos processos de trabalho do órgão porque não são exclusivas de uso do processo de dimensionamento. A fala do entrevistado 1, abaixo, ilustra essa constatação.

O uso e reuso de informação depende da escolha do processo de trabalho
dimensionamento das pessoas que estão gerenciando esse projeto, de quanto em
quanto tempo o dimensionamento vai ser feito. Aí isso de novo é dependente da
disponibilidade de informação. Se por exemplo a informação eu consigo coletar todas
as informações mês a mês é possível eu realizar o dimensionamento mês a mês. Então
o dimensionamento depende da frequência de coleta de informações. Então, depende
da estratégia da organização em relação ao dimensionamento (ENTREVISTADO 1).

A literatura afirma que a frequência com que a informação será utilizada interfere nos atributos do fluxo informacional nas instituições (BEAL, 2004) e na estimativa da demanda a ser atendida (DAVENPORT, 1998). Dessa forma, para que as informações estejam atualizadas e disponíveis em formatos específicos para um dado processo organizacional, é necessário que se defina sua frequência de uso. Portanto, o órgão pesquisado precisa tomar a decisão da periodicidade de aplicação da metodologia, uma vez que isso fornecerá direcionamento aos produtores de informação e aos gerenciadores dos bancos de informações sobre quando disponibilizar os insumos informacionais para o processo de dimensionamento.

Quanto à prática a instituição faz uso dessas informações nas avaliações de desempenho, os entrevistados não perceberam o uso das informações de processos associado 
às avaliações de desempenho de processos ou gestão. Os relatos dos entrevistados foram, mais uma vez, em relação ao fato de o processo de dimensionamento ainda ser novo no órgão, os gestores de áreas ainda não conseguiram enxergar todo o seu potencial de contribuição para outros processos de trabalho da Instituição. A seguir, o entrevistado 1, por exemplo, aponta como o dimensionamento pode auxiliar a organização na implementação da estratégia. Corroborando a fala desse entrevistado, o entrevistado 5, relato seguinte, argumenta que em algumas áreas o dimensionamento já provocou na gestão o interesse de fazer uso das informações geradas em outros processos de trabalho, como planejamento estratégico e gestão de desempenho.

\begin{abstract}
O dimensionamento pode ser usado como uma ferramenta de diagnóstico ou de análise organizacional transversal onde eu paro um momento do tempo faço uma análise de dimensionamento para ver qual o meu índice de produtividade até esse momento no tempo e como vai ser. Eu poderia, por exemplo, definir o dimensionamento como uma etapa de planejamento estratégico. Então toda vez que eu faço uma alteração estratégica dentro da organização eu faço um novo dimensionamento para ver o que eu vou precisar para executar essa estratégia. Acaba sendo uma iniciativa mais pontual ou eu posso assumir o dimensionamento como um processo da organização, mas já está avaliando continuamente como ela está em realça aos processos o que funciona bem para organizações que tem uma tendência de se manter mais em termos estratégicos. A estratégia dela muda em certos aspectos a cada ciclo, mas a estratégia dela e sempre a mesma. Ela tem um propósito já bem especificado e um certo tipo de serviço que ela realiza que é bem especificado faz sentido você ter um dimensionamento mais continuo (ENTREVISTADO 1).
\end{abstract}

Agente teve áreas, por exemplo, que não faziam gestão dessa informação que a gente coletou no dimensionamento. E, depois do dimensionamento, elas passaram a enxergar quais eram as entregas das áreas e isso passou a ser um insumo para o planejamento estratégico e para avaliação de desempenho da própria da área. E o gestor passou a controlar aquela informação a partir disso aqui então eu vou passar a controlar isso mensalmente (ENTREVISTADO 5).

Não houve evidência na pesquisa documental acerca dessa prática no órgão. Isso pode ser devido ao processo de DFT ser novo na Instituição, conforme relatado pelos entrevistados, e, portanto, os gestores ainda estarem se apropriando de seus resultados e de todo seu potencial para subsidiar outros processos de trabalho da Instituição. Resultados de processo de trabalho, por exemplo, é um tipo de informação que pode subsidiar não somente alocação de força de trabalho, como também tomada de decisão relativa ao orçamento, à aquisição de insumos, ao 
espaço físico, dentre outros. Davenport (1998) afirma que o uso para avaliar desempenho agrega valor à informação e fomenta a cultura de uso.

Sobre a prática há reuniões frequentes nas quais se faz uso das informações, os achados evidenciaram que o processo de dimensionamento tem provocado nas unidades reflexão sobre processos de trabalho e não o contrário. Embora os entrevistados reconheçam que as informações de processos utilizadas no contexto do DFT deveriam estar em uso na Instituição para gerir desempenho e produtividade, por exemplo. O entrevistado 1 afirma, a seguir, que o órgão precisa ter um nível de maturidade de gestão de processos maior para conseguir realizar o dimensionamento rapidamente e utilizar os seus resultados de forma tempestiva e em toda a sua potencialidade. Nesse mesmo sentido, o entrevistado 2 afirma que esse nível de maturidade está muito incipiente, uma vez que havia área que se quer sabia as entregas que faziam ao final dos processos de trabalho. Então, de fato ainda há necessidade de amadurecimento de gestão para que a Instituição consiga fazer uso recorrente dessas informações relativas aos processos de trabalho e dimensionamento.

\footnotetext{
O dimensionamento é uma ferramenta que exige um nível alto de maturidade de gestão da organização. $\mathrm{O}$ que a gente observa é que o dimensionamento está criando a demanda por essa maturidade, e não o processo contrário onde a organização desenvolve a maturidade e a partir disso ela começa a fazer o dimensionamento. Então isso que a gente observa no MS (ENTREVISTADO 1).

A área não sabia literalmente o que ela entregava. Se você não sabe o que você entrega, ainda mais medir isso aí. Então, as pessoas que não faziam parte da entrega final mesmo, do resultado, tinham dificuldade de até perceber o porquê do trabalho delas (ENTREVISTADO 2).
}

Sobre essa prática, Davenport (1998) afirma que reuniões regulares são um ambiente propício para fazer uso das informações produzidas no ambiente organizacional e que a difusão dessas nesses espaços de decisão é uma estratégia poderosa de reforçar sua importância. No caso específico das informações relativas aos processos de trabalho, essa pode ser uma alternativa para fomentar na Instituição a sua organização, automação e disponibilização para os usuários, considerando que foi verificada baixa estruturação do fluxo dessas informações. 
Considerando as quatro categorias de resultados possíveis (adota, adota parcialmente, não adota, não identificado) e os critérios usados para esse agrupamento, no Quadro 11 são sintetizados os achados da pesquisa referentes à Categoria 4.

Quadro 11 - Síntese das informações sobre a adoção das práticas referentes à Categoria 4

\begin{tabular}{|l|c|c|c|c|c|l|}
\hline \multicolumn{7}{|c|}{ CATEGORIA 4: USO DAS INFORMAÇÕES } \\
\hline \multicolumn{1}{|c|}{ Práticas } & \multicolumn{2}{|c|}{$\begin{array}{c}\text { Adoção das práticas de acordo com os } \\
\text { entrevistados do Grupo 1 }\end{array}$} & $\begin{array}{c}\text { Análise } \\
\text { documental }\end{array}$ & Resultados \\
\cline { 2 - 7 } & Adota & $\begin{array}{c}\text { Adota } \\
\text { parcialmente }\end{array}$ & $\begin{array}{c}\text { Não } \\
\text { adota }\end{array}$ & $\begin{array}{c}\text { Não } \\
\text { identificado }\end{array}$ & Não adota & Não adota \\
\hline $\begin{array}{l}\text { 22 A instituição estimula e reconhece o } \\
\text { uso das informações }\end{array}$ & $17 \%$ & - & $66 \%$ & $17 \%$ & Não adota & Não adota \\
\hline $\begin{array}{l}\text { 23. A frequência de uso da informação é } \\
\text { conhecida pelo gerador do dado }\end{array}$ & - & - & $50 \%$ & $50 \%$ & Não & Não adota \\
\hline $\begin{array}{l}\text { 24. A instituição faz uso dessas } \\
\text { informações nas avaliações de } \\
\text { desempenho }\end{array}$ & $17 \%$ & - & $50 \%$ & $33 \%$ & identificado & Não adota \\
\hline $\begin{array}{l}\text { 25. Há reuniões frequentes nas quais se } \\
\text { faz uso das informações }\end{array}$ & $17 \%$ & - & $50 \%$ & $33 \%$ & Não adota \\
\hline
\end{tabular}

Fonte: Informações da pesquisa.

A categoria uso das informações foi explorada somente com os entrevistados do Grupo 1. Com relação à adoção das práticas, os resultados das entrevistas demonstram o seguinte: (i) prática 22: $17 \%$ dos entrevistados afirmaram que a prática é adotada e $66 \%$ disseram que não adota. (ii) prática 23: 50\% dos entrevistados afirmaram que a prática não é adotada pelo órgão. (iii) prática 24: 17\% dos entrevistados afirmaram que a prática é adotada e 50\% afirmaram que não é adotada. (iv) prática 25: 17\% dos entrevistados afirmaram que a prática é adotada e 50\% afirmaram que não é adotada.

A pesquisa documental não identificou informações relativas à prática 24 . Não houve evidência de adoção das práticas 22, 23 e 25. A consolidação dos resultados, considerando os critérios estabelecidos, demonstra que as práticas da categoria 4 não são adotadas pelo órgão no contexto pesquisado. Esse resultado pode ser decorrente de o processo de DFT ser novo na 
Instituição e, portanto, ainda necessita de percepção por parte do corpo de gestores sobre seu potencial de contribuição para outros processos de trabalho na Instituição.

\subsection{SÍNTESE DOS RESULTADOS}

Nessa seção é apresentada a síntese dos resultados de adoção das práticas e GI pelo órgão, no contexto pesquisado. Na categoria 1, 72\% das práticas são adotadas, $14 \%$ adotadas parcialmente e $14 \%$ não são adotadas. Na categoria 2, que concentra o maior número de práticas do processo de GI (10), 20\% das práticas são adotadas, 50\% adotadas parcialmente e 30\% não são adotadas. Na categoria 3, cujas práticas fazem uso intensivo de tecnologia de informação, $100 \%$ das práticas são adotadas parcialmente. E, finalmente, na categoria 4, 100\% das práticas não são adotadas.

Quadro 12 - Resultados da adoção de práticas de GI relativos às informações de processos no contexto do DFT

\begin{tabular}{|l|c|c|c|}
\hline \multicolumn{2}{|c|}{ SÍNTESE DOS RESULTADOS POR CATEGORIA DO PROCESSO DE GI } \\
\hline \multirow{2}{*}{ Categorias } & \multicolumn{3}{c|}{ Resultados } \\
\cline { 2 - 4 } & Adota & Adota parcialmente & Não adota \\
\hline 1. Determinação de exigências informacionais & $72 \%$ & $14 \%$ & $14 \%$ \\
\hline 2. Obtenção das informações & $20 \%$ & $50 \%$ & $30 \%$ \\
\hline 3. Distribuição das informações & - & $100 \%$ & - \\
\hline 4. Uso das informaç̃oes & - & - & $100 \%$ \\
\hline
\end{tabular}

Fonte: Informações da pesquisa.

Percebe-se que a maioria das práticas é adotada parcialmente no contexto pesquisado. Por outro lado, fica latente que as práticas referentes ao uso das informações de processo ainda precisam ser reforçadas. Esse é um recurso informacional importante para o processo de dimensionamento e, também, para outros processos de trabalho, como gestão de desempenho. Portanto, a Instituição precisa estimular o uso das informações de processos de trabalho na tomada de decisão gerencial. 


\section{CONCLUSÕES}

A pesquisa desenvolvida nesta dissertação procurou responder às seguintes questões: o Ministério da Saúde adota práticas de gestão da informação no que ser refere às informações de processos de trabalho? Essas informações estão preparadas para atender às demandas do Dimensionamento de Força de Trabalho (DFT)? Para tanto, foi estabelecido como objetivo geral avaliar o grau de adoção de práticas de gestão da informação de processos no contexto do Dimensionamento de Força de Trabalho no MS.

Considerando o referencial teórico base desta pesquisa e o método de pesquisa requerido, foi identificado um conjunto inicial de atores-chave que deveria ser entrevistado, em função de sua participação no Projeto de Pesquisa de Dimensionamento da Força de Trabalho do Ministério da Saúde. Esses atores, por sua vez, apontaram quais outros atores precisariam ser entrevistados, tendo em vista o objeto de estudo desta dissertação. Diante dessa indicação, além das duas primeiras entrevistas coletivas realizadas com o Grupo 1, foram realizadas mais uma entrevista coletiva com 6 participantes (Grupo 2) e duas entrevistas individuais com dois participantes (Grupo 3), totalizando 14 entrevistados. Além dessas fontes primárias, foram coletadas informações secundários em 33 documentos da Instituição, que foram submetidos à análise documental.

Os informações da pesquisa apontaram que a metodologia de dimensionamento adotada no órgão contempla cinco insumos informacionais relativos aos processos de trabalho: produção, tempo, complexidade dos processos, nível de informatização e valor agregado, sendo as três primeiras apontadas pelos pesquisadores do tema DFT como importantes para se dimensionar (CLACK et al. 2001; SOHONI; JOHNSON; BAILEY, 2004; NICOLA; ANSELMI, 2005; DAL BEN; GAIDZINSK, 2007; CRUZ et al., 2014; GRIFFITHS; PRESHAW, 2014; PAIXÃO et al., 2015). 
Foi adotado o modelo de processo de Gestão da Informação (GI) de Davenport (1998), cujas etapas são determinação de exigências, obtenção, distribuição e uso, para, a partir da aplicação de técnicas de análise de conteúdo (BARDIN, 1977), proceder à categorização e à análise das evidências coletados. Para cada uma dessas categorias foram identificadas na literatura práticas correspondentes que precisam ser adotadas pelas organizações para conseguir ter um processo exitoso de GI. Realizada essa etapa, as informações foram analisadas para identificar a manifestação dessas práticas em relação às informações de processos de trabalho no contexto do DFT no órgão pesquisado. Posteriormente, considerando os critérios definidos, foi verificada a adoção dessas práticas pelo órgão.

A análise das informações evidenciou que as seis práticas de GI apontadas na categoria determinações de exigências informacionais estão presentes no contexto do processo de DFT: 1. Clareza dos objetivos a serem alcançados; 2. Compreensão do contexto dos processos administrativos e suas necessidades informacionais; 3. Clareza das informações-chave para os usuários; 4. Avaliação periódica da necessidade de readequação das exigências de informação; 5. Definição clara dos limites das informações (escopo); 6. Clareza das fontes de informação. Além dessas seis, a pesquisa identificou outra prática: identificação das possibilidades e restrições de informações do contexto, que parece ser própria da estruturação do processo de dimensionamento ou de processos em que se aplica uma metodologia de prototipação, experimentação e validação. Desse conjunto de sete práticas dessa categoria, a análise das informações evidenciou que o órgão adota 43\% (práticas 1, 4 e prática identificada no campo), adota parcialmente $43 \%(2,3,5)$ e não adota $14 \%$ (6). Esses resultados apontam que as informações de processos de trabalho não estão suficientemente preparadas para uso pelo processo de DFT.

Diante dessa constatação, algumas recomendações são importantes para aprimorar esse processo: os usuários das informações (responsáveis pelo desenvolvimento do processo de 
dimensionamento) carecem da ampliação da sua compreensão acerca dos processos de trabalho da Instituição e suas necessidades informacionais, que poderá ser facilitado com a construção da cadeia de valor das unidades pelo escritório de processo; as ações de capacitação para os produtores das informações devem ser intensificadas; é preciso haver maior clareza dos limites das informações que serão coletadas para o DFT e isso poderá ser alcançado por meio da definição de um protocolo de coleta de informações detalhado que oriente o produtor da informação. Com relação à prática 4 , de acordo com os entrevistados, em função da dificuldade de definir as fontes de informações a priori, foi feita a escolha pela identificação diretamente com cada responsável pelo processo de trabalho, porém, esse foi apontado como um dos motivos de atraso no cronograma de implantação do processo. Dessa forma, recomenda-se que seja realizado um mapa da informação, conforme sugere Beal (2004), com objetivo de localizar as fontes de informações existentes, as áreas responsáveis e os sistemas associados, para que se tenha conhecimento do que está disponível, o que falta e o que precisa ser gerado, pois isso irá conferir agilidade à realização do dimensionamento de força de trabalho.

Outra constatação do estudo é que as 10 práticas da categoria obtenção das informações estão presentes no contexto do processo de DFT: 7. Exploração do ambiente informacional por meio de abordagens automatizada e humana; 8. A gestão reconhece a necessidade de investir em sistemas que possibilitem a filtragem de informações e a geração de informações para os usuários; 9. Fontes de informações atualizadas, confiáveis e disponíveis; 10. Base de informações integrada que armazena e distribui as informações; 11. Coleta e distribuição eletrônica de informações; 12. Equipes capacitadas e em quantitativos suficientes para a geração e a análise das informações necessárias; 13. Diretriz clara de rotinas a serem adotadas pelo produtor das informações para a classificação, a interpretação e o armazenamento do conteúdo informacional; 14. Estrutura de fornecimento das informações que favorece a autonomia do usuário; 15. Informações categorizadas, classificadas em formatos que facilitam 
a compreensão pelo usuário; 16. Informações produzidas para atender demandas específicas dos usuários. Dessas práticas, 20\% são adotadas (7 e 8), 50\% são adotadas parcialmente (11 a 15) e $30 \%$ não são adotadas (9, 10 e 16). Nessa Categoria, quatro questões chamam a atenção: (i) uma prática elementar para o funcionamento do DFT, que são informações de processos de trabalho confiáveis, atualizadas e disponíveis, não é adotada no órgão. Isso precisa ser sanado, pois pode inviabilizar o uso dos resultados do dimensionamento pelos gestores na tomada de decisão; (ii) fragilidades com relação às bases de dados, gerando retrabalho e demora na geração das informações, o que evidencia a necessidade de melhorar a qualidade da informação e integrar bases; (iii) falta de integração entre as ações de gestão de processos do escritório de processos com os insumos informacionais requeridos pelo DFT; (iv) divergência de percepção entre os especialistas em TI do órgão (Grupo 3) e os demais entrevistados, considerando que as falas desses especialistas oscilam entre adoção das práticas e adoção parcialmente pelo órgão. Isso sugere que as disponibilidades de tecnologia da informação não estão suficientemente compartilhadas com as áreas de negócio.

Com relação à Categoria distribuição das informações, a partir da análise das percepções dos entrevistados, foi verificado que $100 \%$ das práticas são adotadas parcialmente. As práticas dessa categoria (17. A estrutura política favorece a distribuição da informação; 18. Existe estratégia de distribuição de informação bem definida - por demanda, por oferta programada ou mista; 19. Há arquitetura de informações que direciona a informação ao usuário dela; 20. Há repositório eletrônico que integra as diversas bases de informações e distribui as informações; 21. Os meios de distribuição das informações são automatizados) se referem à existência na Instituição de uma política informacional, bem como estratégias, processos, estrutura e soluções informatizadas capazes de levar a informação a quem precisa dela, de acordo com Davenport (1998) e Beal (2004). Novamente, nessa Categoria, as percepções estão polarizadas, de um lado, os especialistas em TI que afirmaram que as práticas são adotadas 
parcialmente, e de outro, parte dos usuários relatou que as práticas não foram percebidas no contexto pesquisado. Esse resultado sugere que, se as práticas existem no órgão, elas não estão documentadas e nem compartilhadas o suficiente com os usuários das informações. Como o dimensionamento faz uso de um volume de informações elevado, requerendo a existência dessas estratégias, processos, estrutura e soluções, diante dessa situação evidenciada na pesquisa, a recomendação é de que a TI se aproprie das necessidades do processo de negócio (DFT) para que as disponibilidades da TI sejam aportadas no processo de dimensionamento.

A percepção dos entrevistados em relação às práticas da Categoria uso das informações (práticas 22. A instituição estimula e reconhece o uso das informações; 23. A frequência de uso da informação é conhecida pelo gerador do dado; 24. A instituição faz uso dessas informações nas avaliações de desempenho; e 25. Há reuniões frequentes nas quais se faz uso das informações) é de que elas não são adotadas no órgão. Os argumentos apresentados para tal resultado foram de que o processo de dimensionamento ainda é recente na instituição (cerca de 2 anos) e que seu potencial de contribuição para os processos de trabalho do órgão ainda não foi explorado. Os resultados apontam também que as informações de processos de trabalho estão sendo produzidas para alimentar o DFT, mesmo se tratando de informações que deveriam ser usadas para monitoramento de desempenho de produção e outras estratégias. Essa situação revela que o DFT está funcionando como indutor de reflexões sobre os processos de trabalho nas áreas, produção, informatização, complexidade e valor agregado. Esses efeitos podem ser extremamente benéficos ao órgão.

As conclusões desse estudo, a partir da análise dos relatos das entrevistas e da pesquisa documental, considerando as quatro categorias, são que as informações de processos de trabalho não estão suficientemente organizadas para serem utilizadas como insumo informacional pelo processo de DFT e que essa situação fragiliza esse processo. Dessa forma, o órgão precisa 
investir no fortalecimento das práticas de Gestão da Informação (GI) para superar as deficiências apontadas neste estudo.

Entende-se que os objetivos específicos e geral desse estudo foram atingidos e com isso ofertada uma contribuição aos estudos relativos ao dimensionamento, principalmente, no que tange às práticas de GI importantes nesse contexto, para garantir que os resultados desse processo sejam viabilizados, confiáveis e que, de fato, possam subsidiar a tomada de decisão gerencial.

O método aplicado também poderia ser utilizado para avaliar a adoção de práticas de GI referentes aos demais insumos informacionais empregados no processo de DFT: estratégia, pessoas, estrutura e legislação, analisando quais informações são requeridas em cada um desses aspectos, bem como o estágio da obtenção, da distribuição e do uso na Instituição. Desse ponto de vista, é possível também utilizar esse método para acompanhar a evolução do processo de GI no contexto pesquisado ou em outros contextos que aplicam o DFT e, com isso, auxiliar os gestores a tomar decisões acerca de ações que venham melhorar a gestão da informação na instituição.

Por fim, algumas limitações foram identificadas nessa pesquisa: a identificação das práticas de GI ter sido limitada a um conjunto de quatro publicações; a verificação da manifestação das práticas no processo de DFT ser realizada somente no processo de uma instituição; o processo ser recente no órgão (cerca de 2 anos), não estando suficientemente maduro em alguns aspectos; e os resultados não poderem ser generalizados, porque, conforme salientado por Bardin (1977), as análises qualitativas realizadas são específicas de um acontecimento. 


\section{REFERÊNCIAS}

ABRUCIO, F. L; SANO, H. Promessas e resultados da nova gestão pública no Brasil: o caso das organizações sociais de saúde em São Paulo. Revista de Administração de Empresas, v. 48 , n. 3, p. 64-80, 2008.

AHLSTRAND, B; LAMPEL, J; MINTZBERG, H. Safári de estratégia: um roteiro pela selva do planejamento estratégico. Tradução de Nivaldo Montingelli Jr. Porto Alegre: Bookman, 2000.

ANGELONI, M. T. Elementos intervenientes na tomada de decisão tomada de decisão. Ciência e Informação, v. 32, n. 1, p. 17-22, 2003.

ARAÚJO, P. G.; PEREIRA, J. R. Análise da aplicabilidade do modelo gerencial na administração municipal. Revista de Administração Pública. v. 46, n. 5, p. 1179-99, 2012.

ARTS, D. G. T; KEIZER, N; SCHEFFER, G. J. Defining and improving data quality in medical registries: a literature review, case study, and generic framework. Journal of the American Medical Informatics Association, v. 9, n. 6, 2002. Disponível em: <http://jamia.oxfordjournals.org $>$. Acesso em: 17 de jan. 2016.

ASSOCIATION OF BUSINESS PROCESS MANAGEMENT PROFESSIONALS (ABPMP). BPM CBOK V3.0: guia para o gerenciamento de corpo comum de conhecimento. 2013. Disponível em:

<http://c.ymcdn.com/sites/www.abpmp.org/resource/resmgr/Docs/ABPMP_CBOK_Guide Portuguese.pdf $>$. Acesso em: 20 de fev. 2016.

BALDAM, R. D; VALLE, R; PEREIRA, H; HILST, S; ABREU, M; SOBRAL, V. Gerenciamento de processos de negócios: BPM-Business Process Management. São Paulo: Érica, 2007.

BARBOSA, R. R. Gestão da informação e do conhecimento: origens, polêmicas e perspectivas. Informação \& Informação, v. 13, n. esp, p. 1-25, 2008.

BARBOSA, R. R.; NASSIF, M. E. Práticas de gestão e de tecnologia da informação e seu relacionamento com o desempenho organizacional. Perspectivas em Gestão \& Conhecimento. v. 2, número especial, p. 104-117, out. 2012. Disponível em: $\langle$ http://periodicos.ufpb.br/index.php/pgc/article/viewFile/13748/8025 >. Acesso em: $7 \mathrm{de}$ jul. 2016.

BARDIN, L. Análise de Conteúdo. São Paulo: Edições 70, 1977.

BEAL, A. Gestão estratégica da informação: como transformar a informação e a tecnologia da informação em fatores de crescimento e de alto desempenho nas organizações. Atlas, 2004.

BONFIM, D; GAIDZINSKI, R. R; SANTOS, F. M; GONÇALES, C. S; FUGULIN, F. M. T. Identificação das intervenções de enfermagem na Atenção Primária à Saúde: parâmetro para o dimensionamento de trabalhadores. Revista da Escola de Enfermagem da USP. São Paulo, v. 46, n. 6, p. 1462-70, dez. 2012. 
BORGES, F. Q. Gestão da informação no Sistema Único da Saúde. Revista Administração FACES Journal. v. 13, n. 2, p. 83-98, 2014. Disponível em:

<http://www.fumec.br/revistas/facesp/article/download/2021/1476>. Acesso em: 04 de nov. 2015.

BRASIL. Lei n. 8.080 de 19 de setembro de 1990. Dispõe sobre as condições para a promoção, proteção e recuperação da saúde, a organização e o funcionamento dos serviços correspondentes e dá outras providências. Diário Oficial da União [da] da República Federativa do Brasil. Seção 1, nº 182, 1-5, 20 de setembro de 1990. Brasília, DF: Casa Civil.

Conselho Federal de Enfermagem (COFEn). Resolução nº. 293, de 21 de setembro de 2004. Fixa e estabelece parâmetros para o dimensionamento do quadro de profissionais de enfermagem nas Unidades Assistenciais das Instituições de Saúde e Assemelhados. Rio de Janeiro; 2004. Disponível em: 〈http://www.corensp.org.br/resoluções/ Resolução293.htm>. Acesso em: 20 de out. 2015.

Decreto $n^{\circ}$. 5.378, de 23 de fevereiro de 2005. Institui o Programa Nacional de Gestão Pública e Desburocratização - GESPÚBLICA e o Comitê Gestor do Programa Nacional de Gestão Pública e Desburocratização, e dá outras providências. Diário Oficial da União [da] da República Federativa do Brasil. Seção 1, nº 37, 2-3, 24 de fevereiro de 2005a. Brasília, DF: Casa Civil.

Lei $n^{\circ} .11 .091$, de 12 de janeiro de 2005. Dispõe sobre a estruturação do Plano de Carreira dos Cargos Técnico-Administrativos em Educação, no âmbito das Instituições Federais de Ensino vinculadas ao Ministério da Educação, e dá outras providências. Diário Oficial da União [da] da República Federativa do Brasil. Seção 1, nº 9, 1-10, 13 de janeiro de 2005b. Brasília, DF: Casa Civil.

Ministério do Planejamento, Orçamento e Gestão. Secretaria de Gestão. Comissão Europeia. Textos de referência em gestão de pessoas: dimensionamento de força de trabalho. Brasília: MP, 2006a.

Decreto ${ }^{\circ}$ 5.707, de 23 de fevereiro de 2006. Institui a Política e as Diretrizes para o desenvolvimento de pessoal da administração pública federal direta, autárquica e fundacional, e regulamenta dispositivos da Lei n. 8.112, de 11 de dezembro de 1990. Diário Oficial da União [da] da República Federativa do Brasil. Seção 1, nº 40, 3-4, 24 de fevereiro de 2006b. Brasília, DF: Casa Civil.

. Decreto $\mathrm{n}^{\circ} .8 .065$, de 7 de agosto de 2013. Aprova a estrutura regimental e o quadro demonstrativo dos cargos em comissão e das funções gratificadas do Ministério da Saúde e remaneja cargos em comissão. Diário Oficial da União [da] da República Federativa do Brasil. Seção 1, no 152, 1-13, 08 de agosto de 2013a. Brasília, DF: Casa Civil.

Ministério da Saúde. Secretaria-Executiva. Departamento de Monitoramento e Avaliação do SUS. Planejamento estratégico do Ministério da Saúde: 2011 - 2015: resultados e perspectivas. Brasília: Ministério da Saúde, 2013b. 160 p.

. Tribunal de Contas da União. Referencial para avaliação de governança em políticas públicas. Brasília: TCU, 2014. 
. Ministério da Saúde. Portal da Saúde. Histórico: do sanitarismo à municipalização. Disponível em: <http://portalsaude.saude.gov.br/index.php/o-ministerio/historico>. Acesso em: 17 de set. 2015.

BRESSER-PEREIRA, L. C. Administração Pública Gerencial: estratégia e estrutura para um novo Estado. Texto para discussão n. 9, 28f. Brasília: MARE/ENAP, 1996.

. Do Estado patrimonial ao gerencial. Letras, v. 222, p. 259, 2001.

. O modelo estrutural de gerência pública. In: Revista de Administração Pública. Rio de Janeiro: FGV, 2008. 42(2): 391-410, 2008.

CAMARGO, C. C; RIBEIRO DO VAL, C. F; CARIBÉ, R. C. S. B; DUTRA, J. S. Do transacional ao estratégico: a transformação de recursos humanos em busca de um novo papel organizacional. In: FISCHER, A. L; DUTRA, J. S; AMORIM, W. A. C (Org.). Gestão de pessoas: práticas modernas e transformação nas organizações. São Paulo: Editora Atlas, 2010.

CAMÕES, M. R. S. Análise do processo de implementação da política nacional de desenvolvimento de pessoal. 2013. 200f. Dissertação (Mestrado em Administração). Universidade de Brasília, Faculdade de Economia, Administração e Contabilidade, Programa de Pós-Graduação em Administração. Brasília, 2013.

CARVALHO, E. L. Informação orgânica: recurso estratégico para tomada de decisão pelos membros do Conselho de Administração da Universidade Estadual de Londrina. 2001. 93f. Dissertação (Mestrado). Faculdade de Biblioteconomia e Ciência da Informação, Pontifícia Universidade Católica de Campinas, São Paulo, 2001.

CHENSO, M. Z. B; HADDAD, M. C. L; SÊCCO, I. A. O; DORIGÃO, A. M; NISHIYAMA, M. N. Cálculo de pessoal de enfermagem em hospital universitário do Paraná: uma proposta de adequação. Semina: Ciências Biológicas e da Saúde. Londrina, v. 25, p. 81-92, 2004.

CHOO, C. W. A organização do conhecimento: como as organizações usam a informação para criar significados, construir conhecimento e tomar decisões. São Paulo: SENAC, 2006.

CLACK, G. B; BATY, M; PERRIN, A; EDDLESTON, A. L. W. F. The development of a more equitable approach to resource allocation and manpower planning for undergraduate teaching in a UK medical school. Medical education, v. 35, n. 2, p. 102-9, 2001. Disponível em:〈https://www.ncbi.nlm.nih.gov/pubmed/11169081〉. Acesso em: 15 de nov. 2015.

COSTA, F. L. História das reformas administrativas no Brasil: narrativas, teorizações e representações. Revista do Serviço Público, Brasília, v.59, n.3, p.271-88, 2008.

COSTA, T. N. S. Indicadores de produção hospitalar: uma forma de medir a produção dos hospitais portugueses. 2011. 200f. Dissertação (Mestrado em Informática Médica). Faculdade de Medicina da Universidade do Porto, Porto, 2011.

CRUZ, C. W. M; BONFIM, D; GAIDZINSKI, R. R; FUGULIN, F. M. T; LAUS, A. M. The use of Nursing Interventions Classification (NIC) in identifying the workload of nursing: an integrative review. International Journal of Nursing Knowledge. Malden. Massachusetts, v. 25, n. 3, p. 154-160, 2014. Disponível em: <https://www.ncbi.nlm.nih.gov/pubmed/ 24674096>. Acesso em: 20 de nov. 2015. 
DAL BEN, L. W; GAIDZINSKI, R. R. Proposta de modelo para dimensionamento do pessoal de enfermagem em assistência domiciliária. Revista da Escola de Enfermagem da USP. São Paulo, v. 41, n. 1, p. 97-103, 2007.

DAVENPORT, T. H. Ecologia da informação. Rio de Janeiro: Campus, 1998.

DESSLER, G. Administração de Recursos Humanos. São Paulo: Pearson, 2003.

DIMITRIOU, V. A; TSANTAS, N. Evolution of a time dependent Markov model for training and recruitment decisions in manpower planning. Linear Algebra and its Applications, v. 433, n. 11, p. 1950-72, 2010. Disponível em:

〈http://www.sciencedirect.com/science/article/pii/S0024379510003587>. Acesso em: 14 de nov. 2015.

FAIRBAIRN, D. Experiences in manpower planning for geomatics. International Archives of the Photogrammetry, Remote Sensing and Spatial Information Sciences. v. 1, p. 25-9, 2014. Disponível em: < http://www.int-arch-photogramm-remote-sens-spatial-inf-sci.net/XL6/25/2014/isprsarchives-XL-6-25-2014.pdf >. Acesso em: 14 de nov. 2015.

FERNANDINO, J. A; OLIVEIRA, J. L. Arquiteturas organizacionais para a área de P\&D em empresas do setor elétrico brasileiro. Revista de Administração Contemporânea, v. 14, n. 6, p. 1073, 2010.Disponível em: 〈 http://www.scielo.br/pdf/rac/v14n6/v14n6a06.pdf >. Acesso em: 14 de fev. 2016.

FISCHER, A. L. O conceito de modelo de gestão de pessoas: modismo e realidade em gestão de recursos humanos nas empresas brasileiras. In: DUTRA, J. S. (Org.). Gestão por competências: um modelo avançado para o gerenciamento de pessoas. São Paulo: Editora Gente, 2001.

FLICK, U. Qualidade na pesquisa qualitativa. Porto Alegre: Bookman, 2009.

FONSECA, D. R; MENESES, P. P. M; SILVA FILHO, A. I. da; CAMPOS, N. G. Autonomia para gestão estratégica de pessoas no setor público federal: perspectivas de análise e agenda de pesquisa. Revista de Administração Pública, v. 47, n. 6, p. 1451-75, 2013.

FRANKLIN, M. A. Estrutura organizacional, orientações para exploitation e exploration e tipos de inovações em institutos de pesquisa e desenvolvimento tecnológicos. 2010. 216f. Tese (Doutorado em Administração de Empresas). Universidade Presbiteriana Mackenzie, Centro de Ciências Sociais e Aplicadas, Programa de Pós-Graduação em Administração de Empresas, São Paulo, 2010.

FUGULIN, F. M. T; ROSSETTI, A. C; RICARDO, C. M; POSSARI, J. F.; MELLO, M. C.; GAIDZINSKI, R. R. Tempo de assistência de enfermagem em Unidade de Terapia Intensiva: avaliação dos parâmetros propostos pela Resolução COFEN n²93/04. Revista LatinoAmericana de Enfermagem, Ribeirão Preto, v. 20, n. 2, p. 325-32, 2012.

GAIDZINSKI, R. R.; FUGULIN, F. M. T.; PERES, H. H. C.; CASTILHO, V.; MASSAROLLO, M. C. K. B.; MIRA, V. L; et al. Dimensionamento informatizado de profissionais de enfermagem: inovação tecnológica. Revista da Escola de Enfermagem da USP [online]. São Paulo, v. 43, n. spe2, p. 1314-19, 2009. 
GALBRAITH, J. R. The future of organization design. Journal of Organization Design, v. 1, n. 1, 2012. Disponível em: 〈http://papers.ssrn.com/sol3/papers.cfm?abstract id=2181960>. Acesso em: 14 de fev. 2016.

GALlOUJ, F.; WEINSTEIN, O. Inovation in services. Research Policy, v. 26, p. 537-56, 1997.

GONÇALVES, E. L. Estrutura organizacional do hospital moderno. Revista de Administração de Empresas, v. 38, n. 1, p. 80-90, 1998.

GONÇALVES, L. Processo de trabalho da enfermagem: bases qualitativas para o dimensionamento da força de trabalho de enfermagem nas unidades de internação. 2007. 304f. Tese (Doutorado em Enfermagem). Universidade Federal de Santa Catarina, Centro de Ciências da Saúde, Programa de Pós-Graduação em Enfermagem. Florianópolis, 2007.

GRIFFITHS, G. S; PRESHAW, P. M. Manpower planning in periodontology - how many specialists do we need? British Dental Journal, v. 217, n. 8, p. 399-402, 2014. Disponível em: 〈http://www.nature.com/bdj/journal/v217/n8/abs/sj.bdj.2014.904.html >. Acesso em: 14 de nov. 2015.

GUERRY, M. A. Hidden heterogeneity in manpower systems: a markov-switching model approach. European Journal of Operational Research, v. 210, n. 1, p. 106-13, 2011. Disponível em: 〈http://www.sciencedirect.com/science/article/pii/S0377221710007411〉. Acesso em: 15 de nov. 2015.

GÜNTER, H. Como elaborar um relato de pesquisa. Brasília: Laboratório de psicologia ambiental. Universidade de Brasília, 2003. 9p. Planejamento de pesquisa nas ciências sociais, n. 2.

GUIMARÃES, T. A; ANGELIM, G. P; SPEZIA, D. S; ROCHA, G. A; MAGALHÃES, R. G. Explorando o construto organização de aprendizagem no setor público: uma análise em órgão do poder executivo federal Brasileiro. Organizações \& Sociedade, v. 10, n. 27, p. 111$125,2003$.

INGRAHAM, P. W; PETERS, G; MOYNIHAN, D. P. Public employment and the future of the public service. In: PETERS, G; SAVOIE, D. J. Governance in the Twenty-First Century: revitalizing the public service. Québec: Canadian Centre for Management Development/ Centre Canadien de Gestion, 2000.

ISIDRO-FILHO, A; SERRANO, A. L. M. Dimensionamento da força de trabalho no setor público: modelo quali-quantitativo aplicado. In: IX Congresso CONSAD de Gestão Pública, 2016.

IVANNIKOVA, V.; KRYSHKEVYCH, K. Application Of Simulation Approach To Manpower Planning At Ukraine International Airlines' Maintenance Department. ScienceFuture of Lithuania/Mokslas-Lietuvos Ateitis, v. 5, n. 5, p. 578-82, 2013. Disponível em: $<$ http://search.proquest.com/openview/abc413eb3519dd19648c72430eae3f27/1?pqorigsite $=$ gscholar $>$. Acesso em: 16 de nov. 2015.

KETTINGER, W. J.; MARCHAND, D. A. Information management pratices (IMP) from the sênior manager's perspective: na investigation of the IMP constructo and its measurement. Information Systems Journal, v. 21, n. 5, p. 385-406, 2011. Disponível em: 
$<$ http://onlinelibrary.wiley.com/doi/10.1111/j.1365-2575.2011.00376.x/full>. Acesso em 7 de jul. 2016.

LACOMBE, F. J. M. Recursos Humanos: princípios e tendências. São Paulo: Saraiva, 2005.

LADIER, A. L.; ALPAN, G.; PENZ, B. Joint employee weekly timetabling and daily rostering: A decision-support tool for a logistics platform. European Journal of Operational Research, v. 234, n. 1, p. 278-91, 2014. Disponível em:

<http://www.sciencedirect.com/science/article/pii/S0377221713008461 >. Acesso em: $17 \mathrm{de}$ nov. 2015.

LEÃO, F. R.; LIMA, E. O. M.; GOMES, A. A. P.; QUELHAS, O. L. G. Metodologia para dimensionamento de equipes, descrição de cargos e identificação de necessidades de treinamento e sua aplicabilidade na gestão de pessoas. Revista Produção Online. Santa Catarina, v. 2, n. 2, p. 1676-1701, 2002.

LI, Y.; CHEN, J.; CAI, X. An integrated staff-sizing approach considering feasibility of scheduling decision. Annals of Operations Research, v. 155, n. 1, p. 361-90, 2007. Disponível em: < http://link.springer.com/article/10.1007/s10479-007-0215-z>. Acesso em: 20 de nov. 2015.

LIMA, E. J. L. Gestão da informação e as novas tecnologias de informação. In: STAREC, C. Gestão estratégica da informação e inteligência competitiva. São Paulo: Saraiva, 2006.

LONGO, F. Mérito e Flexibilidade: gestão das pessoas no setor público. Fundap, 2007.

MACEDO, S. M. S.; BARBOSA, R. R. Gestão da informação, da tecnologia da informação de comportamentos e valores relativos à informação em instituições de ensino superior (IES) de Belo Horizonte. Brazilian Journal of Information Science, v. 7, n. 1, p. 137-53, 2013. Disponível em: < https://dialnet.unirioja.es/servlet/articulo?codigo=4331896 $>$. Acesso em: 29 de dez 2015.

MACHADO, C. R.; POZ, M. R. D. Sistematização do conhecimento sobre as metodologias empregadas para o dimensionamento da força de trabalho em saúde. Saúde debate [online]. Rio Janeiro, v. 39, n.104, p. 239-54, 2015.

MAGALHÃES, A. M. M; RIBOLDI, C. O.; DALL'AGNOL, C. M. Planejamento de recursos humanos de enfermagem: desafio para as lideranças. Revista Brasileira de Enfermagem. Brasília, v. 62, n. 4, p. 608-12, 2009.

MARCELINO, G. F. Em busca da flexibilidade do Estado: o desafio das reformas planejadas no Brasil. Revista de Administração Púbica, Rio de Janeiro, v. 37, n. 3, p. 641-659, 2003.

MARCHAND, D. A.; KETTINGER, W. J.; ROLINS, J. D. Information Orientation: people, technology and the bottom line. Sloan Management Review, Summer, v. 41, n. 4, p. 69-80, 2000. Disponível em:

$<$ http://search.proquest.com/openview/cc43725352489aa694cb52fa4d7d7705/1?pqorigsite $=$ gscholar $>$. Acesso em: 7 de jul. 2016.

MARCHIORI, Patrícia Zeni. A ciência e a gestão da informação: compatibilidade no espaço profissional. Ciência da Informação, Brasília, v. 31, n. 2, p. 72-79, 2002. 
MARINHO, B. L.; VASCONCELLOS, E. P. G. Dimensionamento de recursos humanos: desenvolvimento de um modelo conceitual e sua aplicação. Revista de Gestão da USP. São Paulo, v. 14, n. 2, p. 61-76, 2007.

MATSUSHITA, M. S.; ADAMI, N. P.; CARMAGNANI, M. I. S. Dimensionamento do pessoal de enfermagem das unidades de internação do Hospital São Paulo. Acta Paulista de Enfermagem. São Paulo, v. 18, n. 1, p. 9-19, 2005.

MAYA, C. M.; SIMOES, A. L. A. Implicações do dimensionamento do pessoal de enfermagem no desempenho das competências do profissional enfermeiro. Revista Brasileira de Enfermagem [online]. Brasília, v. 64, n.5, p. 898-904, 2011.

MINAYO, M. C. S. O desafio do conhecimento: pesquisa qualitativa em saúde. Rio de Janeiro: ABRASCO; 2012.

MINTZBERG, H. Criando organizações eficazes: estruturas em cinco configurações. Ed. $2^{\mathrm{a}}$, 7 reimpressão. São Paulo: Atlas, 2012.

MONTEIRO, N. A.; VALENTIM, M. L. P. Necessidades informacionais e aprendizagem no ciclo de vida de um projeto. RDBCI: Revista Digital de Biblioteconomia e Ciência da Informação, v. 5, n. 2, p. 53-66, 2008. Disponível em:

<http://www.sbu.unicamp.br/seer/ojs/index.php/rbci/article/view/380>. Acesso em: 04 de jan. 2016.

MORESI, E. A. D. Delineando o valor do sistema de informação de uma organização. Ciência da Informação, Brasília, v. 29, n. 1, p. 14-24, 2000.

NASCIMENTO, L. M. M.; TOMAÉL, M. I. Qualidade das informações dos processos licitatórios para a contratação de obras de engenharia na Universidade Estadual de Londrina (UEL). Brazilian Journal of Information Science, v. 7, n. 1, p. 154-77, 2013. Disponível em: <https://dialnet.unirioja.es/servlet/articulo?codigo=4332002>. Acesso em: $29 \mathrm{de}$ dez 2015.

NEIS, M. E. B.; GELBCKE, F. L.; SALUM, N. C.; OLIVEIRA, T. T. Centro de material e esterilização: estudo do tempo efetivo de trabalho para dimensionamento de pessoal. Revista Eletrônica de Enfermagem. Goiânia, v. 13, n. 3, p. 422-30, 2012.

NICOLA, A. L.; ANSELMI, M. L. Dimensionamento de pessoal de enfermagem em um hospital universitário. Revista Brasileira de Enfermagem. Brasília, v. 58, n. 2, p. 186-90, 2005.

OCDE. Avaliação da gestão de recursos humanos no Governo - Relatório da OCDE: Brasil, Governo Federal. 2010. Disponível em <www.oecd-ilibrary.org > Acesso em: 15 dez. 2015.

OLETO, R. R. Percepção da qualidade da informação. Ciência da Informação, v. 35, n. 1, p. 57-62, 2006.

OLIVARES, J. E. L. Análise da estrutura organizacional em rede e suas negociações no contexto de alianças estratégicas. 2003. 230f. Tese (Doutorado em Administração). Universidade de São Paulo, Faculdade de Economia, Administração e Contabilidade, Departamento de Administração, Programa de Pós-Graduação em Administração, 2003. 
OLIVEIRA, A. G.; BIANCHINI, D.; ABBADE, M. L. F. Métricas para dimensionar recursos humanos nos Centros de Operações de Redes. In: Simpósio Brasileiro de Redes de Computadores e Sistemas Distribuídos, 25, 2007, São Paulo. Disponível em: <http://ceresd.facom.ufms.br/sbrc/2007/078.pdf>. Acesso em: 11 de ago. 2015.

OLIVEIRA, D. P. R. Planejamento estratégico: conceitos, metodologias e práticas. In: Planejamento estratégico: conceitos, metodologias e práticas. Atlas, 2010.

OLIVEIRA, D. P. R. Sistemas, organização e métodos: uma abordagem gerencial. Ed. $20^{\mathrm{a}}$. São Paulo: Atlas, 2011.

OSTROM, E. Crossing the great divide: coproduction, synergy, and development. World Development, v. 24, n. 6, p. 1073-87, 1996. Disponível em: <http://www.sciencedirect.com/science/article/pii/0305750X9600023X $>$. Acesso em: 12 de mar. 2016.

PACHECO, R. S. Política de recursos humanos para a reforma gerencial: realizações do período 1995-2002. Revista do Serviço Público, v. 53, n. 4, p. 79-106, 2002. Disponível em: <http://seer.enap.gov.br/index.php/RSP/article/view/295>. Acesso em: 02 de fev. 2016.

PAIM, I.; NEHMY, R. M. Q.; GUIMARÃES, C. G. Problematização do conceito "Qualidade" da Informação. Perspectivas em Ciência da Informação, v. 1, n. 1, 1996. Disponível em: <http://portaldeperiodicos.eci.ufmg.br/index.php/pci/article/view/8 > . Acesso em: 24 de jan. 2016.

PAIM, R.; CARDOSO, V.; CAULLIRAUX, H.; CLEMENTE, R. Gestão de processos: pensar, agir e aprender. Porto Alegre: Bookman, 2009.

PAIXÃO, T. C. R.; CAMPANHARO, C. R. V.; LOPES, M. C. B. T.; OKUNO, M. F. P.; BATISTA, R. E. A. Dimensionamento de enfermagem em sala de emergência de um hospitalescola. Revista da Escola de Enfermagem da USP. São Paulo, v. 49, n. 3, p. 481-87, 2015.

PAULA, A. P. P. de. Métodos e técnicas de pesquisa em administração. Revista de Administração Contemporânea, São Paulo, v. 9, n. 3, p. 217-19, 2005.

PEREIRA, I. M.; GAIDZINSKI, R. R.; FUGULIN, F. M. T.; PERES, H. H. C.; LIMA, A. F. C.; CASTILHO, V; et al. Dimensionamento informatizado de profissionais de enfermagem: avaliação de um software. Revista da Escola de Enfermagem da USP. São Paulo, v.45, n.esp., p. 1600-05, 2011.

PORTO, B. C. S.; NEVES, F. S. Dimensionamento de força de trabalho: ponto de partida para o controle dos gastos de pessoal e para a sustentabilidade financeira das políticas de segurança pública no estado de Minas Gerais. In: Congresso de Gestão Pública - CONSAD, 7, 2014, Brasília. Disponível em: 〈http://banco.consad.org.br/handle/123456789/1085>. Acesso em: 10 ago. 2015.

REIS, M. C. A. Coprodução e inovação em serviços: uma análise de experiências inovadoras de gestão na administração pública federal. 2015. 77f. Dissertação (Mestrado em Administração). Universidade de Brasília, Brasília, 2015.

REIS, C.Z.T; FREITAS, Á. M. R.; MARTINS, S.; OLIVEIRA, A. R.; MARTINS, S.; OLIVEIRA, A. R. Aspectos impactantes no dimensionamento da força de trabalho em 
uma instituição de ensino superior. Revista Gestão Universitária na América LatinaGUAL, v. 8, n. 2, p. 28-49, 2015. Disponível em:

<http://www.redalyc.org/articulo.oa?id=319338455002 >. Acesso em: 05 de dez. 2015.

RIBEIRO, M. C. F. Uma análise sobre os processos de trabalho do setor de projetos e obras de um Instituto de P\&D em saúde no Brasil: um olhar sobre a informação como apoio à inovação em saúde.2009. 234f. Dissertação (Mestrado Profissional em Política e Gestão de Ciência, Tecnologia e Inovação (CT\&I) em Saúde). Escola Nacional de Saúde Pública Sergio Arouca, Rio de Janeiro, 2009.

ROESCH, S. M. A. Projetos de estágio e de pesquisa em administração. São Paulo: Atlas, 2006.

RUEDIGER, M. A; RICCIO, V. Grupo focal: métodos e análise simbólica da organização e da sociedade. In: VIEIRA, M. M. F; ZOUAIN, D. M. (Orgs.) Pesquisa qualitativa em administração. Rio de Janeiro: Editora FGV, 2006.

SANTOS, A. M. B. Produtividade de mão-de-obra e do capital investido na Petrobrás: sua relação com o dimensionamento da força de trabalho. 1998. 107f. Dissertação (Mestrado em Administração Pública). Fundação Getúlio Vargas, Rio de Janeiro, 1998.

SCHIKMANN, R. Gestão Estratégica de Pessoas: bases para a concepção do curso de especialização em gestão de pessoas no serviço público. In: PANTOJA, M. J; CAMÕES, M. R. S; BERGUE, S. T. (Orgs.). Gestão de pessoas: bases teóricas e experiências no setor público. Brasília: ENAP, 2010.

SIQUEIRA, M. V. S; MENDES, A. M. Gestão de pessoas no setor público e a reprodução do discurso do setor privado. Revista do Serviço Público Brasília, v. 60, n. 3, p. 241-50, 2009.

SECCHI, L. Modelos organizacionais e reformas da administração pública. Revista de Administração Pública, Rio de Janeiro, v. 43, n. 2, p. 347-69, 2009. Disponível em:

SOHONI, M. G; JOHNSON, E. L; BAILEY, T. G. Long-range reserve crew manpower planning. Management Science. Catonsville, v. 50, n. 6, p. 724-39, 2004. Disponível em: $<$ http://pubsonline.informs.org/doi/abs/10.1287/mnsc.1030.0141>. Acesso em: 02 de nov. 2015.

SOUZA, E. D; DIAS, E. J. W; NASSIF, M. E. A gestão da informação e do conhecimento na ciência da informação: perspectivas teóricas e práticas organizacionais. Informação \& Sociedade, v. 21, n. 1, 2011.

SLACK, N.; JOHNSTON, R.; CHAMBERS, S. Administração da produção. São Paulo: Atlas, 1997.

ULRICH, D. Human Resource Champions: the next agenda for adding value and delivering results. Cap. 2. Boston: Harvard Bussiness School Press, 2013.

VALENTIM, M. L. P; CERVANTES, B. M. N.; CARVALHO, E. L; GARCIA, H. D; LENZI, L. A. F; CATARINO, M. E; et al. O processo de inteligência competitiva em organizações. DataGramaZero, Rio de Janeiro, v. 4, n. 3, p. 1-23, 2003. Disponível em: <http://www.datagramazero.org.br/jun03/Art_03.htm〉. Acesso em: 05 de jan. 2016. 
VALENTIM, M. L. P. Ambientes e fluxos de informação em contextos empresariais: o caso do setor cárnico de Salamanca/Espanha. Brazilian Journal of Information Science, v. 7, n. 1, p. 299-323, 2013. Disponível em:

<https://dialnet.unirioja.es/servlet/articulo?codigo=4334520 > . Acesso em: 16 de out. 2015.

VASCONCELLOS, E.; HEMSLEY, J. R. Estrutura das organizações: estrutura tradicional, estrutura para inovação, estrutura matricial. Ed. $3^{a}$. São Paulo: Pioneira, 1997.

VIANNA, C. M. M; PIERANTONI, T. C. F.; MAGNAGO, M. P. S. R.; MORICI, M.C. Modelos econométricos de estimativa da força de trabalho: uma revisão integrativa da literatura. Revista de Saúde Coletiva, v. 23, n. 3, p. 925-50, 2013.

VILLARDI, B. Q; FERRAZ, V. N; DUBEUX, V. J. C. Uma metodologia para diagnóstico de clima organizacional: integrando motivos sociais e cultura brasileira com fatores do ambiente de trabalho do Poder Judiciário. Revista de Administração Pública, v. 45, n. 2, p. 304-29, 2011.

VITURI, D. W; LIMA, S. M; KUWABARA, C. C. T; GIL, R. B; ÉVORA, Y. D. M. Dimensionamento de enfermagem hospitalar: modelo OPAS/OMS. Texto \& Contexto Enfermagem. Florianópolis, v. 20, n. 3, p. 547-56, 2011.

YIN, R. Estudo de caso: planejamento e métodos. 3 ed. Porto Alegre: Bookman, 2005. 


\section{APÊNDICES}

\section{APÊNDICE I - FORMULÁRIO DE ANÁLISE DOCUMENTAL}

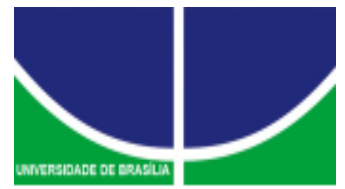

Universidade de Brasília

Faculdade de Economia, Administração e Contabilidade (FACE)

Programa de Pós-Graduação em Administração (PPGA)

Mestrado Profissional em Administração (MPA)

Nome da pesquisa: Gestão da informação associada ao processo de dimensionamento de força de trabalho: estudo de caso no Ministério da Saúde.

Objetivo: Avaliar a presença de práticas de gestão da informação de processos no contexto do

Dimensionamento de Força de Trabalho (DFT).

Mestranda: Delciene Aparecida Oliveira Pereira

Orientador: Prof. Dr. Antônio Isidro da Silva Filho

FORMULÁRIO DE ANÁLISE DOCUMENTAL

\section{BLOCO I - IDENTIFICAÇÃO DOS DOCUMENTOS}

\begin{tabular}{|c|c|c|c|c|c|c|c|c|c|}
\hline $\begin{array}{c}\mathbf{N}^{\circ} \text { do } \\
\text { documento }\end{array}$ & Quantitativo & Nome & Formato & Autoria & Ano & Natureza & Objetivo & $\begin{array}{c}\mathbf{N}^{\mathbf{0}} \text { de } \\
\text { Páginas }\end{array}$ & Observação \\
\hline & & & & & & & & & \\
\hline
\end{tabular}

BLOCO II - PRÁTICAS RELATIVAS A GESTÃO DA INFORMAÇÃO DE PROCESSO NO CONTEXTO DO DIMENSIONAMENTO - ETAPAS DE DETERMINAÇÃO DE EXIGÊNCIAS, OBTENÇÃO, DISTRIBUIÇÃO E USO - DOCUMENTOS PRODUZIDOS NO ÂMBITO DO PROCESSO DE DFT

\begin{tabular}{|c|c|c|c|c|c|c|}
\hline $\begin{array}{c}\mathbf{N}^{0} \text { da } \\
\text { Questão }\end{array}$ & Questão & \multicolumn{2}{|c|}{$\begin{array}{c}\text { Prática } \\
\text { identificada }\end{array}$} & $\begin{array}{c}\text { Evidência da } \\
\text { prática no } \\
\text { órgão }\end{array}$ & $\begin{array}{c}\text { Frequência em que } \\
\text { aparece }\end{array}$ & Documento \\
\hline \multicolumn{7}{|c|}{$\begin{array}{l}\text { BLOCO III - PRÁTICAS RELATIVAS A GESTÃO DA INFORMAÇÃO DE PROCESSOS - EPATAS DE } \\
\text { OBTENÇÃO E DISTRIBUIÇÃO - DOCUMENTOS PRODUZIDOS NO ÂMBITO DA TECNOLOGIA DA } \\
\text { INFORMAÇÃO }\end{array}$} \\
\hline $\begin{array}{c}N^{0} \text { da } \\
\text { Questão }\end{array}$ & \multicolumn{2}{|c|}{$\begin{array}{c}\text { Questão } \\
\text { direcionadora }\end{array}$} & Resposta & Evidência & Documento & Observação \\
\hline
\end{tabular}




\section{APÊNDICE II - ROTEIRO DE ENTREVISTA - GRUPO 1}

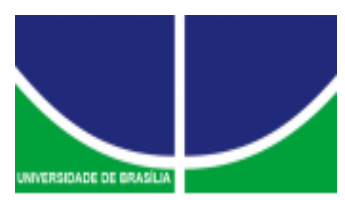

Universidade de Brasília

Faculdade de Economia, Administração e Contabilidade (FACE)

Programa de Pós-Graduação em Administração (PPGA)

Mestrado Profissional em Administração (MPA)

Nome da pesquisa: Gestão da informação associada ao processo de dimensionamento de força de trabalho: estudo de caso no Ministério da Saúde.

Objetivo: Avaliar a presença de práticas de gestão da informação de processos no contexto do Dimensionamento de Força de Trabalho (DFT).

Mestranda: Delciene Aparecida Oliveira Pereira

Orientador: Prof. Dr. Antônio Isidro da Silva Filho

\section{ROTEIRO DE ENTREVISTA GRUPO 1 - PESQUISADORES E COMITÊ TÉCNICO}

1. Como se deu o processo de identificação das exigências de informação relativa a processos para o dimensionamento da força de trabalho?

2. Considerando a metodologia adotada no Ministério da Saúde, quais informações relativas aos processos de trabalho são chave para realização do dimensionamento da força de trabalho?

3. Como se dá a obtenção das informações relativas aos processos no contexto do dimensionamento da força de trabalho?

4. Como se dá a distribuição das informações relativas a processos para o dimensionamento da força de trabalho?

5. Como se dá o uso das informações relativas a processos no contexto do dimensionamento de força de trabalho?

6. Quais atores-chave são capazes de apontar a presença ou não das práticas relativas a gestão de informações de processos (obtenção, distribuição, uso) no contexto do MS? 


\section{APÊNDICE III - ROTEIRO DE ENTREVISTA - GRUPO 2}

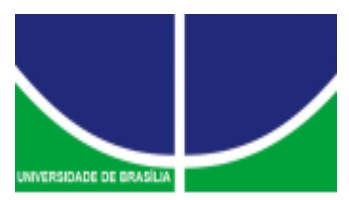

Universidade de Brasília

Faculdade de Economia, Administração e Contabilidade (FACE)

Programa de Pós-Graduação em Administração (PPGA)

Mestrado Profissional em Administração (MPA)

Nome da pesquisa: Gestão da informação associada ao processo de dimensionamento de força de trabalho: estudo de caso no Ministério da Saúde.

Objetivo: Avaliar a presença de práticas de gestão da informação de processos no contexto do Dimensionamento de Força de Trabalho (DFT).

Mestranda: Delciene Aparecida Oliveira Pereira

Orientador: Prof. Dr. Antônio Isidro da Silva Filho

\section{ROTEIRO DE ENTREVISTA GRUPO 2 - ESPECIALISTAS EM PROCESSOS}

1. A cadeia de valor do Ministério da Saúde e de suas unidades está definida e documentada?

2. Os processos de trabalho do Ministério da Saúde estão mapeados?

3. Quais informações são disponibilizadas para o MS a partir do mapeamento de processo?

4. Como se dá o acesso à base de informações relativas aos processos já mapeados no MS?

5. Essa base de informações está integrada com outros sistemas do MS? 


\section{APÊNDICE IV - ROTEIRO DE ENTREVISTA - GRUPO 3}

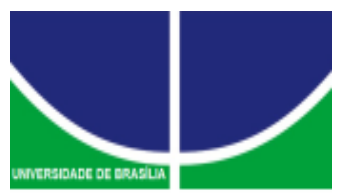

Universidade de Brasília

Faculdade de Economia, Administração e Contabilidade (FACE)

Programa de Pós-Graduação em Administração (PPGA)

Mestrado Profissional em Administração (MPA)

Nome da pesquisa: Gestão da informação associada ao processo de dimensionamento de força de trabalho: estudo de caso no Ministério da Saúde.

Objetivo: Avaliar a presença de práticas de gestão da informação de processos no contexto do Dimensionamento de Força de Trabalho (DFT).

Mestranda: Delciene Aparecida Oliveira Pereira

Orientador: Prof. Dr. Antônio Isidro da Silva Filho

\section{$\underline{\text { ROTEIRO DE ENTREVISTA - GRUPO } 3 \text { - ESPECIALISTA EM TECNOLOGIA DA }}$ INFORMAČ̃̃O}

1. Existe uma arquitetura de informação na instituição?

2. Existe uma política informacional que favorece a autonomia do usuário das informações?

3. Como ocorre a distribuição de informações para os diversos usuários?

4. As informações são categorizadas em formatos que facilitam compreensão pelo usuário?

5. As bases de informações que armazenam e distribui as informações são integradas?

6. A gestão reconhece a necessidade de investir sistemas que possibilitem a filtragem de informações e geração de informações para os usuários? 


\section{APÊNDICE V - TERMO DE CONSENTIMENTO LIVRE E ESCLARECIDO}

\section{Termo de Consentimento Livre e Esclarecido}

Nome da pesquisa: Gestão da informação associada ao processo de dimensionamento de força de trabalho: estudo de caso no Ministério da Saúde.

Objetivo: Avaliar a presença de práticas de gestão da informação de processos no contexto do Dimensionamento de Força de Trabalho (DFT).

Mestranda: Delciene Aparecida Oliveira Pereira

Orientador: Prof. Dr. Antônio Isidro da Silva Filho

Telefones para contato: (61) 8360-8841 / (61) 4141-7265

Convidamos o (a) senhor (a) para participar da Pesquisa "Gestão da informação associada ao processo de dimensionamento de força de trabalho: estudo de caso no Ministério da Saúde", sob a responsabilidade da pesquisadora Delciene Aparecida Oliveira Pereira, a qual pretende avaliar as práticas de gestão da informação de processos no contexto do dimensionamento de força de trabalho.

Sua participação é voluntária e se dará por meio de participação em grupos focais ou entrevistas. Os diálogos ocorridos nos grupos focais e/ou entrevistas serão gravados para possibilitar a degravação ou consulta para fins de análise de conteúdo.

Se você aceitar participar, estará contribuindo para a identificação de práticas de gestão de informação de processos que contribuem para o êxito de projetos de dimensionamento de força de trabalho, além de desenvolver as teorias atuais sobre planejamento de pessoal no setor público.

Se depois de consentir em sua participação o(a) senhor(a) desistir de continuar participando, tem o direito e a liberdade de retirar seu consentimento em qualquer fase da pesquisa, seja antes ou depois da coleta dos informações, independente do motivo e sem nenhum prejuízo a sua pessoa. O (a) senhor (a) não terá nenhuma despesa e também não receberá nenhuma remuneração. Os resultados da pesquisa serão analisados e publicados, mas sua identidade não será divulgada, sendo guardada em sigilo. Para qualquer outra informação, o (a) senhor (a) poderá entrar em contato com o pesquisador.

Consentimento Pós-Informação

$\mathrm{Eu}$, fui informado (a) sobre o que o pesquisador quer fazer e porque precisa da minha colaboração e entendi a explicação. Por isso, eu concordo em participar do projeto, sabendo que não serei remunerado pela participação e que poderei não mais participar se assim decidir. Este documento é emitido em duas vias que serão assinadas pelas duas partes, que ficarão cada um com uma via.

Assinatura do pesquisador responsável

Assinatura do participante 


\section{APÊNDICE VI - ARTIGOS QUE FIZERAM PARTE DO ESTUDO BIBLIOMÉTRICO}

(Continua)

\begin{tabular}{|c|c|c|}
\hline $\mathbf{N}^{\mathbf{o}}$ & Referência Completa do Artigo (ABNT) & Tema do artigo \\
\hline 1 & $\begin{array}{l}\text { NICOLA, A. L.; ANSELMI, M. L. Dimensionamento de pessoal de } \\
\text { enfermagem em um hospital universitário. Revista Brasileia de } \\
\text { Enfermagem. Brasília, v. 58, n. 2, p. 186-90, } 2005 .\end{array}$ & $\begin{array}{l}\text { Dimensionamento de } \\
\text { pessoal }\end{array}$ \\
\hline 2 & $\begin{array}{l}\text { DAL BEN, L. W.; GAIDZINSKI, R. R. Proposta de modelo para } \\
\text { dimensionamento do pessoal de enfermagem em assistência domiciliária. } \\
\text { Revista da Escola de Enfermagem da USP. São Paulo, v. 41, n. 1, p. } 97 \text { - } \\
\text { 103, } 2007 .\end{array}$ & $\begin{array}{l}\text { Dimensionamento de } \\
\text { pessoal }\end{array}$ \\
\hline 3 & $\begin{array}{l}\text { CHENSO, M. Z. B. et al. Cálculo de pessoal de enfermagem em hospital } \\
\text { universitário do Paraná: uma proposta de adequação. Semina: Ciências } \\
\text { Biológicas e da Saúde, Londrina, v. 25, p. 81-92, jan-dez. } 2004 .\end{array}$ & Cálculo de Pessoal \\
\hline 4 & $\begin{array}{l}\text { NEIS, M. E. B. et al. Centro de material e esterilização: estudo do tempo } \\
\text { efetivo de trabalho para dimensionamento de pessoal. Revista Eletrônica } \\
\text { de Enfermagem. Goiânia, v. 13, n. 3, p. 422-30, } 2012 \text {. }\end{array}$ & $\begin{array}{l}\text { Dimensionamento de } \\
\text { pessoal }\end{array}$ \\
\hline 5 & $\begin{array}{l}\text { NUNES, B. K.; TOMA, E. Dimensionamento de pessoal de enfermagem } \\
\text { de uma unidade neonatal: utilização do Nursing Activities Score. Revista } \\
\text { Latino-Americana de Enfermagem. Ribeirão Preto, v. 21, n. 1, p. 348- } \\
\text { 55, fev. } 2013 \text {. }\end{array}$ & $\begin{array}{l}\text { Dimensionamento de } \\
\text { pessoal }\end{array}$ \\
\hline 6 & $\begin{array}{l}\text { MARINHO, B. L.; VASCONCELLOS, E. P. G. Dimensionamento de } \\
\text { recursos humanos: desenvolvimento de um modelo conceitual e sua } \\
\text { aplicação. REGE Revista de Gestão. São Paulo, v. 14, n. 2, p. 61-76, } \\
2007 .\end{array}$ & $\begin{array}{l}\text { Dimensionamento de } \\
\text { pessoal }\end{array}$ \\
\hline 7 & $\begin{array}{l}\text { NICOLUSSI, A. C. et al. Dimensionamento de pessoal de enfermagem nos } \\
\text { serviços hospitalares: revisão integrativa da literatura. Revista Eletrônica } \\
\text { de Enfermagem. Goiânia, v. } 15, \text { n. } 2 \text {, p. } 551-63,2013 \text {. }\end{array}$ & $\begin{array}{l}\text { Dimensionamento de } \\
\text { pessoal }\end{array}$ \\
\hline 8 & $\begin{array}{l}\text { PEREIRA, I. M. et al. Dimensionamento informatizado de profissionais de } \\
\text { enfermagem: avaliação de um software. Revista da Escola de } \\
\text { Enfermagem da USP [online]. São Paulo, vol.45, n.spe, p. 1600-05, } 2011 .\end{array}$ & $\begin{array}{l}\text { Dimensionamento de } \\
\text { pessoal }\end{array}$ \\
\hline 9 & $\begin{array}{l}\text { MAYA, C. M.; SIMOES, A. L. A. Implicações do dimensionamento do } \\
\text { pessoal de enfermagem no desempenho das competências do profissional } \\
\text { enfermeiro. Revista Brasileia de Enfermagem [online]. Brasília, vol.64, } \\
\text { n.5, p. 898-904, 2011. }\end{array}$ & $\begin{array}{l}\text { Dimensionamento de } \\
\text { pessoal }\end{array}$ \\
\hline 10 & $\begin{array}{l}\text { BONFIM, D. et al. Identificação das intervenções de enfermagem na } \\
\text { Atenção Primária à Saúde: parâmetro para o dimensionamento de } \\
\text { trabalhadores. Revista da Escola de Enfermagem da USP [online]. São } \\
\text { Paulo, vol.46, n.6, p. 1462-70, dez, } 2012 .\end{array}$ & $\begin{array}{l}\text { Dimensionamento de } \\
\text { trabalhadores }\end{array}$ \\
\hline 11 & $\begin{array}{l}\text { CAMPOS, L.; MELO, M. R. A. C. Visão de coordenadores de } \\
\text { enfermagem sobre dimensionamento de pessoal de enfermagem: conceito, } \\
\text { finalidade e utilização. Revista Latino-Americana de } \\
\text { Enfermagem. Ribeirão Preto, v. 15, n. 6, p. 1099-04, dez. } 2007 .\end{array}$ & $\begin{array}{l}\text { Dimensionamento de } \\
\text { pessoal }\end{array}$ \\
\hline 12 & $\begin{array}{l}\text { FAKIH, F. et al. Dimensionamento de pessoal de enfermagem em um } \\
\text { hospital de ensino. Revista Brasileira de Enfermagem [online]. Brasília, } \\
\text { v. 59, n. 2, p. 183-87, abr. } 2006 .\end{array}$ & $\begin{array}{l}\text { Dimensionamento de } \\
\text { pessoal }\end{array}$ \\
\hline 13 & $\begin{array}{l}\text { GAIDZINSKI, R. R. et al. Dimensionamento informatizado de } \\
\text { profissionais de enfermagem: inovação tecnológica. Revista da Escola de } \\
\text { Enfermagem da USP [online]. São Paulo, v. 43, n. spe2, p. 1314-19, dez. } \\
2009 .\end{array}$ & $\begin{array}{l}\text { Dimensionamento de } \\
\text { pessoal }\end{array}$ \\
\hline 14 & $\begin{array}{l}\text { MATSUSHITA, M. S.; ADAMI, N. P.; CARMAGNANI, M. I. S. } \\
\text { Dimensionamento do pessoal de enfermagem das unidades de internação } \\
\text { do Hospital São Paulo. Acta Paulista de Enfermagem. São Paulo, v. 18, } \\
\text { n. 1, p. 9-19, mar. 2005. }\end{array}$ & $\begin{array}{l}\text { Dimensionamento de } \\
\text { pessoal }\end{array}$ \\
\hline
\end{tabular}


(Continuação)

\begin{tabular}{|c|c|c|}
\hline $\mathbf{N}^{\mathbf{o}}$ & Referência Completa do Artigo (ABNT) & Tema do artigo \\
\hline 15 & $\begin{array}{l}\text { VITURI, D. W. et al. Dimensionamento de enfermagem hospitalar: modelo } \\
\text { OPAS/OMS. Texto \& Contexto Enfermagem. Florianópolis, v. 20, n. 3, } \\
\text { p. 547-56, set. } 2011 \text {. }\end{array}$ & $\begin{array}{l}\text { Dimensionamento de } \\
\text { pessoal }\end{array}$ \\
\hline 16 & $\begin{array}{l}\text { FUGULIN, F. M. T. et al. Tempo de assistência de Enfermagem em } \\
\text { Unidade de Terapia Intensiva: avaliação dos parâmetros propostos pela } \\
\text { Resolução COFEN nº293/04. Revista Latino-Americana de } \\
\text { Enfermagem. Ribeirão Preto, v. 20, n. } 2 \text {, p. } 325-32 \text {, abr. } 2012 .\end{array}$ & $\begin{array}{l}\text { Dimensionamento de } \\
\text { pessoal }\end{array}$ \\
\hline 17 & $\begin{array}{l}\text { MAGALHAES, A. M. M.; RIBOLDI, C. O.; DALL'AGNOL, C. M. } \\
\text { Planejamento de recursos humanos de enfermagem: desafio para as } \\
\text { lideranças. Revista Brasileira de Enfermagem. Brasília, v. 62, n. 4, p. } \\
\text { 608-12, ago. } 2009 \text {. }\end{array}$ & $\begin{array}{l}\text { Dimensionamento de } \\
\text { pessoal }\end{array}$ \\
\hline 18 & $\begin{array}{l}\text { ROSSETTI, A. C.; GAIDZINSKI, R. R. Estimativa do quadro de pessoal } \\
\text { de enfermagem em um novo hospital. Revista Latino-Americana de } \\
\text { Enfermagem. Ribeirão Preto, v. 19, n. 4, p. 1011-17, ago. } 2011 .\end{array}$ & $\begin{array}{l}\text { Dimensionamento de } \\
\text { pessoal }\end{array}$ \\
\hline 19 & $\begin{array}{l}\text { GAVIRIA-NOREÑA, D. L. Planning the required nursing personnel to } \\
\text { respond to care needs. Investigación y Educación en Enfermeria. } \\
\text { Medellin, v. 31, n.1, p. 116-24, mar. 2013. }\end{array}$ & $\begin{array}{l}\text { Dimensionamento de } \\
\text { pessoal }\end{array}$ \\
\hline 20 & $\begin{array}{l}\text { SOHONI, M. G.; JOHNSON, E. L.; BAILEY, T. G. Long-range reserve } \\
\text { crew manpower planning. Management Science. Catonsville, v. 50, n. 6, } \\
\text { p. 724-39, 2004. }\end{array}$ & $\begin{array}{l}\text { Planejamento de } \\
\text { recursos humanos }\end{array}$ \\
\hline 21 & $\begin{array}{l}\text { CLACK, G. B. et al. The development of a more equitable approach to } \\
\text { resource allocation and manpower planning for undergraduate teaching in a } \\
\text { UK medical school. Medical education, v. } 35, \text { n. } 2 \text {, p. } 102-109,2001 \text {. }\end{array}$ & $\begin{array}{l}\text { Planejamento de } \\
\text { recursos humanos }\end{array}$ \\
\hline 22 & $\begin{array}{l}\text { WU, Yan-Kuen. On the manpower allocation within matrix organization: a } \\
\text { fuzzy linear programming approach. European Journal of operational } \\
\text { research, v. } 183, \text { n. } 1, \text { p. } 384-93,2007 \text {. }\end{array}$ & $\begin{array}{l}\text { Alocação de recursos } \\
\text { humanos }\end{array}$ \\
\hline 23 & $\begin{array}{l}\text { SHIVANAGARAJU, C. et al. Beta-distributed age in manpower planning } \\
\text { models. Applied Mathematical Modelling, v. 22, n. 1, p. 23-37, } 1998 .\end{array}$ & $\begin{array}{l}\text { Planejamento de } \\
\text { recursos humanos }\end{array}$ \\
\hline 24 & $\begin{array}{l}\text { DOHN, A.; KOLIND, E.; CLAUSEN, J. The manpower allocation } \\
\text { problem with time windows and job-teaming constraints: A branch-and- } \\
\text { price approach. Computers \& Operations Research, v. 36, n. 4, p. 1145- } \\
\text { 57, } 2009 .\end{array}$ & $\begin{array}{l}\text { Alocação de recursos } \\
\text { humanos }\end{array}$ \\
\hline 25 & $\begin{array}{l}\text { IVANNIKOVA, V.; KRYSHKEVYCH, K. Application Of Simulation } \\
\text { Approach To Manpower Planning At Ukraine International Airlines' } \\
\text { Maintenance Department. Science-Future of Lithuania/Mokslas- } \\
\text { Lietuvos Ateitis, v. 5, n. 5, p. 578-82, } 2013 \text {. }\end{array}$ & $\begin{array}{l}\text { Planejamento de } \\
\text { recursos humanos }\end{array}$ \\
\hline 26 & $\begin{array}{l}\text { VUNDAVALLI, S. Dental manpower planning in India: Current scenario } \\
\text { and future projections for the year } 2020 \text {. International dental journal, v. } \\
64, \text { n. } 2 \text {, p. } 62-7,2014 \text {. }\end{array}$ & $\begin{array}{l}\text { Planejamento de } \\
\text { recursos humanos }\end{array}$ \\
\hline 27 & $\begin{array}{l}\text { GRIFFITHS, G. S; PRESHAW, P. M. Manpower planning in } \\
\text { periodontology - how many specialists do we need? British Dental } \\
\text { Journal, v. } 217 \text {, n. } 8 \text {, p. } 399-402 \text {, oct. } 24,2014 \text {. }\end{array}$ & $\begin{array}{l}\text { Planejamento de } \\
\text { recursos humanos }\end{array}$ \\
\hline 28 & $\begin{array}{l}\text { LADIER, A. L.; ALPAN, G.; PENZ, B. Joint employee weekly } \\
\text { timetabling and daily rostering: A decision-support tool for a logistics } \\
\text { platform. European Journal of Operational Research, v. 234, n. 1, p. } \\
\text { 278-91, 2014. }\end{array}$ & $\begin{array}{l}\text { Dimensionamento de } \\
\text { pessoal }\end{array}$ \\
\hline 29 & $\begin{array}{l}\text { ONGGO, S. et al. Behavioural modelling of career progression in the } \\
\text { European Commission. European Journal of Operational Research, v. } \\
\text { 222, n. } 3 \text {, p. } 632-41,2012 \text {. }\end{array}$ & $\begin{array}{l}\text { Planejamento de } \\
\text { recursos humanos }\end{array}$ \\
\hline 30 & $\begin{array}{l}\text { FAIRBAIRN, D. Experiences in manpower planning for geomatics. } \\
\text { ISPRS-International Archives of the Photogrammetry, Remote Sensing } \\
\text { and Spatial Information Sciences. v. 1, p. } 25-29,2014 \text {. }\end{array}$ & $\begin{array}{l}\text { Planejamento de } \\
\text { recursos humanos }\end{array}$ \\
\hline 31 & $\begin{array}{l}\text { GUPTA, A.; GHOSAL, A. A manpower planning model based on length } \\
\text { of service under varying class sizes. OPSEARCH, v. 51, n. 4, p. 615-23, } \\
2014 \text {. }\end{array}$ & $\begin{array}{l}\text { Planejamento de } \\
\text { recursos humanos }\end{array}$ \\
\hline
\end{tabular}


(Conclusão)

\begin{tabular}{|c|c|c|}
\hline $\mathbf{N}^{\mathbf{0}}$ & Referência Completa do Artigo (ABNT) & Tema do artigo \\
\hline 32 & $\begin{array}{l}\text { DIMITRIOU, V. A.; TSANTAS, N. Evolution of a time dependent } \\
\text { Markov model for training and recruitment decisions in manpower } \\
\text { planning. Linear Algebra and its Applications, v. 433, n. 11, p. 1950-72, } \\
2010 .\end{array}$ & $\begin{array}{l}\text { Planejamento de } \\
\text { recursos humanos }\end{array}$ \\
\hline 33 & $\begin{array}{l}\text { GUERRY, M. A. Hidden heterogeneity in manpower systems: A Markov- } \\
\text { switching model approach. European Journal of Operational Research, v. } \\
210, \text { n. 1, p. 106-13, } 2011 \text {. }\end{array}$ & $\begin{array}{l}\text { Planejamento de } \\
\text { recursos humanos }\end{array}$ \\
\hline 34 & $\begin{array}{l}\text { GREEN, L. V.; SAVIN, S.; SAVVA, N. "Nursevendor problem": } \\
\text { Personnel staffing in the presence of endogenous absenteeism. } \\
\text { Management Science, v. 59, n. 10, p. 2237-56, } 2013 .\end{array}$ & $\begin{array}{l}\text { Planejamento de } \\
\text { recursos humanos }\end{array}$ \\
\hline 35 & $\begin{array}{l}\text { ŠKULJ, D.; VEHOVAR, V.; ŠTAMFELJ, D. The modelling of manpower } \\
\text { by Markov chains-a case study of the Slovenian armed forces. Informatica, } \\
\text { v. } 32 \text {, n. 3, p. 289-91, aug. } 2008 \text {. }\end{array}$ & $\begin{array}{l}\text { Dimensionamento de } \\
\text { pessoal }\end{array}$ \\
\hline 36 & $\begin{array}{l}\text { PAIXÃO, T. C. R. et al. Dimensionamento de enfermagem em sala de } \\
\text { emergência de um hospital-escola. Revista da Escola de Enfermagem da } \\
\text { USP. São Paulo, v. 49, n. } 3 \text {, p. 481-87, } 2015 \text {. }\end{array}$ & $\begin{array}{l}\text { Dimensionamento de } \\
\text { pessoal }\end{array}$ \\
\hline 37 & $\begin{array}{l}\text { LI, Y.; CHEN, J.; CAI, X. An integrated staff-sizing approach considering } \\
\text { feasibility of scheduling decision. Annals of Operations Research, v. 155, } \\
\text { n. 1, p. } 361-90 \text {, jul. } 2007 \text {. }\end{array}$ & $\begin{array}{l}\text { Dimensionamento de } \\
\text { pessoal }\end{array}$ \\
\hline 38 & $\begin{array}{l}\text { VIANNA, C. M. M. et al. Modelos econométricos de estimativa da força } \\
\text { de trabalho: uma revisão integrativa da literatura. Physis Revista de Saúde } \\
\text { Coletiva. Rio de Janeiro, v. } 23 \text {, n. } 3 \text {, p. } 925-50 \text {, set. } 2013 \text {. }\end{array}$ & $\begin{array}{l}\text { Dimensionamento de } \\
\text { pessoal }\end{array}$ \\
\hline 39 & $\begin{array}{l}\text { CRUZ, C. W. M. et al. The Use of Nursing Interventions Classification } \\
\text { (NIC) in Identifying the Workload of Nursing: An Integrative Review. } \\
\text { International Journal of Nursing Knowledge. Malden. Massachusetts, v. 25, } \\
\text { n. 3, p. 154-60, oct. } 2014 \text {. }\end{array}$ & $\begin{array}{l}\text { Dimensionamento de } \\
\text { pessoal }\end{array}$ \\
\hline 40 & $\begin{array}{l}\text { INOUE, K. C.; MATSUDA, L. M. Dimensionamento de pessoal de } \\
\text { enfermagem em Unidade de Terapia Intensiva para adultos. Acta Paulista } \\
\text { de Enfermagem. São Paulo, v. 23, n. 3, p. 379-84, jun. } 2010 .\end{array}$ & $\begin{array}{l}\text { Dimensionamento de } \\
\text { pessoal }\end{array}$ \\
\hline
\end{tabular}

